Old Dominion University

ODU Digital Commons

Educational Foundations \& Leadership Theses

\& Dissertations

Spring 2011

\title{
A Cultural Approach to Understanding Professional Experiences of Foreign-Born Faculty in U.S. Educational Leadership Preparation Programs
}

Iryna M. Khrabrova

Old Dominion University

Follow this and additional works at: https://digitalcommons.odu.edu/efl_etds

Part of the Bilingual, Multilingual, and Multicultural Education Commons, Educational Leadership Commons, Higher Education Commons, and the Higher Education Administration Commons

\section{Recommended Citation}

Khrabrova, Iryna M.. "A Cultural Approach to Understanding Professional Experiences of Foreign-Born Faculty in U.S. Educational Leadership Preparation Programs" (2011). Doctor of Philosophy (PhD), Dissertation, Educational Foundations \& Leadership, Old Dominion University, DOI: 10.25777/ckpr-nn93 https://digitalcommons.odu.edu/efl_etds/136

This Dissertation is brought to you for free and open access by the Educational Foundations \& Leadership at ODU Digital Commons. It has been accepted for inclusion in Educational Foundations \& Leadership Theses \& Dissertations by an authorized administrator of ODU Digital Commons. For more information, please contact digitalcommons@odu.edu. 
A CULTURAL APPROACH TO UNDERSTANDING PROFESSIONAL

EXPERIENCES OF FOREIGN-BORN FACULTY IN U.S. EDUCATIONAL

LEADERSHIP PREPARATION PROGRAMS

by

Iryna M. Khrabrova

B.A. June 1992, Gorlovka State Pedagogical Institute, Ukraine

M.S. May 2006, Old Dominion University

A Dissertation Submitted to the Faculty of

Old Dominion University in Partial Fulfillment of the

Requirement for the Degree of

DOCTOR OF PHILOSOPHY

EDUCATIONAL LEADERSHIP

OLD DOMINION UNIVERSITY

May 2011

Approved by:

Karen_sanzo (Director)

Steve'Mvran (Méŕhber)

William Owings (Membet) 


\section{ABSTRACT}

\section{A CULTURAL APPROACH TO UNDERSTANDING PROFESSIONAL EXPERIENCES OF FOREIGN-BORN FACULTY IN U.S. EDUCATIONAL LEADERSHIP PREPARATION PROGRAMS}

Iryna M. Khrabrova

Old Dominion University, 2011

Director: Dr. Karen L. Sanzo

The purpose of this study was to investigate professional experiences of foreignborn faculty members serving in U.S. educational leadership preparation programs utilizing a cultural approach to discern their lived experiences related to professional life. Cultural values reflected in professional life experiences were explored. The information gathered through phenomenological approach was used to analyze the influence of national background on the professional experiences of foreign-born faculty in educational leadership preparation programs. 


\section{ACKNOWLEDGMENTS}

As humans, we are the same. And yet, we are different. I would like to express my appreciation to the eleven foreign-born faculty members who participated in this study. They gave me the opportunity to capture and describe their difference by sharing their professional life stories. Without their participation, this study would not have been possible.

I am deeply grateful to my dissertation committee members. My sincere thanks go to my chair, Dr. Karen Sanzo, a great teacher and an amazing character. Her professional knowledge, capacity for detail, and ability to inspire and guide through the exciting maze of study are admirable. I extend my deepest thanks to Dr. Steve Myran for his methodological insight, profound help with structuring this study and giving me valuable ideas and advice when needed. I owe particular thanks to Dr. William Owings for his guidance, flexibility, ongoing support during my academic career, and, above all, for his sense of humor, which helped me in the down moments of this long process.

During the study, I have received support and encouragement from many individuals, professionals, friends and family members, to whom I am eternally grateful. I am especially thankful to my friend Bill for teaching me to never give up and encouraging me to realize my full potential. I also thank my friends Natalia and Aey for their inspiring interest and support on this path.

Most of all, I am grateful to my mother Anna and my sister Natasha for their love, valuing everything I do, and for being my best friends always.

I thank you all for being by my side and supporting me on this exciting trip to new knowledge and discoveries about the world and myself. 


\section{Chapter}

I. INTRODUCTION

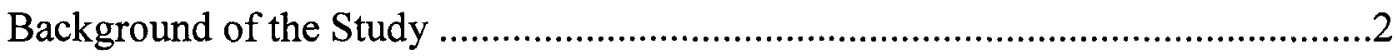

Problem Statement ...................................................................................

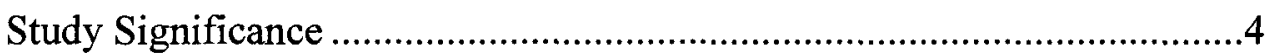

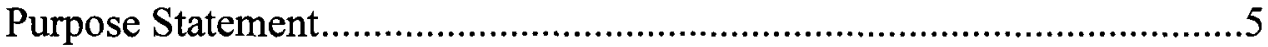

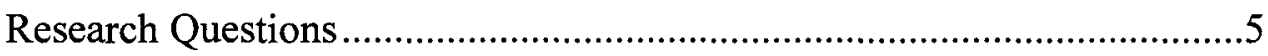

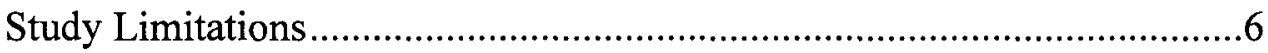

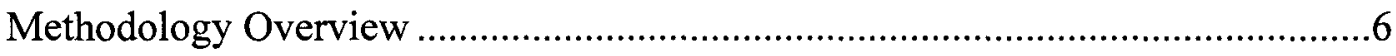

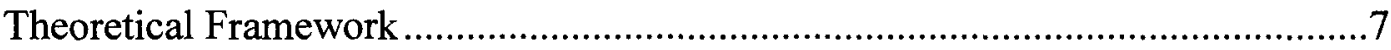

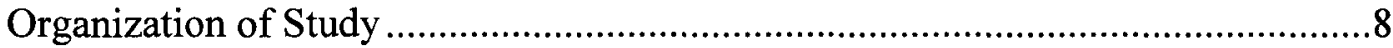

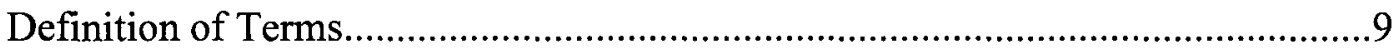

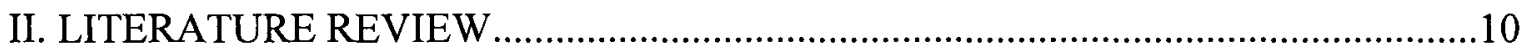

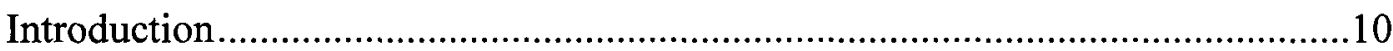

Overview of the Chapter.....................................................................11

Internationalization of U.S. Higher Education ....................................................

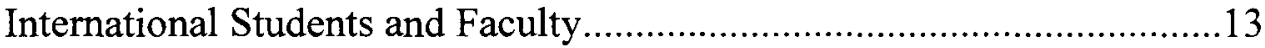

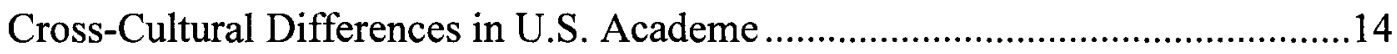

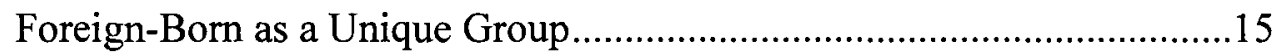

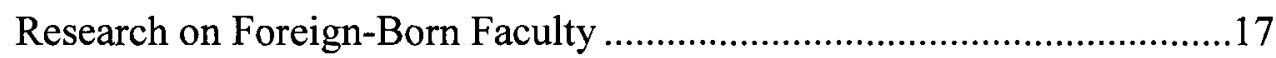

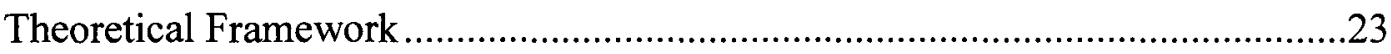

Theories of Culture

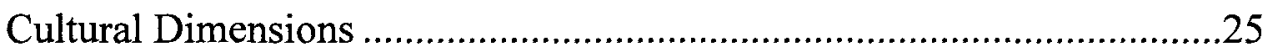

Cultural Leadership Differences Across Nations ....................................29

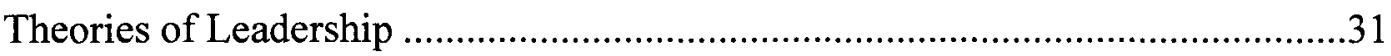

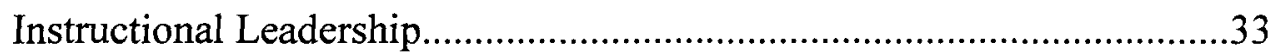

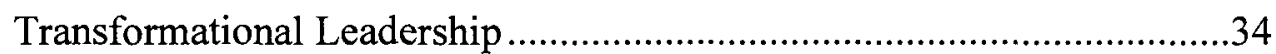

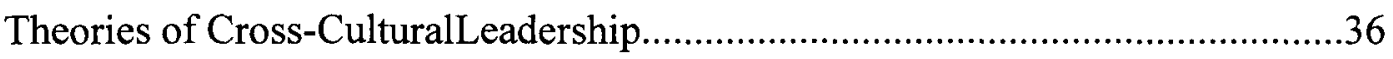

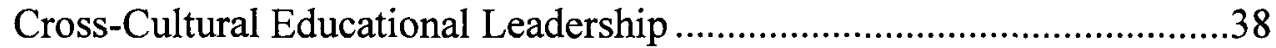

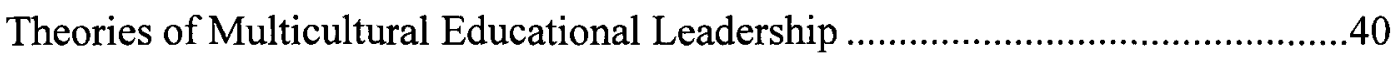


Summary

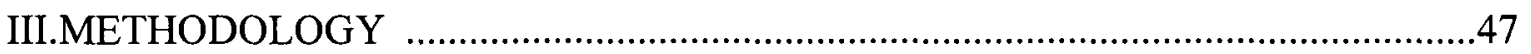

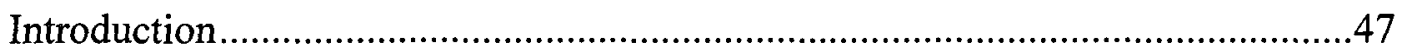

Methodological Framework.........................................................................

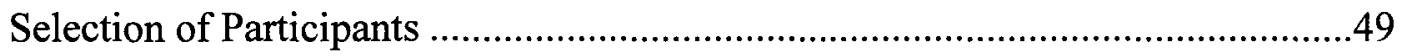

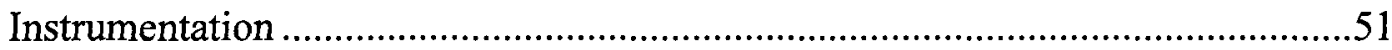

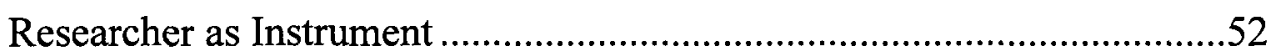

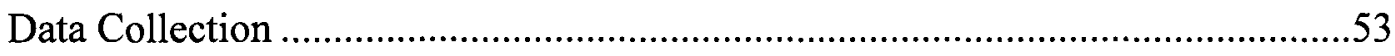

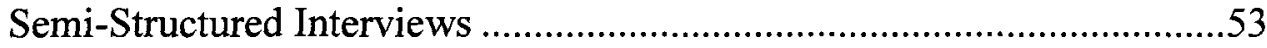

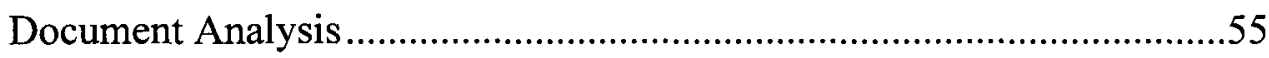

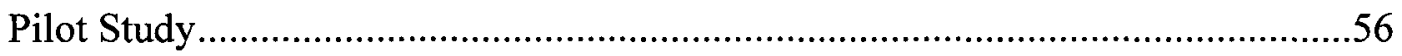

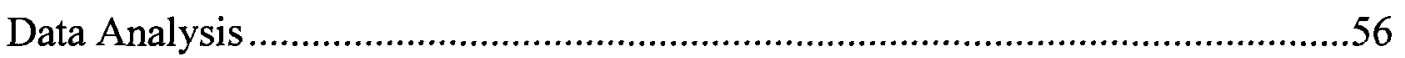

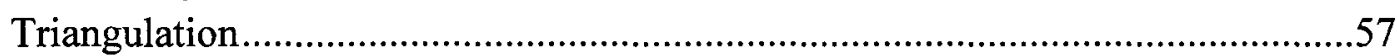

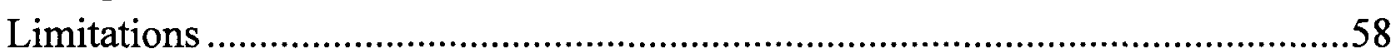

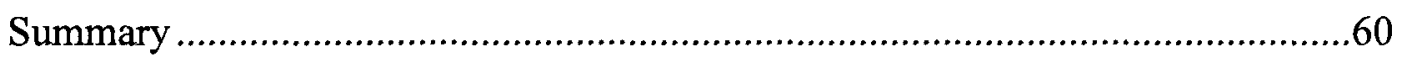

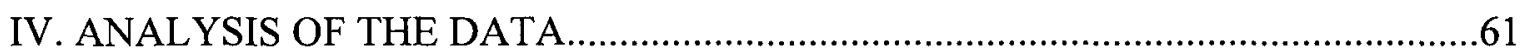

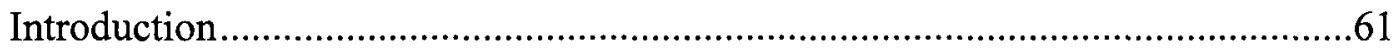

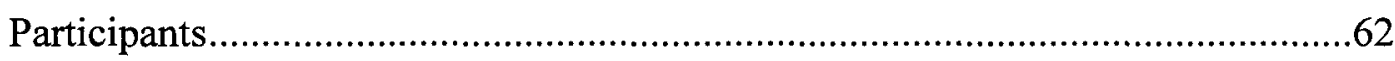

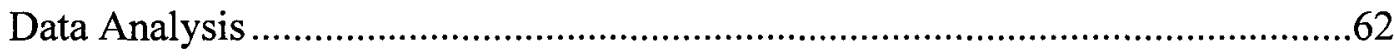

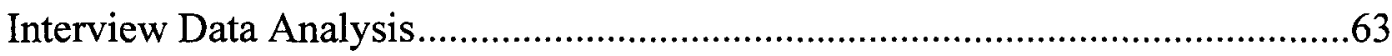

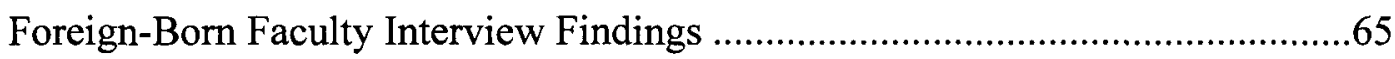

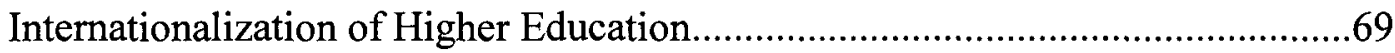

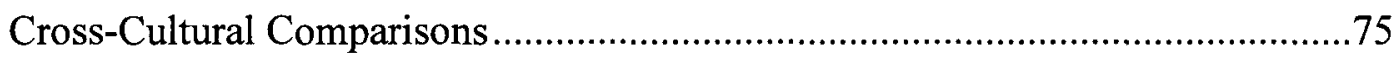

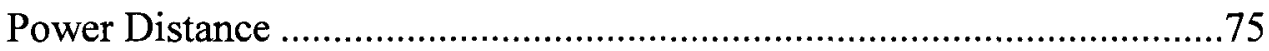

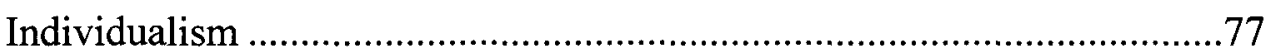

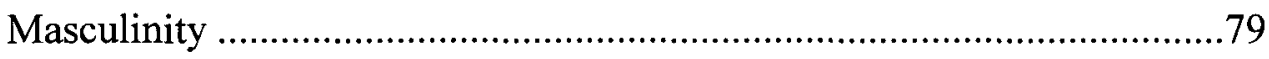

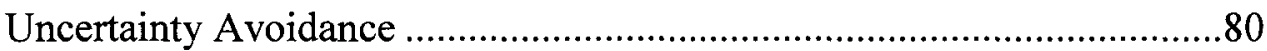

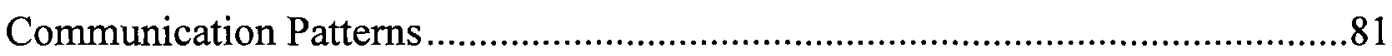

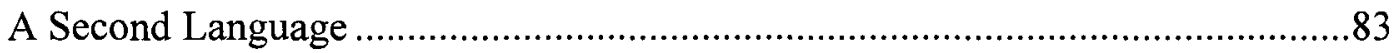

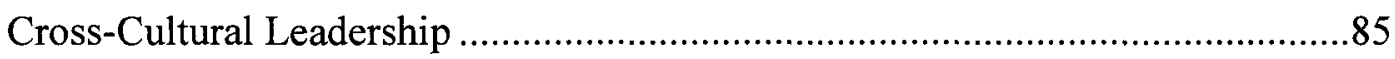

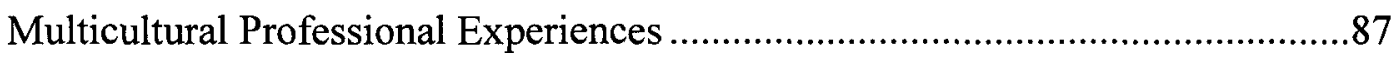

The Role of U.S. Graduate School Training .............................................89

Cultural Attitude Toward Teaching ......................................................

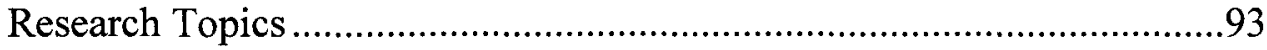

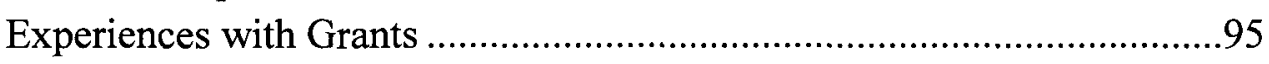

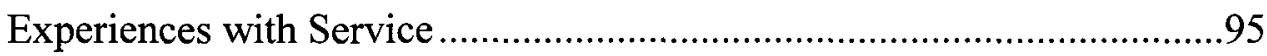

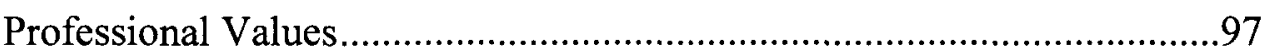

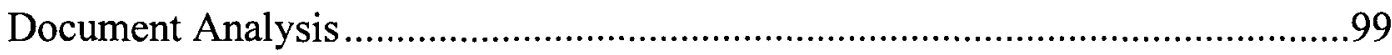


Summary 102

V. DISCUSSION

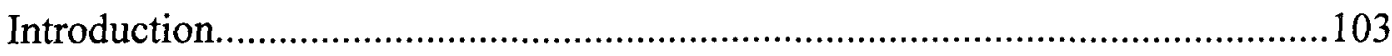

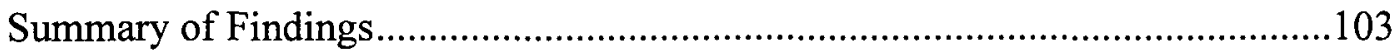

Findings Related to Question 1 ...........................................................103

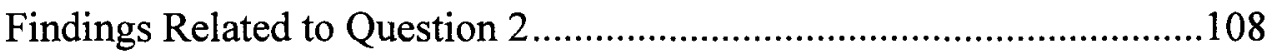

Findings Related to Question 3 ..........................................................111

Findings Related to Question 4 ........................................................113

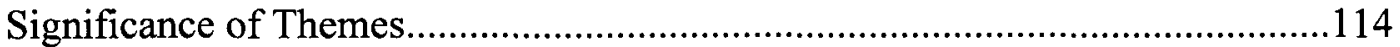

Cultural Diversity on Campus ..............................................................115

Impact of Cultural Background on Professional Life ...............................117

Impact of Culture on Leadership ........................................................118

Multicultural Leadership for Social Justice .........................................120

Culturally-Responsive Leadership.....................................................123

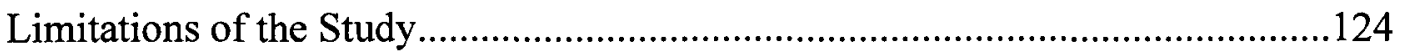

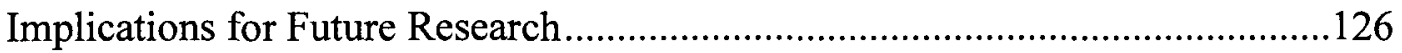

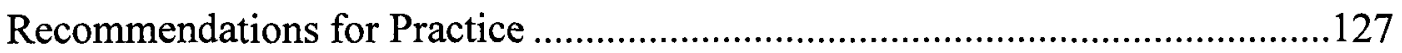

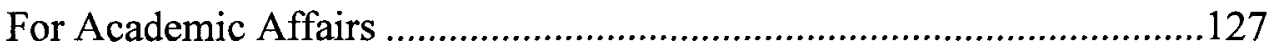

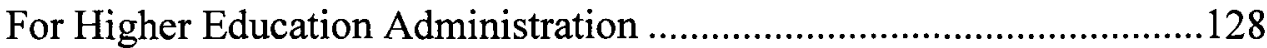

For Foreign-Born - U.S.-Born Academic Professional Relations...........129

For Educational Leadership Preparation Programs ................................130

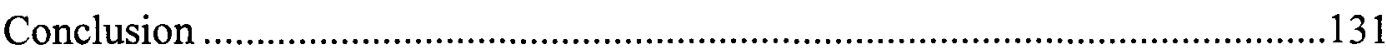

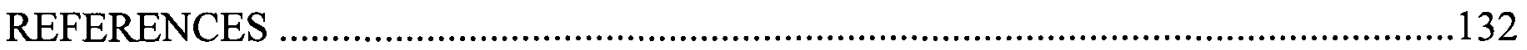

APPENDICES:

A. FOREIGN-BORN FACULTY INVITATION LETTER …………................144

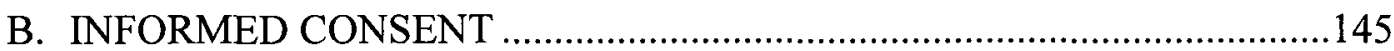

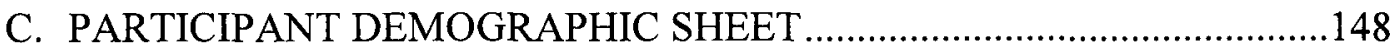

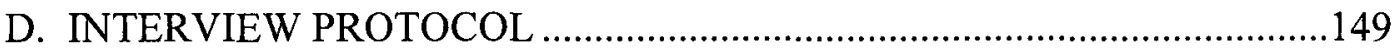

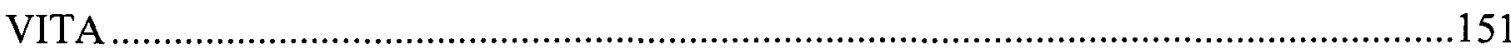




\section{LIST OF TABLES}

Table

Page

1. Hofstede's Four Cultural Dimensions ................................................................24

2. Academic Qualifications of Interviewed Foreign-Born Faculty .............................49

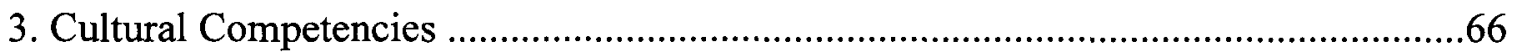

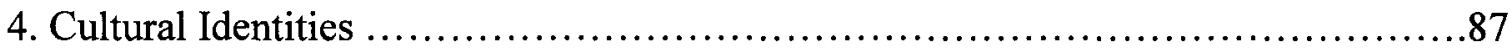




\section{CHAPTER I \\ INTRODUCTION \\ Background of the Study}

America has historically benefited from imported talents. When immigrants arrive in the United States, they carry along diverse histories, narratives, cultures, and beliefs (Banks, 2006). They bring and acquire a collection of formal problem solving techniques and informal rules learned from experience, education, and families (Collins, 2008). Immigrants also bring a determination to succeed. Those two characteristics cognitive diversity and desire - enable immigrants to make contributions to their new environment (Corley \& Sabharwal, 2007).

A rapid demographic shift is occurring in American society. The ethnic and racial composition of U.S. population has been changing substantially over the past four decades (Suarez-Orozco, 2007). In 1970, 9.6 million foreign-born individuals lived in the United States, making up only $4.7 \%$ of the population. However, by $2009,47.4$ million foreign-born individuals lived in the country, comprising $18.5 \%$ of the population (U.S. Census Bureau).

As the United States is being transformed by continuing levels of immigration, American education system in undergoing change and transformation as well (Stromquist, 2007). Altbach (2006) identified the essential shifts in the cultural, ethnic, and racial diversity of the population are reflected in the diverse student and faculty bodies in higher education institutions. Universities desire to attract increasing numbers of foreign-born faculty for the richness they offer to the learning community.

Internationalization is a recent trend in U.S. higher education (Spring, 2008). Internationalization has been a reason for hiring foreign-born faculty (Theobald, 2008). 
The processes that constitute internationalization on American campuses vary widely, and conversations regarding best practice in the global education field are beginning (Altbach, 2008; Bhattacharjee, 2004). Walker and Dimmock (2002) established internationalism as a "desirable educational phenomenon, especially in the new millennium of global trade, multicultural societies, and the Internet" (p.13).

The new ways of seeing and thinking brought to the United States by immigrants from around the world translate into diverse professional experiences (Chan \& Dimmock, 2008). Considering the global realities of the $21^{\text {st }}$ century, foreign-born faculty members establish an important part of the diversity on college and university campuses (Hoffman, 2003). Foreign-born faculty offer unique and different perspectives on subject matters, philosophies, and worldview (Marvasti, 2005). They provide an opportunity for many U.S. students to interact with different cultures at this globalization age (Hser, 2005). For this reason, there is much to gain from utilizing the foreign-born faculty's knowledge and experiences. These serve as evidence that cross-cultural learning and sharing is possible as both parties develop skills in cultural awareness, respect, and tolerance and bridgebuilding communication skills which reduce their ethnocentrism (Lin, Pearce, \& Wang, 2009). Moreover, the exposure to different points of view from a diverse cultural perspective gives students the first-hand insights into other places and cultures as well as helps eliminate stereotypes and builds a more diversified and rich knowledge base (Alberts, 2008).

New campus leaders are needed who are able to embrace the challenge of leadership and continued educational success. Leadership exists in all societies and is essential to the functioning of organizations within societies (Bass, 1985). However, the 
attributes that are seen as characteristics for leaders may vary across cultures (Den Hartog et al., 1999). Hofstede (1991) noted that prevailing theories of leadership are North American in character and are based on the assumptions of individualism as opposed to collectivism, rationality rather than ascetics, hedonistic rather than altruistic motivation, centrality of work, and democratic value orientation. Cross-cultural psychology and sociology research shows that many cultures do not share these assumptions (Den Hartog et al., 1999).

Globalization of educational policy and practice dictates the urge to develop a comparative and international branch of educational leadership and management (Dimmock \&Walker, 1998, 2000, 2005). Hallinger and Leithwood (1996) argued the importance of societal culture in studies of educational leadership and educational administration. Walker and Dimmock (2002) supported the argument and claimed the significance of a comparative approach to educational leadership and management that "can expose the value of theory and practice from different cultural perspective, which may then, in turn, inform and influence existing dominant Western paradigms" (p.17).

\section{Problem Statement}

Despite their growing presence and significance on U.S. campuses, foreign-born faculty in social sciences have been a largely unknown resource in higher education literature. The existing research on foreign-born faculty indicates their coming to the U.S. with different world-views, professional and cultural beliefs and social expectations which are challenged (Alberts, 2008; Collins, 2008). The foreign-born faculty members experience difficulties in adjusting to different academic standards, grading systems, and student behavior (Hoffman, 2003). Additionally, little support is available to foreign- 
born instructors that could help them avoid problems due to their 'foreignness' (Alberts, 2008) which is further identified as a teaching resource requiring additional examination for establishing its effects in the process of instruction (Alberts, 2008; Neves \& Sanyal,1991). There is a growing interest in how foreign-born faculty and students contribute to global issues within the curriculum, increase diversity of campus life, or serve as community resources without compromising their cultural values and beliefs to the demands of studying, teaching, and research (Bhattacharjee, 2004; Hoffman, 2003; Theobald, 2008). As universities are investing more resources in hiring and retaining foreign-born faculty members, it is critical to understand their professional approaches and experiences (Mamiseishvili, 2009).

This study builds on the previous research and provides a more comprehensive examination of foreign-born faculty in educational leadership departments at U.S universities.

\section{Study Significance}

This study can contribute to the body of knowledge on foreign-born faculty on American campuses. It can also provide additional insight into the institutional change needed for hiring, retention, and development of faculty of other cultural background. This study seeks to increase the knowledge on the cross-cultural differences in learning and teaching. It employs emerging concepts of a comparative and international branch of educational leadership and yields discussion about the types of leaders needed in the $21^{\text {st }}$ century schools and the optimal forms of leadership preparation. Educational leaders are likely to understand the issues that are prevalent in education internationally and support the realization of diversity in schooling practices within and across different societies 
which, along with the increased progress in world communication, can broaden the possibilities for collaboration with colleagues holding similar interests in varied global settings. Ethno-cultural empathy, or understanding feelings of individuals that are ethnically and/or culturally different from one's self thus taking into account other peoples' perspectives, accepting cultural differences, and being empathically aware of each other's differences, is a determinant of a successful leadership in varied educational environments.

\section{Purpose Statement}

The proposed phenomenological study served two purposes. This study sought to describe professionally related experiences of foreign-born faculty working in educational leadership programs in American universities. In addition, this study attempted to reach an understanding of the cultural processes by which foreign-born educational leadership faculty professionally adapt and adequately function in U.S. higher education system.

\section{Research Questions}

This study was guided by the major research question:

What are the professional experiences of foreign-born faculty serving in educational leadership preparation (ELP) programs?

The three sub-questions were used to seek additional information on the theme:

1) What role does culture play in professional experiences of foreign-born faculty in ELP programs?

2) What factors do foreign-born faculty perceive as having impact on their professional experiences in ELP programs? 
3) To what extent, if any, do their ethnicity and culture affect their leadership philosophy as faculty members in ELP programs?

\section{Study Limitations}

The limitations of this study stem from the examination of a particular group of academic professionals and no claims can be made about the extent these scholars in general can influence U.S. higher education system. This research concern was an attempt to explain partially how the international knowledge system functions. It tapped on the cultural perspectives in educational leadership theories and practices as perceived by a specific group of scholars. Therefore, it will be necessary for further studies to deal with areas relating to educational research and cooperation between nations in order to further explore and understand the complexity of the international knowledge system.

\section{Methodology Overview}

This overview presents a brief description of the participants, research procedures, and research data analysis. Chapter III provides further explanation.

\section{Participants}

This study focused on foreign-born faculty members who were born in foreign countries to non-American parents and whose immigrant status is citizens, permanent residents, or temporary residents. Foreign-born faculty were chosen from public universities which consider both research and teaching to be of equal importance. Faculty members were chosen from the field of educational leadership. 
Procedures

This research utilized a phenomenological method examining professionally related experiences of foreign-born faculty members serving in educational leadership preparation programs in U.S higher education system. The research questions were addressed through semi-structured personal interviews with the participants. These questions sought to determine the salient professional themes of meaning for foreignborn faculty through the lens of their ethnic backgrounds. The interview process allowed the researcher to be involved in an active cross-cultural interaction with ethnically diverse faculty.

\section{Theoretical Framework}

The internationalization of educational administration offers an opportunity to keep abreast of the expanding forces of globalization in policy and practice. In their theory, Dimmock and Walker $(2000,2005)$ called for the expansion of inquiry into comparative and international educational leadership and management. Noting that educational research and theory in this area have fallen behind developments in other fields, they urge for a renewed focus on exploring educational leadership across national boundaries and cultures, mental and geographical borders (Dimmock \& Walker, 2005).

Hofstede $(1980,1991,2001)$ argued that cultural values serve as a frame of reference to construct the way people receive and process information and interpret their social environment. Hofstede (1980) conducted a comprehensive study of how values in the workplace are influenced by culture. From the initial results (Hofstede, 1980) and later additions, Hofstede $(1991,2001)$ developed a model that identifies four primary Dimensions to assist in differentiating cultures: Power Distance, Individualism, 
Masculinity, and Uncertainty Avoidance. The four Dimensions were generated into a scale with a score assigned to a particular culture with relation to the aforementioned cultural categories.

This study also utilized the theory outlined by Leithwood and Duke (1998) identifying instructional leadership model, leadership styles, and transformational leadership model as the integral parts for a reasonably comprehensive framework of concepts of leadership for a cross-cultural leadership study. They argued "the research outside of education suggests that there are differences across cultures in terms of how people define leadership. The early stages of research into cross-cultural conceptions of leadership should try to explore the meaning of leadership from the perspective of people within a given culture" (Leithwood \& Duke, 1998, p. 31). The collection of evidence from the qualities people related to leadership is perceived as important. This view provides a rationale for this cross-cultural study. It seeks to reveal data as to how different populations conceive, identify and evaluate characteristics of effective leadership and behavior through the lens of their ethnic perspective (Derr, Roussillon, \& Bournois, 2002; Walker \& Dimmock, 2000). This study examined the current standing of foreign-born faculty serving in educational leadership preparation programs in American colleges and universities to reveal the role the culture plays in professional experiences of those faculty members. The experiences of foreign-born faculty were explored in three dimensions: teaching and research, leadership preparation, and contributions of ethnicity and culture to professional practices. 


\section{Organization of Study}

Chapter I states the background of the study, problem statement, purpose statement, research questions, significance of study, methodology overview, theoretical framework, and limitations of study. Chapter II reviews the research existing in the area of internationalization of education, theories of culture, and theories of leadership. Chapter III provides the research design and rationale for the specific research methods employed in this study. Chapter IV reports the findings that emerged from the data collected for this study. Chapter $\mathrm{V}$ presents the discussion of results and implications of this study for future research and practices.

\section{Definitions of Terms}

Several terms are used throughout this study. Academe. A higher education community of students and scholars involved in education and research.

Cross-cultural. Referring to two or more cultures.

Culture. Intellectual patterns, values, and beliefs distinguishing the members of one group of people from another.

Foreign-born. Anyone who is not born a U.S. citizen.

Internationalization. An inclusion and consideration of different cultures in the process of education.

Leadership. An ability to lead and influence a group of people.

Multicultural. Acceptance and support of multiple ethnic cultures at the organizational level. 


\section{CHAPTER II}

\section{LITERATURE REVIEW}

Introduction

In the globally interdependent society of the 21 st century, international faculty members are becoming essential to vibrant and diverse college and university campuses. Internationalization of higher education offers an opportunity to keep abreast of the expanding forces of globalization in educational policy and practice. At present, higher education institutions seek to recruit and retain excellent and diverse faculty members, including some who are drawn from outside the United States. This study examined the current standing of foreign-born faculty serving in educational leadership preparation programs in U.S. colleges and universities and is focused on professionally and culturally related experiences of those faculty members. This exploratory study seeks to increase the knowledge on the cross-cultural differences in learning and teaching. It employs emerging concepts of an international branch of educational leadership and discusses the types of leaders needed in the $21^{\text {st }}$ century schools.

In the midst of demographic change, students need leaders and advocates who are prepared to be cultural change agents—educators armed with the knowledge, strategies, support, and courage to make curriculum, instruction, student engagement, and family partnerships culturally responsive. Despite limitations in terms of complexities of the social, economic, cultural and political circumstances of each country, educators should import and borrow policy and practices from the global community in their attempts to resolve multifaceted educational problems. This study is viewed as the contribution to the theory and practices of multicultural educational leadership preparation. 


\section{Overview of the Chapter}

Chapter 2 includes a "Literature Review". This review assists in providing a foundation for studying professional experiences of foreign-born faculty serving in educational leadership preparation programs in U.S. higher education system. This exploratory study also seeks to identify the factors that might impact professional experiences of foreign-born faculty and draws on two bodies of literature. The first body of literature focuses on the development of theories of internationalization of U.S. higher education system. The second body of literature investigates existing theories of culture and leadership as related to cross-cultural educational leadership models. This chapter reviews: 1) internationalization of U.S. higher education; 2) cross-cultural differences in U.S. academe; 3) theories of culture; 4) theories of leadership; 5) theories of crosscultural approach to educational administration; and 6) multicultural educational leadership.

Internationalization of U.S. Higher Education

Institutions of higher education face many challenges in the 21 st century because of internationalization. Internationalization has been a worldwide trend in higher education (Spring, 2008; Stromquist, 2007). It has increased the demand for individuals who can manage effectively in a foreign environment and who are able to understand and work with people from diverse cultures (Childress, 2009; Schmidt, 2009).

Internationalization has been defined as making campuses more internationally-oriented, and implementing the integration of international elements into the curricula to increase the presence of international faculty and students on campus (Deardorff, 2004; Ellingboe, 1998; Hanson \& Meyerson, 1995). 
Internationalization not only affects academic programs, faculty, and students, but also creates new administrative structures and expectations (Knight, 2004; Seifert \& Umbach, 2008). In recognizing the need for internationalization, many universities and colleges in the United States are making great efforts to internationalize their institutions in order to prepare their students to live and work in the $21^{\text {st }}$ century global society (Chan \& Dimmock, 2008; Mamiseishvili \& Rosser, 2009). Encouraged by national leaders and educators, universities and colleges have developed and expanded international activities, study-abroad programs, student and faculty exchange programs, hiring of foreign-born faculty, and have strengthened international studies within their curricula (Chan \& Dimmock, 2008). They have added the concepts of internationalization and globalization to their mission statements (Hser, 2005). These changes have enriched the learning experience for American students in the classroom and added diversity to campus life (Hser, 2005; Theobald, 2008; Trice, 2003). Notably, productive interaction between individuals from a wide and diverse background is a necessary part of better understanding the world issues related to global cooperation and advancement (Marvasti, 2005; Sanderson, 2008).

It would, therefore, seem that internationalization of program offerings and student recruitment has become today the new form of entrepreneurialism, moving into new conceptions of students and knowledge. The search for new student markets and attractive programs unleashes a need for more students, more faculty to teach them, and timely decisions based on constant scanning of the environment - both national and international. 


\section{International Students and Faculty}

American universities always have been a popular destination for thousands of students and scholars from all over the world (Spring, 2008; Trice, 2003). Throughout North America, educators always have dealt with students from a variety of cultural backgrounds, but that level of diversity is accentuated by increasing internationalization and is more crucial now than ever (Altbach, 2006). International students have been more common in U.S. universities as national boundaries have become more blurred: the increasing homogenization of cultures has made it psychologically easier to travel and to live and study in a foreign culture (Deardorff, 2004).

During the 2008-2009 academic year, 113,494 international scholars with nonimmigrant visa status were teaching or conducting research on U.S. campuses, an increase of 7\% from the previous year (Open Doors 2009: International Scholars 2009). In addition, in 2008-2009, there were 671,616 international students enrolled in U.S. higher education institutions, an increase of $7.7 \%$ from the previous year (Open Doors 2009: International Students in the United States 2009). In 2010, 53\% of U.S. campuses reported increased overall enrollments of international students (Open Doors: International Student Enrollment 2010). In education, the number of the international students also increased from 17,775 in $2007-2008$ to 18,120 in $2008-2009(1.9 \%$ increase) (Open Doors 2009: International Students in the United States 2009). The proportion of doctoral degrees awarded to international students rose from $11 \%$ in 1974 to $31 \%$ in 2005 (Hoffer et al., 2005). Many of these international students choose to stay in the United States after completing their doctoral degrees and join academe as faculty members (Altbach, 2006). It is projected that by 2014 colleges, universities, and 
professional schools will witness an employment growth of 35.3\% (Bureau of Labor Statistics, 2010). Thus, issues of faculty satisfaction, retention, diverse approaches and philosophies, and persistence will become profoundly important for university administrators and education policy makers.

The need to study foreign-born faculty professional experiences at universities also stems from the fact that intellectual and social structures of higher education are changing over time (Altbach \& Knight, 2007; Slater et al., 2002). Increasingly, women and minorities are more likely to occupy higher ranks of the professoriate. As senior faculty members retire at the leading U.S. universities over the next decade, it is likely that they will be replaced by younger faculty members who are women, underrepresented minorities and/or foreign-born scholars (Collins, 2008; Rusch, 2004). According to the "National Study of Postsecondary Faculty" report on faculty and instructional staff, the percentage of full-time minority professors in degree- granting institutions has increased steadily to $24 \%$ from $16 \%$ in 2003 , and $9 \%$ in 1990 (National Center for Education Statistics, 2010).

As these census statistics show, impressive progress has been made in increasing the numbers of international students and minority faculty in higher education. This changing landscape of faculty members at U.S. universities will require that university administrators address issues related to faculty across a variety of personal and professional dimensions. The internationalization of American institutions has, therefore, created an important need to better understand the thinking and impact that foreign-born faculty are having on U.S. institutions of higher learning and vice versa. 


\section{Cross-Cultural Differences in U.S. Academe}

Diversity of people on campus reflects the changing immigration patterns in the United States and growth experienced by higher education institutions during the last decades of the $20^{\text {th }}$ century and the beginning of the $21^{\text {st }}$ century (Collins, 2008; Stromquist, 2007). Ethnic and cultural diversity encourages a society where all people are equally respected, symbolizing society's democratic commitment to human dignity and equality (Taormina \& Selvarajah, 2005). Moreover, ethnic and cultural diversity on campus allows professors and students to retain their personal identities, have a sense of belonging, take pride in their own heritage, gain an appreciation of their own and different cultures, and foster an appreciation of diversity among the entire college community (Stohl, 2007). The findings on professional productivity appeared linked to the U.S.-born faculty members' exposure to faculty members from abroad (Schmidt, 2009; Sheppard, 2004). Research suggests that all other things being equal, the larger the proportion of international faculty members on a campus, the more productive its domestic faculty members are (Seifert \& Umbach, 2008).

Foreign-born faculty who accept an appointment at an American institution not only step into a potentially unfamiliar departmental context but also into the situations of increasing access to higher education for individuals from a wider variety of socioeconomic and educational backgrounds than to which foreign-born faculty might be accustomed. This review of foreign-born faculty's standing in U.S. higher education contributes to the conversation about diversity on American campuses.

\section{Foreign-Born as a Unique Group}

What do internationalization efforts and ideas look like to someone who does not share the same cultural perspective as a majority member, and why would studying this 
view matter? The research defined the foreign-born as subjected to unique stresses in important ways (Thomas \& Johnson, 2004). Included are the taxing process of immigration, language barriers, loss of important relationships, a less developed support system, and adaptation to the new culture (Basti, 1996). Additionally, the adoption of the values of the dominant culture is linked to a repudiation of past values, which may lead to a degree of self-rejections (Collins, 2008). Foreign-born faculty must adjust and cope with differences in cultural authority structures, social relationships, education systems, and educational practices as well as student resistance (Collins, 2008). Culturally based differences in methods and styles of teaching may affect communication in the classroom (Foote, Li, Monk, \& Theobald, 2008). A culturally based communication problem is sometimes misconstrued as a language barrier and the loss of traditional ritual structures prevent acculturated immigrants from effectively dealing with the stresses defined above (Han, 2008).

Most foreign-born faculty may be faced with many social and professional problems in their adaptation to U.S. campus life. Aside from language barriers, the foreign-born faculty may have different values, attitudes about education, and instructional styles (Anderson \& Smith, 2005; Hanson \& Meyerson, 1995). Furthermore, the foreign-born faculty may be adversely affected by institutional and individual racism in American society (Johnsrud \& Sadao, 1998).

However, the presence of foreign-born faculty is beneficial (Corley \& Sabharval, 2007; Kavas \& Kavas, 2008) and more research would provide insights and understanding that can enrich teaching and contribute to a more harmonious professional atmosphere in U.S. academe. 


\section{Research on Foreign-Born Faculty}

A few studies have examined experiences of U.S.-born and foreign-born faculty members in various academic settings (Corley \& Sabharwal, 2007; Lin, Pearce, \& Wang, 2009; Mamiseishvili \& Rosser, 2009; Skachkova, 2007; Taormina \& Selvarajah, 2005). These studies explicitly categorize foreign-born faculty as a distinct group and explore their unique experience in U.S. colleges and universities. Moreover, these studies produce conflicting results.

According to Corley and Sabharwal (2007), U.S.-born scientists benefit from the cultural influences of their immigrant colleagues and expand their research horizons. Immigrant scientists often gravitate to scientific problems of pressing interest back home, and they tend to build links between researchers in the United States and their country of origin as the way for increased global collaboration. However, in the study of foreignborn faculty across disciplines and nationalities, Liu (2001) found foreign-born faculty have to work hard to prove constantly their capabilities as researchers, teachers, and colleagues.

Foreign-born faculty face greater challenges when it comes to advancement in their careers, and they are more likely to be stuck in lower ranks (Basti, 1996; Corley \& Sabharwal, 2007). Facilitating the success of internationalization efforts has to involve the recognition of foreign-born faculty (Basti, 1996). Foreign-born faculty help promote campus internationalization as they represent educational and cultural resources. They enrich the learning experience but remain a largely untapped international asset for higher education. Importantly, foreign-born faculty offer first hand intercultural learning 
opportunities to the students and they add diversity to campus life (Basti, 1996; Thomas, 2002).

The culture of American colleges and universities is based on white European cultural values and norms (Manrique \& Manrique, 1999). Foreign-born faculty are frequently subjected to varied views of what being "foreign" means to others (Seagren \& Wang, 1994). In addition to facing prevailing negative social views of immigrants, foreign-born faculty must contend with the fact that they will be perceived as ethnic minorities. Accompanying this additional label are stereotypes which differ according to ethnic background (Skachkova, 2007).

A separate segment of literature dealing with the experiences of foreign students and faculty concerns Asian minority, who appear quite different from the dominant culture (Lee, 2002, 2004; Lin, Pearce, \& Wang, 2009; Liu, 2001; Wei, 2007). The majority of ethnic and racial minority faculty interviewed perceived that they must be bicultural to enter and advance successfully in the university setting (Wei, 2007). The faculty discussed biculturalism as a means of functioning effectively in two cultural milieus: their ethnic heritage and the white Western university system (Lee, 2002; Wei, 2007).

A nationwide opinion survey of 2,400 foreign-born faculty at various universities in the USA during the 1993-1995 period by Cecelia Manrique and Gabriel Manrique (1999) revealed the challenges foreign-born faculty face at educational institutions in the USA. The survey results show that $22 \%$ of foreign-born faculty recognize that their accent can be a barrier to their effectiveness in the classroom. However, the respondents believe that student reaction to their accent usually improves over time. According to 
this survey, the longer a foreign-born faculty member interacts with a native student, the more likely he or she is to allay student skepticism. The results also indicate that approximately one quarter of the respondents, mostly non-Europeans, report that they have experienced prejudice and discrimination at universities (Manrique \& Manrique, 1999).

All foreign-born faculty need help adjusting to a new academic environment (Collins, 2008; Hoffman, 2003; Thomas \& Johnson, 2004). In particular, each needs to be equipped with profound intercultural competencies in the host country (Han, 2008; Hser, 2005). A study focusing on the effectiveness of foreign-born economics faculty found that formal and informal constraints may hinder foreign-born faculty from realizing their full potential in academic institutions (Marvasti, 2005).

Several studies have also explored the relationship between academic research and teaching (Mamiseishvili \& Rosser, 2009; North, 1995). By analyzing the employment patterns of immigrants and U.S. citizens, North (1995) found U.S. citizens are more likely to be employed in management-based positions, while immigrants tend to be employed in research and design. Even though these results are not specific to academic faculty, these findings can be used to hypothesize that foreign-born academic scientists were likely to spend more time on research and less time on teaching when compared with U.S.-born scientists.

Another important indicator of professional activities is the number of research grants awarded to faculty members. Norris (2004) explored the relationship between grant acquisition and citizenship. It was found that the level of grant activity is more strongly and positively correlated with publication productivity for U.S.-born professors 
than for foreign-born professors. Even though Norris (2004) found the relationship between grant funding and publication productivity is stronger for U.S.-born scientists, this does not mean foreign-born scientists are receiving fewer grants. In fact, Lee (2004) found there was no significant difference in grant amounts and grant acceptance rate between native U.S. scientists and foreign-born scientists.

A modest body of research results provides an understanding into how foreignborn faculty are perceived on educational campuses (Alberts, 2008; Anderson \& Smith, 2005; Kavas \& Kavas, 2009; Neves \& Sanyal, 1991). The majority of respondents rated foreign-born faculty very highly with regard to knowledge and competence in the subjects they teach, social skills, empathy level and interaction skills (Alberts, 2008; Kavas \& Kavas, 2009). In another study, the perceptions of teaching ability ranged over a wider spectrum, but a majority of students would, if given a choice, prefer to have their classes taught by U.S.-born faculty (Marvasti, 2005).

Difficulties in adjusting to different academic standards, grading system, student behavior, and support available to foreign-born instructors that could help them avoid problems due to their 'foreignness', represent the issues that require additional investigation in institutional settings (Alberts, 2008). Many students find advantages to having professors who grew up outside the United States and hold a critical perspective of their home country (Collins, 2008; Foote, Li, Monk, \& Theobald, 2008). Therefore, 'foreignness' has both advantages and disadvantages, and cooperation is required of all those involved, i.e. foreign-born faculty, students, institutional administration, to provide for the smooth reconciliation of differences and integration of multiple perspectives into the diverse picture of internationalization on U.S. campuses. Students note that foreign- 
born professors have different teaching styles and interact with students differently (Kavas \& Kavas, 2009). For some students, this is an advantage. However, higher expectations from foreign-born professors may be the factor for some students to avoid their classroom (Alberts, 2008).

Much of the previous qualitative research on foreign-born faculty members has focused primarily on their adjustment issues, suggesting they experience the sense of isolation, marginality, and lack of collegiality on U.S. college campuses (Seagren \& Wang, 1994; Skachkova, 2007; Thomas \& Johnson, 2004). An early study in this area (Johnsrud \& Sadao, 1998) asserted minority faculty experience academe differently than their majority counterparts. The majority of ethnic and racial minority faculty perceived they must be bicultural to enter and advance successfully in the university setting. They must find a balance that enables them to recognize which lens to employ when confronting a particular situation. It can be assumed ethnic and racial minority faculty must constantly compromise their cultural values and norms out of deference to Western values. The findings of Johnsrud and Sadao (1998) suggested ethnic and minority faculty members do understand the norms and standards of the academic culture. They are willing to accommodate in many respects, but they bring alternative perspectives to their academic careers which they believe deserve reciprocal accommodation from majority faculty members. The perceptions and experiences described by faculty in this study indicated that those alternative perspectives are not honored; rather, they are denigrated (Johnsrud \& Sadao, 1998).

One of the more recent qualitative studies by Skachkova (2007), particularly relevant to this research, focused on the experiences of women foreign-born faculty in 
U.S. academe. The study drew on the interviews with 34 women faculty members who were born abroad and were employed at a research university in New York State. The sample of women in the study was a very diverse group of individuals: they came from 22 different countries and were from 26 academic fields. The researcher concluded their narratives were "immigration success stories but only a few of them were academic success stories"' (Skachkova, 2007, p. 728). The findings of this study suggest of the adverse effect of social climate prevailing in the participants' departments and institutions that affects their academic careers (Skachkova, 2007).

Given the evidence from the previous research, the framework of experiences of foreign-born faculty in academe provides a rationale for further investigation. The foreign-born faculty in the abovementioned studies described their efforts to accommodate to university culture. Despite their diversity, foreign-born faculty are eager to blend with and contribute to the adopted country. Combined talents of the foreignborn certainly enhance the stock of human capital in this country. This faculty help infuse the campus and the larger society with greater respect for education. The foreignborn cannot but bring certain values from their countries of origin and experiences there that are beneficial to the USA. The presence of the foreign-born certainly advances cultural diversity on any campus. Academic debate should be more concerned with better understanding the unique qualities and needs and determining what kind of support foreign-bon professors should receive in order to make them effective teachers and contributors to their institutions. 


\section{Theoretical Framework}

Based on the above review of relevant concepts, the prior literature has identified internationalization of higher education and cultural differences in the composition of faculty members as the factors that may contribute to or impact professional experiences of foreign-born faculty members working in educational leadership preparation programs in U.S. higher education system. The following section provides the theories structured around the following major factors relevant to this research: 1) theories of culture; 2) theories of leadership; 3 ) theories of cross-cultural approach to educational administration; and 4) theories of multicultural educational leadership.

\section{Theories of Culture}

Geert Hofstede is a central figure in the development of literature on cultural variation and the dimension-based approach to assessing and classifying cultures. In his foundational work on culture, Hofstede $(1980,1991)$ asserted that culture is "the collective programming of the mind which distinguishes the members of one group or category of people from another" (Hofstede, 1991, p. 5). Barnouw (1985) defined culture as "the way of a group of people, the complex of shared concepts and patterns of learned behavior that are handed down from one generation to the next through the means of language and imitation" (Barnouw, 1985, p. 5). Hofstede (1991) noted every individual is born with and thus inherits a set of universal and generic characteristics of human nature. However, he highlighted the individual's personality is formed from both inherited and learned characteristics. "We begin to acquire the mental programming we call culture from the day we are born, and the process continues throughout our life in a particular society" (Hofstede, 1991, p. 65). Therefore, culture, at its different levels, 
appears to be producing a mediating influence to affect the learned part of behavior and personality (Hofstede, 1991).

The most widely cited framework for exploring the influence of culture on management and leadership practice remains that developed by Hofstede $(1980 ; 1991$; 1994, 2001). In his original IBM studies, Hofstede $(1980,1991)$ assessed many national cultures and created a descriptive matrix ranking the country in relationship to each of the four dimensions of culture. Table 1 lists the four cultural dimensions and the description of each dimension.

Table 1

Hofstede's Four Cultural Dimensions

Power Distance

Individualism

Masculinity

Uncertainty Avoidance
The extent to which people accept unequal distribution of power. It suggests that a society's level of inequality is endorsed by its followers as much as by its leaders. It ranges from relatively equal (small power distance) to extremely unequal (large power distance). All societies are unequal, but some are more unequal than others. The extent to which individuals are integrated into groups. Individualism leads to reliance on self and a focus on individual achievement.

The extent to which assertiveness and interdependence from others are valued. High masculinity leads to a focus on interdependence, ambition, and material goods. The extent to which a culture tolerates ambiguity and uncertainty. It implies the degree to which people in a country prefer structured over unstructured situations. High uncertainty avoidance leads to low tolerance for uncertainty and to a search for absolute truth.

Note. Adapted from Hofstede, G. (1980). Cultures consequences: International

differences in work-related values. Beverly Hills, CA: Sage.

Hofstede's Four Cultural Dimensions provide a framework that functions as a starting point for examining different perspectives and paradigms held by diverse 
populations. His study and the ensuing results garnered much attention from scholars not only in the business field but also in other disciplines in order to understand how culture explains patterns in not only economic but also social activities of individuals, groups, organizations, nations, or regions (Javidan, Dorfman, de Luque, \& House, 2006).

\section{Cultural Dimensions}

To be open-minded and to understand the cultures of different countries, it is important to be able to compare one's own culture with other countries. Power and inequality are fundamental aspects of any society, and any individual with some international experience is aware that all societies are basically unequal, but some are more unequal than others (Ardichvili \& Kuchinke, 2002).

Power Distance is the degree to which members of a collective expect (and should expect) power to be distributed equally (Hofstede, 1980). A high power distance score reflects unequal power distribution in a society. Countries that scored high on this cultural practice are more stratified economically, socially, and politically; those in positions of authority expect, and receive, obedience (Hofstede, 1991). Businesses in high power distance countries like Thailand, Brazil, and France tend to have hierarchical decision making processes with limited one-way participation and communication (Hofstede, 1994)

The second dimension, Individualism, implies the degree to which people in a country prefer to act as individuals rather than as members of groups (Hofstede, 1980). The opposite of individualism can be called Collectivism, so collectivism is low individualism. Institutional Collectivism is the degree to which organizational and societal institutional practices encourage and reward (and should encourage and reward) 
collective distribution of resources and collective action (Hofstede, 1991). Organizations in collectivistic countries like Singapore and Sweden tend to emphasize group performance and rewards, whereas those in more individualistic countries like Greece and Brazil tend to emphasize individual achievement and rewards (Hofstede, 1994). Masculinity versus its opposite, Femininity, refers to the distribution of roles between genders as another fundamental issue for any society that may involve a range of solutions (Hofstede, 1980). It identifies the degree to which tough values like assertiveness, performance, success and competition, which in nearly all societies are associated with the role of men, prevail over tender values like the quality of life, maintaining warm personal relationships, service, care for the weak, and solidarity, which in nearly all societies are more associated with women's roles. Analysis of the IBM data (Hofstede, 1991) revealed that women's values differ less among societies than do men's values. The women in the feminine countries have the same nurturing values as the men; in the masculine countries they are somewhat more assertive and competitive, but not as much so as the men, so that these countries show a gap between men's values and women's values (Hofstede, 1991). People in highly assertive countries such as the United States and Austria tend to have can-do attitudes and enjoy competition in business; those in less assertive countries such as Sweden and New Zealand prefer harmony in relationships and emphasize loyalty and solidarity (Hofstede, 1994).

The three dimensions described so far all refer to three types of expected social behavior: behavior toward people higher or lower in rank (Power Distance), behavior toward the group (Individualism/Collectivism), and behavior according to one's gender (Masculinity/Femininity). The values corresponding to these cultural choices are bred in 
the family: Power Distance by the degree to which children are encouraged to have a will of their own, Individualism/Collectivism by the cohesion of the family with respect to other people, and Masculinity/Femininity by the role models the parents and older children present to the younger child (Hofstede, 1991, 1994).

The fourth dimension found in the IBM studies refers to Uncertainty Avoidance that indicates to what extent a culture programs its members to feel either uncomfortable or comfortable in unstructured situations (Hofstede, 1980). "Unstructured situations" are defined as novel, unknown, surprising, or different from usual (Hofstede, 1980). Uncertainty-avoiding cultures try to minimize the possibility of such situations by adhering to strict laws and rules, safety and security measures, and a belief in absolute Truth (Hofstede, 1991). Uncertainty-accepting cultures are more tolerant of behavior and opinions that differ from their own; they try to have as few rules as possible, and on the philosophical and religious level they are relativist, allowing many currents to flow side by side (Hofstede, 1991). People within these cultures are more phlegmatic and contemplative; their environment does not expect them to express emotions (Hofstede, 1991). Organizations in high uncertainty avoidance countries like Singapore and Switzerland tend to establish elaborate processes and procedures and prefer formal detailed strategies. In contrast, businesses in low uncertainty avoidance countries like Russia and Greece tend to prefer simple processes and broadly stated strategies. They are also opportunistic and enjoy risk taking (Ardichvili \& Kuchinke, 2002; Hofstede, 1994).

At the organizational level, differences among cultures in these four dimensions have many consequences for management practices (Hofstede \& McCrae, 2004). For example, both Power Distance and Individualism affect the type of leadership most likely 
to be effective in a country. The ideal leader in a culture in which Power Distances are small would be a resourceful democrat; on the other hand, the ideal leader in a culture in which Power Distances are large is a benevolent autocrat (Hofstede, 1994). In Collectivist cultures, leadership should respect and encourage employees' group loyalties; incentives should be given collectively, and their distribution should be left up to the group (Hofstede, 1994). In individualist cultures, people can be moved around as individuals, and incentives should be given to individuals. Masculinity and Uncertainty Avoidance affect people's motivations: competition is more effective in a masculine culture, and personal risk is more acceptable if Uncertainty Avoidance is low (Hofstede $\&$ McCrae, 2004). Power Distance and Uncertainty Avoidance together affect the image people form of what an organization should be; larger Power Distances are associated with greater centralization, while stronger Uncertainty Avoidance is associated with greater formalization (Hofstede, 1994).

In sum, cultural dimensions differ from one nation to another in ways which are seldom fully recognized and often misunderstood. Every nation has a considerable moral investment in its own intellectual power, which explains why it is not easy to make cultural differences clearly discernable. This offers great possibilities for synergy and for learning from each other in a world which to an increasing extent demands intercultural cooperation and leadership effective across nations.

\section{Cultural Leadership Differences Across Nations}

Should we also expect that leadership processes, like management practices, are similarly influenced by culture? Existing empirical evidence indicates leader attributes, behavior, status, and influence vary considerably as a result of culturally unique forces in 
the countries or regions in which the leaders function (Manning, 2003; Robertson \& Weber, 2000; Walker \& Dimmock, 2002). Graen, Hui, Wakabayashi, and Wang (1997) noted cross-cultural research is essentially focused on comparability, and that etics and emics are the foci. "Emics are things that are unique to a culture, whereas etics are things that are universal to all cultures. Emics are by definition not comparable across cultures. One task of cross-cultural researchers, hence, is to identify emics and etics" (Graen, Hui, Wakabayashi, \& Wang, 1997, p. 162).

Emanating from the previous research on culture, the two of the abovementioned factors - individualism-collectivism and power distance - seem to be relevant to the discussion.

Individualism-collectivism. Cultures differ in the degree to which they encourage individuals to pursue their own interests and goals and to limit their compliance with demands made by groups. Individualist cultures (e.g., the 'mainstream' USA and Australia) do encourage this; in contrast, collectivist cultures (e.g., traditional Japan, Honk Kong, Venezuela) subordinate individual goals to those of important groups such as family and co-workers (Hofstede, 1980). Individualism fosters the development of an independent self-image, such that an individual focuses on his or her unique capabilities and seeks to apply these capabilities to his or her personal ambitions. Collectivism emphasizes one's interdependence with others and promotes the goals of fitting in and adjusting one's goals so as to maximize the well-being of the in-group (Hofstede, 1994). In collectivist cultures, people remain sensitive to the demands of the particular social situation, and are well aware of shifts in their own behavior to accommodate these demands (Taormina \& Selvarajah, 2005). 
Power distance refers to the degree to which a culture accepts the idea that power is distributed unequally. In cultures low in power distance (Denmark, Israel), hierarchies of status are relatively flexible and informal. It would not be uncommon for subordinates to address bosses or teachers by their first names or to socialize with them. In cultures high in power distance (Mexico, Singapore, Turkey), subordinates are often quite sensitive to their roles and statuses within organization (Hofstede, 1980). In educational setting, high power distance often manifests itself in classrooms filled with students who refrain from asking questions, which might be interpreted as a challenge to the instructor's expertise or authority.

Broadly, Hofstede (1991) identified Anglo-American cultures as individualist and most Asian cultures as group oriented or collectivist. Conversely, however, collaborative learning, being generally acknowledged as an effective teaching method, appears to be more applicable for student socialization in group-oriented, rather than self-oriented cultures (Dimmock \& Walker, 2005).

Educational systems around the globe tend to reflect Western theories and practices with a little consideration of their cultural fit (Hofstede, 1994). Therefore, a focus on culture and cross-cultural comparisons can help generate theories of leadership for the countries that differ in subtle but significant ways, from the theories developed for Western societies to those applied in Asia and East (Dimmock \& Walker, 1998). A cultural perspective on administrative leadership reframes current attempts to develop a knowledge base for professional practice in Western countries. Personality has been evidenced to have had important implications for managerial attitudes and behavior (Jepson, 2009). Individuals bring to their work environment and managerial positions 
their cultural and personality traits. Culture is important because it shapes the different ways to recognize and react to events in work lives. It shapes how people experience the world of work and how they express meaning in their own work (Cunningham \& Gresso, 1993).

Therefore, a cultural lens may stimulate the research to rethink the constructs identifying universally desirable and undesirable leadership attributes as a critical step in effective cross-cultural leadership. It may illustrate while there are differences among countries, there are also similarities. Such similarities give some degree of comfort and ease to leaders and can be used by them as a foundation to build on.

Theories of Leadership

Hofstede's cultural dimensions $(1980,1991)$ provided a useful framework to broaden our understanding of leadership research. Walker \& Dimmock (2002) assumed leadership comprises eight interrelated elements as follows: collaboration and participation; motivation; planning; decision-making processes; interpersonal communication; conflict resolution; staff evaluation and appraisal; and staff development. They explored the above framework and offered a comparative investigation of educational leadership that can be conceptualized around six dimensions of societal culture, namely: Power distributed/ Power concentrated; Group-oriented/Self-oriented; Consideration/ Aggression; Pro-activism/Fatalism; Generative/ Replicative; and Limited relationship/Holistic relationship. Western societies' principals are more inclined to consider the individual needs of both teachers and students in the operation of schools (Cheng, 1998). On the other hand, in East-Asian societies, such as China, Thailand and Japan, education is seen as a means by which students adapt to the expectations of the 
community (Dimmock \& Walker, 2000). In such group-oriented societies, the role of the school and the principal may focus on developing and ensuring harmony among staff and enforcing common, standard approaches to governance, organization, curriculum and instruction (Walker \& Dimmock, 2000). Internationalization has once again made us realize that a single dominant approach cannot work for an inclusive society.

The two primary theories of school principalship have prevailed in recent decades-instructional leadership and transformational leadership (Hallinger, 1992; Heck \& Hallinger, 2005). These two models focus explicitly on the manner in which educational leadership is exercised by school administrators and teachers to bring about improved educational outcomes (Leithwood \& Jantzi, 2005; Southworth, 2002). These two leadership theories were chosen because they dominate empirical research on educational leadership and their research programs have yielded sufficient evidence for analysis (Hallinger, 2005; Hallinger \& Heck, 1998; Leithwood \& Jantzi, 2005; Leithwood, Tomlinson, \& Genge, 1996).

\section{Instructional Leadership}

Instructional leadership models emerged in the early 1980s from the research on effective schools. This body of research identified strong, directive leadership focused on curriculum and instruction from the principal as a characteristic of elementary schools that were effective at teaching children in poor urban communities (Leithwood \& Montgomery, 1982).

Scholars conducted a substantial body of international studies on instructional leadership since 1980. A new global wave of principal preparation and development programs spawned during the late 1990s (Hallinger \& Heck, 1998; Hallinger, 2005; 
O'Donnell \& White, 2005; Southworth, 2002). A review of the literature by Hallinger and Heck (1998) found instructional leadership was the most frequently studied model of school leadership over the past twenty-five years. Consequently, there is a more systematic knowledge base today than in 1980 .

Recent analyses have found a distinct programmatic emphasis on ensuring that principals are able to fulfill their instructional leadership role (Hallinger, 2003; Huber, 2004). Instructional leadership assumes that "the critical focus for attention by leaders is the behaviors of teachers as they engage in activities directly affecting the growth of students" (Leithwood, Jantzi, \& Steinbach, 1999, p. 8). The effective instructional leader is able to align the strategies and activities of the school with the school's academic mission. Thus, instructional leaders focus not only on leading, but also on managing. Their managerial roles include coordinating, controlling, supervising, and developing curriculum and instruction (Huber, 2004).

The most frequently used conceptualization of instructional leadership was developed by Hallinger (2003). This model proposes three dimensions of the instructional leadership construct: defining the school's mission, managing the instructional program, and promoting a positive school-learning climate (Hallinger, 2005).

This renewed focus on the improvement of learning and teaching has once again brought the issue of principal instructional leadership to the forefront. There appears to be a new and unprecedented global interest among government agencies towards training principals to be instructional and transformational leaders for the improved academic achievement in students. 


\section{Transformational Leadership}

Transformational leadership redirects focus toward the emotional relationship between the leader and the followers (Bass, 1985). The essence of transformational leadership is to inspire, develop, and empower followers while meeting organizational goals (Hallinger, 1992). A work environment in which frequent and recurrent changes happen, transformational leadership guides the followers to enact revolutionary change (Bass, 1997, 1998). Notably, transformational leadership focuses on problem finding, problem solving, and collaboration with stakeholders with the goal of improving organizational performance (Hallinger, 1992; Heck \& Hallinger, 2005). This augmenting effect of transformational leadership is due to the transformational leader's ability to motivate subordinates to perform beyond their initial expectations (Bass, 1998).

Leithwood and colleagues have described and assessed the effectiveness of transformational leadership in schools (Leithwood, 1995; Leithwood, Dart, Jantzi,\& Steinbach,1993; Leithwood \& Jantzi, 2005; Leithwood, Jantzi,\& Fernandez,1994; Leithwood, Jantzi,\& Steinbach, 1999; Leithwood, Tomlinson, \& Genge, 1996). Transformational leadership provides intellectual direction and aims at innovating within the organization, while empowering and supporting teachers as partners in decision making (Leithwood, 1995).

An essential question arises: Is transformational leadership effective crossculturally? Bass $(1997,1998)$ relied on studies in many types of organizations across the world to support that claim. Den Hartog, House, and Hanges (1999), House and Aditya (1997) confirmed that elements of transformational leadership such as vision, proactivity, and ability to motivate are recognized universally as effective change leadership, while 
leaders whose task and relationship behaviors are congruent with culturally accepted models of leadership are more effective in a given culture.

Marks and Printy (2003) suggested although the importance transformational leadership places on vision building can create a fundamental and enduring sense of purpose in the organization, the model lacks an explicit focus on teaching and learning. Instructional leadership, emphasizing the technical core of instruction, curriculum, and assessment, provides direction and affects the day-to-day activities of teachers and students in the school (Leithwood, Jantzi, \& Steinbach, 1999). The action orientation of shared instructional leadership moves a school staff forward to accomplish each goal thus enacting the vision. Transformational leadership builds organizational capacity whereas instructional leadership builds individual and collective competence (Cooper, 2009). Instructional leadership, if shared in that specific leadership function, is carried out by many people working in collaboration (Huber, 2004).

Building on the premise outlined above, it is assumed that while transformational leadership is necessary for reform-oriented school improvement, it is insufficient to achieve high-quality teaching and learning. Shared instructional leadership essentially describes the dynamic collaboration between the principal and teachers on curricular, instructional, and assessment matters to further the core technology of schools-teaching and learning. Thus, a suggested line of inquiry follows the relationship of transformational and shared instructional leadership to the pedagogical practice of teachers and to student performance on authentic measures of achievement. This study intends to look at the leadership practices as culturally perceived and used for the 
instructional purposes by the foreign-born educational leadership faculty members working in U.S. higher education system.

\section{Theories of Cross-Cultural Leadership}

The recent surge in research on how cultural values impact human behavior calls for cross-cultural validation of leadership theories. For example, Hofstede $(1980,1994)$ argued that many leadership theories developed in North American culture may not be applied in different cultural settings because they are conceptually bounded within American culture. According to Hofstede (1994), U.S. theories of leadership do not allow a certain amount of cultural relativity and tend to be prescriptive with regard to a leadership style. Thus, these theories will only be valid in cultures where cultural dimensions are similar to those of the U.S. culture. The growing international commonality in educational policy and in institutional structures makes culture and cultural differences an important area gaining increased significance (Leeman, 2003; McCray, Alston, \& Beachum, 2006).

The most recent and comprehensive attempts to analyze differences in leadership across countries support the general argument that culture and leadership interact in a variety of different ways in a variety of different contexts (Cunningham \& Gresso, 1993; Jung, Bass, \& Sosik, 1995; Manning, 2003; Turetgen, Unsal, \& Erdem, 2008). Dorfman (1995) argued the study of leadership across cultures is important for theoretical and practical reasons, and an understanding of cultures other than the West is important in order "to develop leadership theories that transcend cultures" (p. 269). The analyses of the qualitative interview data (Jepson, 2009) showed the importance and role of different contextual factors other than national culture. National origin was found to be just one of 
many others influencing an individual's understanding of leadership (Ardichvili \& Kuchinke, 2002). Definitions of leadership and descriptions of existing leadership differed in wording and content across individuals and reflect personal experiences (Turengen, Unsal, \& Erdem, 2008). Yet, the analyses also found similarities within the definitions and descriptions of leadership that reflect the importance of national, organizational, hierarchical and departmental contexts on a participant's understanding of leadership (Jepson, 2009). The importance of these different contexts was identified as varying across individuals. Therefore, the application of a cultural lens as a contextual factor can be useful to study educational leadership across different nations.

\section{Cross-Cultural Educational Leadership}

In the past decade, societies have become more pluralistic, and educational demands and needs of interest groups in communities being more diversified and insistent than ever, are clearly identifiable (Walker \& Dimmock, 2002). Additionally, the essential role of leaders in effective schools and successful school improvement processes has been established (Hallinger \& Heck, 1999; Hallinger, 2003; Huber, 2004).

Leaders in schools comprised of large numbers of ethnic minority students face different demands than those in more ethnically homogeneous settings (Marshall, 2004). It is, therefore, assumed if leaders in intercultural schools are to make a difference then they must learn to understand the cultural influences affecting their schools. This calls for the development of leader authenticity (McCray, Alston, \& Beachum, 2006). Leadership authenticity within intercultural schools involves more than leaders simply clarifying and articulating personal values, beliefs and purpose statements (Robertson \& Webber, 2000). Rather, it must carefully account for the cultures which comprise the 
school and how these impact relationships, curriculum, learning and teaching, among other things (Walker \& Shuangye, 2007). If this proposition is accepted, the issue becomes what leaders can do to build their authenticity in intercultural school contexts. If it is further accepted that schools and values configurations are constantly shifting, adapting and evolving within and outside organizations, seeking leader authenticity is actually a process of learning in and from the context within which leaders lead (Walker, 2005). When leaders seek authenticity through understanding and valuing other cultural perspectives, they encourage like behavior throughout the school (Walker \& Shuangye, 2007).

Cross-cultural studies help to better understand leadership behaviors in different cultures or in multicultural environments (Walker \& Dimmock, 2000; Yan \& Hunt, 2005). They also provide useful advice and guidelines for practitioners to achieve leadership effectiveness in organizations with workforces and management teams that are getting more and more culturally, ethnically, and internationally diverse (Taormina \& Selvarajah, 2005).

Cross-cultural research into leadership has grown in importance and number of research contributions (Dickson, Den Hartog, \& Mitcheson, 2003) but has, to date, been characterized by the modernist assumptions underlying much of the above-mentioned Western view on the individual leader (Jepson, 2009). Additionally, with rapidly increasing globalization, educational leadership in diverse contexts is gaining greater access to information and ideas from outside their own societies, but the information generated tends to emanate predominantly from Western perspectives (Walker \& Dimmock, 2000). 
According to Dimmock and Walker (2005), culture has a significant influence on school leadership in and within different societies, because it helps shape school leaders' thoughts and actions about leadership followership, communication, teaching, and learning. They further suggest looking to "societal culture for at least partial explanations of school leaders' behaviours and actions" (Dimmock \& Walker, 2005, p.21).

Cross-cultural leadership theories consider the establishment of international learning networks that address the interrelationships among school and society (Walker \& Dimmock, 2002). The importance of international learning networks was also asserted by Robertson and Webber (2002) who pointed out policy makers in different countries communicate with one another and are familiar with other nations' educational policies. Therefore, they argued, educational leaders should form parallel international learning networks. Similarly, Sen (1999) suggested that though we should respect cultural uniqueness, we also should strive for sophisticated understandings of cross-cultural influences and "not lose our ability to understand one another and to enjoy the cultural products of different countries in the passionate advocacy of conservation and purity"(p.244).

Shield (2002) asserted the lack of coherency within the body of literature related to cross-cultural leadership in education. A comparative approach to educational leadership can add value from a position of diverse multicultural perspectives. Basically, it can promote understanding within the international educational community (Dimmock $\&$ Walker, 1998). The purpose for developing a cross-cultural comparative framework is to improve understanding of the influence of national or societal culture on educational leadership. Cross-cultural research may reveal data as to how different populations 
conceive, identify and evaluate characteristics of effective leadership and behavior (Den Hartog et al., 1999).

In summary, the investigation of educational leadership across cultural settings is potentially a rich area for empirical exploration. It may both broaden and deepen an understanding of how cultural context may impact the theory and practice of educational administration preparation for multicultural leadership.

Theories of Multicultural Educational Leadership

The 21 st century realities of global interdependence and diverse institutions require schools effectively and appropriately respond to diverse groups in the school and school community and prepare all young people for positive interactions with people who are culturally different (Banks, 2006). As the demographics of communities change and a wider array of cultures is encountered in classrooms, the impulse that educators feel to raise students' awareness about culture cannot be ignored (McCray, Alston, \& Beachum, 2006).

Society is becoming more diverse than ever before in its history, and many of U.S. school systems reflect this diversity in their student populations (Spring, 2008). According to the United States Department of Education (2010), public schools are becoming a nation of minorities. In the United States today, schools are composed of diverse students, faculty and staff population who come from differing, socioeconomic, cultural and language backgrounds that are unique to each culture (Leeman, 2003). For instance, today, one-third of the entire student population in America consists of minority students, and by the year 2020, one-half of all students in America will belong to a minority group (Suarez-Orozco, 2007). Furthermore, by the year 2050, the United States 
will become a "nation of minorities," with less than half of the population being nonHispanic White (Suarez-Orozco, 2007). Due to this increasing amount of diversity that is taking place in society and schools, school principals must play a central role in initiating and infusing multicultural concepts and ideas into school cultures mainly because these individuals set the cultural climate for the school (Walker \& Dimmock, 2002).

The demographic shift in student enrollment from one mainstream culture to cultural pluralism has become a reality that calls for principals with multicultural competencies (Yao, Buchanan, Chang, Powell-Brown, \& Pecina, 2009). Designed to achieve equal educational opportunity to all citizens, the U.S. Congress passed the No Child Left Behind Act of 2001 as a policy. The complex school leadership responsibilities and accountability, including the issues facing minority students, necessitate the demand to have a well-trained school leader to ensure that a standardsbased quality education is provided to culturally and linguistically diverse students and for students with special needs (Marshall, 2004).

Multicultural leadership can be defined broadly in terms which enable principals to address diversity within a school setting through affirming cultural pluralism and educational equity (Shield, 2002). It can be conceptualized as the work principals do to ensure multicultural aims, objectives, curricular content, assessment content, and pedagogy are implemented effectively (Yao et al., 2009). In this endeavor, the moral growth dimension of transformational leadership is realized when administrators, faculty, and students are elevated by the actions that recognize and seek to accommodate diverse values (Leithwood \& Jantzi, 2005). The confluence of various perspectives enables the 
development of an environment in which mutual respect and caring is fundamental to achieving the goals of multicultural education.

At the school level, the school leader is the designee appointed to ensure each student receives a quality education (Walker \& Shuangye, 2007; Witziers, Bosker \& Kruger, 2003). The effectiveness of a school's educational program is determined by the leadership and attitude of the school administrator (McCray, Alston, \& Beachum, 2006; Robinson, Lloyd \& Rowe, 2008). Cunningham and Cordeiro (2006) asserted educational leadership is the number one variable associated with effective schools. School leaders produce the climate that makes learning possible and programs successful (Riehl, 2000). Hence, they should play a key role in providing culturally responsive leadership for multicultural students.

Clearly, administrators who embrace multiculturalism, recognize and address the differences of their teachers, students, and parent population (i.e., linguistic, ethnic, racial, socioeconomic, and learning differences) view student differences as qualities that make each individual unique and valuable; recognize and promote cultural differences; and provide opportunities for growth and development (Evans, 2007). Additionally, such school leaders are aware of their personal strengths and weaknesses as they collaborate with and empower teachers and other staff around them to help provide all students with support (Walker \& Shuangye, 2007).

School leaders who embrace and utilize multicultural practices in their schools exhibit a sense of self-confidence that allows others to feel comfortable, and they do not prohibit others from being themselves (Walker \& Dimmock, 2002). They trust and motivate others to work together to meet the academic and social needs of all students 
(Gardiner \& Enomoto, 2006). In this learning community, school leaders establish a purpose and collaborate with teachers, parents, and community leaders to create a cohesive and cooperative environment that benefits all students, especially multicultural students (Yao et al., 2009). They do not look for ways to categorize students; they encourage individualities and build on them to create a multifaceted, multicultural and multitalented learning community (Riehl, 2000). This community works together to meet individual needs, value each member, and ensure higher learning through increased participation of various community members.

School leaders need to cultivate a school culture that offers an appropriate education for immigrant students (McKenzie, Skrla, \& Scheurich, 2006). The incorporation of students' languages, cultures, and experiential knowledge need not conflict with providing students with academic content knowledge and learning skills. Immigrant students come to school bringing their diverse cultures and assets. School leaders need to conceptualize the culture and language of immigrant students as assets rather than deficits in order to accept and celebrate these students' attributes and diversity (McKenzie, Skrla, \& Scheurich, 2006). A unique cultural contribution of immigrant children is their cross-cultural expertise. Tsolidis (2002) emphasized that students with cross-cultural expertise are likely to be more successful global citizens than those who are monocultural. At the same time, immigrant students can offer their cultural knowledge to others and gain respect from native students as they do so since all students need to know how to function between cultures (Tsolidis, 2002).

An inclusive school culture is one that reflects the ethnic and cultural diversity of the broader school community. Riehl (2000) defined an inclusive school culture as one 
in which students from diverse racial, ethnic, and social groups believe that they are heard and valued and experience respect, belonging, and encouragement. To build and sustain an inclusive culture, the principals must promote the participation and representation of all students, teachers, parents, and community groups. They must establish structures for this involvement, such as student councils, professional development days, prefect systems, and community-linked groups (Walker \& Dimmock, 2005).

It appears, therefore, understanding the concepts of multicultural education can help school leaders be more inclusive. Emphasizing diversity and fostering respect and caring are the concepts that school leaders can encourage. The exposure to the educational leadership faculty with a culturally diverse background can contribute to the development of school leaders' multicultural values and beliefs. The new leaders must have a better understanding of educational issues that are prevalent in education internationally and support the realization of diversity in schooling practices which, along with the increased progress in world communication, can broaden the possibilities for collaboration with colleagues holding similar interests in varied global settings.

\section{Summary}

This chapter reviewed the factors pertinent to the understanding of the context of studying professional experiences of foreign-born faculty working in educational leadership preparation programs on U.S. campus. This review illustrated the cultural differences existing within U.S. higher education faculty. With an increasing number of foreign-born scholars seeking academic employment in the United States, there is a need to go beyond just determining their status in academe. Previous studies focused on job 
satisfaction and acculturation issues of foreign-born faculty in science and engineering departments. In an increasingly globalizing world it is assumed, therefore, that it is important to investigate which qualities in people and their cultures are universal, and which are culturally distinct. However, the empirical studies reviewed do not constitute a robust evidence-base for the professional experiences of the foreign-born faculty in the programs related to educational leadership preparation. The consideration of the implications of the cultural context for the nature and forms of educational leadership at a time of reform, design, and restructuring appears ubiquitous. Educational leaders and their staff need to be knowledgeable about diversity to provide education that is culturally sensitive to difference, is free from discrimination and prejudice, and promotes educational equity. School principals serve an important role. Because of the increasing amount of cultural and social diversity occurring in the society and schools, school leaders must create environments that promote cultural pluralism and provide every student with an opportunity to succeed. 


\section{CHAPTER III}

\section{METHODOLOGY}

Introduction

The proposed phenomenological study served two purposes. This study sought to describe the lived professionally related experiences of foreign-born faculty working in educational leadership preparation programs in U.S. higher education. In addition, this study sought to reach an understanding of the cultural processes by which foreign-born educational leadership faculty professionally adapt and adequately function in U.S. higher education system. It aimed at studying the impact produced by the cultural background on the professional approaches and self-perceived leadership styles. This study was guided by the major research question:

What are the professional experiences of foreign-born faculty serving in educational leadership preparation (ELP) programs?

The three sub-questions were used to seek additional information on the theme:

1) What role does culture play in professional experiences of foreign-born faculty in ELP programs?

2) What factors do foreign-born faculty perceive as having impact on their professional experiences in ELP programs?

3) To what extent, if any, do their ethnicity and culture affect their leadership philosophy as faculty members in ELP programs?

The two techniques were used for data collection in this study: semi-structured interviews of individual participants and analysis of relevant individual and/or organizational documents and archival data about participants' professional experiences. The methodology employed to test the research questions is presented in this chapter. 
The chapter is organized into five sections: 1) methodological framework; 2) selection of participants; 3) instrumentation; 4) data collection; and 5) data analysis.

\section{Methodological Framework}

The literature available on the professional experiences of faculty members who were born into and grew up in a culture different from the U.S. identified cultural background as a factor affecting foreign-born faculty's work attitudes and experiences. Given the limited literature examining the experiences of foreign-born faculty working in educational leadership departments in U.S. higher education, the research questions were approached through the use of qualitative inquiry because exact variables and a theory base are unknown for this specific population.

The methodological framework for this research was based upon the phenomenological tradition within the qualitative paradigm. According to Patton (2002), the phenomenological approach is characterized by "the assumption that there is an essence or essences to shared experiences. These essences are the core meanings mutually understood through a phenomenon commonly experienced" (p.106). According to Bogdan and Biklen (2003), phenomenology assumes that "multiple ways of interpreting experiences are available to us through interacting with others, and that it is the meaning of our experiences that constitutes reality" (p.23). Thus, reality is assumed to be socially constructed. As identified by Creswell (1998), "A phenomenological study describes the meaning of the lived experiences for several individuals about a [particular] concept or phenomenon" (p.51). In this study, professional experiences were the phenomenon under analysis. The lived experiences of foreign-born faculty were referred to as their day-to-day experiences in academe. Thus, the study attempted to uncover how foreign-born faculty make meaning of their everyday experiences in academe. This leads 
to one of the most salient aspects of the qualitative paradigm - the challenge to gain the insiders' viewpoint (Bogdan \& Biklen, 2003).

According to Lincoln and Guba (1985), reality is "a multiple set of mental constructions". The judgment of validity of the study depended upon the researcher, who represented these multiple constructions and perceptions of reality in the context in which they are presented (Marshall \& Batten, 2003). Internal validity measured the extent to which the findings were congruent with reality. A qualitative inquiry required that the investigator adopt a neutral stance where the researcher is not setting out to prove a particular perspective or predetermined results. The researcher needed to be balanced in reporting evidence which may confirm or may fail to confirm the initial assumption (Patton, 2002).

\section{Selection of Participants}

The sample was comprised of eleven foreign-born faculty working within the University Council for Educational Administration (UCEA) institutions. The UCEA is a consortium of 86 public and private doctoral degree-granting universities. The participants were selected from the four regions of the United States: North, South, Midwest, and West. The target population of this study was foreign-born faculty members working in educational leadership programs within the aforementioned academic association.

The following steps were taken in selecting a certain number of foreign-born faculty for interviews. The first step was to contact a department of personnel at each university to inquire about the possibility to access a full list of foreign-born faculty members in educational leadership preparation departments. In general, information on 
faculty's ethnicity is treated as private and confidential by the universities. Therefore, it was necessary to consider an alternative route to get access to the lists of foreign-born faculty. Selecting foreign names from the university directories was considered as alternative. Due to the assumed difficulties in gaining access to the lists of foreign-born faculty at each institution, it was not be possible to apply the same mode of selection to different institutions.

As this is an exploratory study of under-investigated population, a heterogeneous sample of participants was sought. A purposive sampling strategy was used to collect as much rich data as possible and obtain an in-depth understanding of the phenomenon under study from the perspective of the participants. As noted by Seidman (1998), an indepth phenomenological interviewing of "a sample of participants who all experience similar structural and social conditions gives enormous power to the stories of a relatively few participants" (p.48). This study relies on the definition of those who were born and earned bachelor's degree in foreign countries. Professorial status of the participants was considered not as a major criterion of selection. Table 2 presents gender and academic data of the participating faculty.

Table 2

Academic Qualifications of Interviewed Foreign-Born Faculty

Gender

Professor

Assistant

Associate

Full

Female

8

1

Male

1

0 
Additionally, in light of differentiating foreign-born faculty, this study categorized them into two groups: (1) Those who come from neither Western nor English-speaking countries, and (2) Those who come from either Western or Englishspeaking countries.

\section{Instrumentation}

The first instrument in this study was semi-structured, open-ended interviews with eleven participants working in U.S educational leadership preparation programs. Merriam (1998) defined semi-structured interviews as interviews that evolve from inquiry composed of a mix of both structured and unstructured questions. The unstructured questions were open-ended to allow the participants more freedom and creativity to respond to the questions.

The semi-structured interview approach provided standard data across participants but also allowed the flexibility to probe answers more deeply and gather more information than is found in a structured interview (Gall, Borg, \& Gall, 1996). All the interview questions were directly correlated to the research questions and based upon the Theories of Culture and Theories of Leadership presented in Chapter II. Questions were designed to allow participants an opportunity to reflect upon their professional experiences and how they relate to the abovementioned cultural and leadership theories.

The second instrument in this study was the analysis of relevant individual and organizational documents and archival data about participants' professional experiences. As suggested by Patton (2002), documents and interviews should be used to supplement, complement, and reinforce one another in order to obtain as complete picture of phenomena being studied as possible. Therefore, document analysis was also employed 
as a way to subsidize the interview data. The data derived from documents pertaining to the internationalization efforts of the participants' institutions were coded according to the three categories linked to the research questions: (a) the definition of the mission of internationalization, (b) the desired implementation of internationalization, and (c) the role of foreign-born faculty. Document analysis provided this study with the information regarding organizational culture and other environmental factors that influence the foreign-born faculty's professional experiences.

The process of data collection and analysis were conducted concurrently. By conducting data collection and analysis simultaneously, the initial results of data analysis were used to adjust data collection strategies in order to provide a focus for future data collection so that needless repetition and extensive quantities of data were minimized (Merriam, 1998).

\section{Researcher as Instrument}

In this study, the primary role of the researcher was to "respond to the situation by maximizing opportunities for collecting and producing meaningful information" (Merriam, 1998, p.20). The researcher adopted the position of "empathic neutrality" (Patton, 2002, p.50) in order to understand the phenomenon as it unfolds, and to stay true to complexities and multiple perspectives as they emerge in the process of the research. It was also considered important to keep balance in reporting all kinds of evidence with regard to any conclusions offered (Marshall \& Batten, 2003). The researcher's background of foreign-born proved to be advantageous in establishing rapport and communicating effectively with the participants. It was considered as important to have prior knowledge about the country of every participant in order to ask proper and relevant 
questions. The researcher needed to adopt a cultural perspective on the interviewing techniques specific to the communicative peculiarities of each participant's nationality to be sure how deeply or comprehensively they can talk about some topics.

\section{Data Collection}

The two strategies for data collection were used for this study. They were semistructured interviews, and analysis of archival organizational and individual documents regarding to the organizational environment in general and the individual participants of the study.

\section{Semi-Structured Interviews}

This study employed semi-structured interviews as a dominant strategy for data collection. A semi-structured interview means that some general questions play a role in guiding the interview but the interviewer leaves space for the interviewees to construct the topic with their own categories and contents (Bogdan \& Biklen, 2002). Semistructured interviews were conducted with purposefully selected participants to gain insights into how individuals perceive, attend to, or otherwise deal with incidents relevant to their professional experiences in academe. Comparison of nationality as one of the research goals was another reason for the choice of the semi-structured interview. For comparison, it was significant to get comparable data across the entire population of interviewees rather than to have simply diversified data without any common criteria (Bogdan \& Biklen, 2002).

The first phase in data collection included contacting the participants about their agreement to participate in the study. The pre-interview sheets were faxed to the participants explaining the purpose of this research and eliciting background information 
on these foreign-born faculty members. The questions included nationality, the place of the first degree (BA, BS, etc.), major field and specialty at present, rank at their university, gender, administrative position now and previously, and duration of employment at the university. Along with the interview consent forms, a request for a convenient time for the telephone interview was sent to every participant. Every participant of the interview was informed about the purpose of the study as well as the methodology employed in advance. To enhance the openness of the participant's responses, it was assured that the data will be collected without disclosing their names and private concerns and will not be used for any other purpose without their consent. Confidentiality was a high priority, given the foreign-born faculty represent a small portion of faculty in their work units.

A semi-structured interview protocol was used to provide a general framework for the interview in order to engage the participants into the critical reflection about the factors with regards to their professional experiences. In addition, the interview aimed at eliciting unanticipated but relevant issues that may be brought up by the interviewees. During the telephone interview, the participants were asked to reflect upon their professional experiences with respect to their cultural background. The participants were encouraged to give examples of situations, people, and organizations that fit their specific perception of the leadership theory, thus making the interview more of an informal conversational interview. The strength of the informal conversational approach to interviewing was that it allowed the interviewer to be responsive to individual differences and changes (Patton, 2002). One of the benefits of this type of the interview was that questions could be individualized to establish in-depth communication with the person 
being interviewed (Patton, 2002). Interviews lasted approximately 45-60 minutes and were recorded and transcribed. Notes were typically made after the interview. Following the note taking, the interview record was labeled and dated. All interview records were reviewed as soon as possible. The records were listened to prior to transcription to get used to the speech patterns of the participants, thereby making transcriptions more efficient. It also allowed for the early identification of patterns and themes. Interview records were transcribed verbatim in preparation for data analysis. Confidentiality of all codes was assured by keeping them in a secure location and in the possession of the researcher.

Notes were made during transcription that identified key issues and perspectives, seeming contradictions in an interviewee's perspectives, divergence between the perspectives of the interviewee and other data sources, and themes and issues to be followed up in the future data collection. The interview transcripts were then sent to the participants for their review to assure accuracy. All participants' responded, and only minor editing was done to some of the transcripts.

\section{Document Analysis}

The second phase of data collection included the analysis of the documents. Documents are primary data sources that provide direct information about events, decisions, activities, and processes (Patton, 2002). The study rested on the strength of this method of collecting data as "unobtrusive and nonreactive" (Marshall \& Rossman, 2006, p. 108). Another advantage of using documentary material is its stability. Even though less active or interactive when compared to other forms of qualitative data collection such as interviews, documents represent a useful and "a ready-made source of data, easily accessible to the imaginative and resourceful investigator" (Merriam, 1998, 
p.112). Relevant institutional policies and programs announced and implemented in the organization under study with respect to diversity and international issues in education were sought for analysis. In addition, participants' professional CV's, personal written accounts of critical events with respect to diversity issues at their institution were collected and analyzed.

\section{Pilot Study}

Once the questions were produced and the necessary permission granted, a pilot study was conducted to verify the interview protocol. The pilot study of the interview protocol was undertaken in November 2010. The four foreign-born faculty members from the researcher's institution agreed to be interviewed. They were interviewed about their professional experiences and the influence of their national background on their professional experiences. The interview questions appeared to elicit the desired information. The interview protocol was judged to be clear and understandable to the interviewees. It confirmed the content, structure, and sequencing of questions would allow the researcher to obtain useful data to answer the major and secondary research questions. Nonetheless, the pilot study permitted the further refinement of the protocol. The protocol underwent several iterations prior to its use during the actual study.

\section{Data Analysis}

One of the challenges of the data analysis in this exploratory study was discerning meaningful and significant findings when there is not a large sample population. The interpretive framework for this study was content analysis which was used "to identify core consistencies and meanings" (Patton, 2002, p.453) within the amount of collected data. The largely inductive qualitative data analysis was guided by Hofstede's (1980) 
comprehensive study of how values in the workplace are influenced by culture. It was comprised of the analysis of similarities and differences, coding and categorizing, and constant comparison. The eleven telephone interview were recorded and transcribed word for word. Using the constant comparative method, the interviews were compared to each other as they were collected to determine similarities and differences. Categories were formed, coded, and triangulated for both the telephone interview data and document analysis data by using a color code representing different themes that emerged from the data. Themes were determined for each research question and those themes were compared to each other for further analysis.

Additionally, themes from the data were compared to existing literature on crosscultural studies in educational leadership and the role of culture in professional experiences. Therefore, the constant comparative method provided for the beginning of the formal analysis early in the study and was almost completed by the end of data collection (Bogdan \& Biklen, 1998). This method of data analysis was implemented after each phase of data collection, constantly analyzing and comparing each new interview received in the course of the study.

The findings of the research were reported in the aggregate, without addressing differences by ethnicity, race, or nationality. Although significant differences within the aggregated group were acknowledged, the research was focused on the primary interest the extent to which foreign-born faculty members serving in educational leadership preparation programs in U.S. higher education report common experiences in their approach to leadership preparation. 


\section{Triangulation}

Methods triangulation involves the use of multiple research methods in a single study so that one type of data verifies or supplements another, providing a more concise interpretation, and increasing the accuracy and credibility of findings (Patton, 2002). The reliability and validity of this study were addressed with the techniques of triangulation: member check and audit trail (Lincoln \& Guba, 1985), and thick description of contexts and personal accounts of experiences (Denzin \& Lincoln, 1994). Additionally, an expert team of university professors validated telephone interview questions for face validity.

The content analysis of the documents was conducted to triangulate the findings of the study. The documents included organizational records relevant to foreign-born faculty's professional experiences or institutional diversity initiatives. Initial themes were continuously identified. Theory triangulation was also used in this study as it relies on the research in the fields of psychology, sociology, organizational behavior, and higher education to triangulate the data.

An audit trail was maintained at all stages of data collection and analysis by keeping detailed records of how data were collected, how categories were derived, and how decisions were made throughout the processes of the research.

\section{Limitations}

There are several inherent methodological limitations of this study. In view of the impact of language on interviewing, it is important to question how significantly speaking in a non-native language affects the quality of an interview. It is argued that "language is more than a means of communication about reality: it is a tool for constructing reality. Different languages create and express different realities" 
(Spradley, 1979, p. 17). Given that the interview method is concerned not only with factual descriptive information but with implicit meanings embedded in the contents conveyed by the interviewee, it was a point of special consideration because English was the non-native language to the researcher and the majority of the participants of foreignborn background.

There is also a possibility both of the researcher's bias in interpreting the interviews and a possibility that interview participants may not feel comfortable openly discussing issues related to their academic status with someone who does not share that identity. Therefore, the researcher made every effort to express an interest in responses, convey the worth of the project, and ensure anonymity to encourage uninhibited responses.

Participants were the representatives of varied national and cultural backgrounds. This also posed challenges to the researcher as an individual who was brought up in a different culture. The interpretations of data may be subject to the researcher's personal and professional background. In addition, some cultures may be particularly reluctant to complain or admit to having conflicts with colleague. The discomfort in admitting to difficulties may contribute to altering or omission of some aspects in the responses of the participants. To counter this, prompts were given and follow up questions were asked.

The sample size studied may also influence the findings. As with the number of questions addressing a given value, a small number of participants can lessen the importance of the finding.

There are a few concerns about the limitation in the analysis of the documents. First, the research considered documents are not produced for research purposes, and the 
information they offer may not be in the form that is useful or clear for the purposes of the study. In addition, the research determined authenticity and accuracy of the documents under analysis.

However, this is an exploratory study and findings are intended to shed light on the understanding of foreign-born faculty professional experiences with respect to the impact of their national background as well as to suggest areas for more in-depth research. The interviewing strategy was enhanced by the analysis of the relevant documents thus serving as a basis for future research.

\section{Summary}

This chapter restated the purpose of this study and presented the research questions. The participants were chosen through the purposive sample of foreign-born faculty members working in educational leadership preparation programs of UCEA institutions. The selection of the eleven participant sample from the target population was discussed. In addition, the validity and reliability of the instruments were presented. The data collection procedures were also discussed in this chapter. Finally, the methods of data analysis were presented followed by a discussion of power analysis. Results of data analysis are presented in the following chapter. 


\section{CHAPTER IV}

\section{ANALYSIS OF THE DATA}

Introduction

This phenomenological study analyzed the professional experiences of foreignborn faculty members serving in educational leadership preparation programs in the United States. The study explored how foreign-born faculty members contribute to the cultural diversity on campus by collecting data about the influence of national background on the professional experience of those faculty members. In addition, the study attempted to ascertain the cultural contribution of the foreign-born faculty members to the multicultural leadership preparation in educational leadership programs. The research process was guided by the following questions: What are the professional experiences of foreign-born faculty serving in educational leadership preparation (ELP) programs? What role does culture play in professional experiences of foreign-born faculty in ELP programs? What factors do foreign-born faculty perceive as having impact on their professional experiences in ELP programs? To what extent, if any, do their ethnicity and culture affect their leadership philosophy as faculty members in ELP programs? The study utilized a qualitative approach to discern the phenomenon. The first stage involved the analysis of the eleven interviews using a sequential analysis of data for emergent patterns and themes. The data collected in this manner were then used in analyzing the documents pertinent to the themes gleaned from the interview process.

The first part of this chapter presents the analysis of the interview data. The second part addresses the characteristics identified from the analysis of the documents. Each part examines the characteristics of the themes identified through the analysis of 
data. The chapter includes both data analysis and the interview results. Tables depicting the data are included in each part.

\section{Participants}

Data were obtained from eleven foreign-born faculty interviewed during Fall 2010 - Winter 2011 academic year. The participants included ten female professors and one male professor serving in educational leadership preparation programs at eleven UCEA-affiliated institutions. The participants held the rank of assistant professor, associate professor, or professor. A detailed demographic overview of the participants was provided in Table 3 of the preceding chapter. Throughout the analysis, each participant is referred by a pseudonym.

\section{Data Analysis}

Qualitative data analysis attempted to comprehend the phenomenon under study, synthesize information, explain relationships, theorize about how and why the relationships appear as they do, and reconnect the new knowledge with what is already known, all in an interpretative way (Patton, 1990). In this study, the researcher became familiar with the data and transcribed the interviews. Interview transcripts and document analysis data formed the body of the data analyzed. The data were arranged by interviews, by interview questions, and by document review. Document review consisted of: (1) those pertaining to the individual academic and professional records of the participants; (2) those pertaining to the strategic plan for internationalization and diversity within the schools and departments.

The interviews and document reviews were coded according to the themes of cultural diversity on campus, the impact of culture on professional life, and multiculturalism in educational leadership preparation. In developing coding categories 
of the interview data, the two major domains were considered: participant codes and topic codes. For the participant codes, each interviewee was coded by country of origin, professorial status, gender, and currently affiliated institution. Topic categories were first elicited from the research questions. Some of the theoretical frameworks also contributed to developing topic coding categories.

At the early stage of data analysis, the researcher read through the interview data several times in search for some regularities and patterns as well as for topics the data encompassed. Reading several times was important for expanding and elaborating coding categories. Repeated readings allowed emerging topics and themes to lead the researcher to reread other data again and understand it in new ways. Each of the questions from the interview was coded and the responses from each interview were categorized by theme. Interpretations and analysis from the themes coded from the interviews and document data were made on the basis of the extent to which culture and national background have impact on the professional life. Every participant was assigned a pseudonym to insure privacy.

\section{Interview Data Analysis}

Interviews and data analysis occurred simultaneously until the end of the study. Data were analyzed using the constant comparative method. The development of categories came from the data. Upon the receipt of new data the existing categories were tested and new categories were created, tested, and changed with each subsequent receipt of data. The process was continuous and emerging. Content analysis was used to identify themes and issues emerged from both sources (Patton, 1990). The researcher searched for words and phrases that represented themes, topics, and patterns. A coding 
system was developed to organize the emerging themes from the collected data. After completing the coding, the units of data categorized by codes were cut and pasted on separate color cards. On each card, the researcher noted a participant's real name, pseudo name and a number of symbols to indicate nationality, professional status, gender and affiliated institution. At the top of each card, the researcher placed the major theme or topic of that specific part of data. A stack of cards were arranged along specific topics and themes so that a group of cards could be pulled out, when needed. The emerging themes were taken from the data instead of using a set of categories and themes that were "imposed on them prior to data collection" (Patton, p. 390). Regularities and patterns were noted. This resulted in discovering points of commonality and areas of significant divergence.

The collected data were interpreted using Hofstede's Conceptual Framework for Assessing Culture (Hofstede, 1980, 1991, 1994). Hofstede gathered extensive data on the world's cultures, which were generated into the scale to help to better understand the many sublet implications contained in his raw data (2001). In this study, as the interview transcripts were examined and re-examined, the data were coded according to the framework. New categories emerged as the transcription examination progressed. With each new transcript, the researcher continued to watch for the emergence of potential new categories. The constant comparison led to the categories that were both descriptive and explanatory (Lincoln \& Guba, 1985).

The four overarching themes identified throughout the data analysis process were: (1) Issues of internationalization of U.S. higher education; (2) Cultural competencies of the foreign-born faculty members serving in educational leadership preparation 
programs; (3) Cultural approaches to leadership as identified by the interviewed foreignborn faculty members; and (4) Contributions of the interviewed foreign-born faculty members with regard to multiculturalism of American education.

Foreign-born Faculty Interview Findings

This section presents the results gleaned from the eleven foreign-born faculty member interviews conducted during Fall 2010 - Winter 2011 academic year with regards to their professional experiences. The interview questions are located in Appendix D of this document. The researcher asked questions about the participants' beliefs and perspectives, about the facts, feelings, motives, past and present behaviors, standards of behavior as to what people thought should be done in certain situations, and conscious reasons for actions or feelings (Silverman, 1993). The interview responses contained the beliefs, thoughts, and ideas of the person being interviewed. Because the research data were derived from these responses, it was important the questions be appropriate and deliberate. Probes were also used as necessary to elucidate additional details of various statements. During the interview, the researcher had control over the line of questioning and could record the information as it was revealed. The researcher was familiar with the questions and their sequence so that the interviews flowed smoothly and with a conversational tone that refrained from expressing approval or surprise at the responses. At the end of each interview, the participant was asked if there was anything else she or he wanted to say about their experiences reported. The interviews were carried out over several months. Attempts to minimize threats to validity arising from personal biases were carried out by the researcher and the participants' not knowing each other. 
The research questions asked during the interviews with the foreign-born faculty members were derived from the themes in the literature review. Theories of culture promoted themes that emphasized the impact of national background on the professional life. The questions that were concerned with the participants' multiculturalism attempted to ascertain the promotion of multiculturalism in educational leadership preparation programs.

Table 4 lists competencies from several sources. Competencies listed in Column $\# 1$ are a presentation of responses collected from the participants' interviews and the analysis of the documents. During the interviews, the participants were asked about the influence of their national background on their professional experiences. The participants were not limited to a single response. Each participant provided multiple competencies. The data analysis consisted of the identification and coding of data according to emergent patterns. Several concepts emerged from the data and formed a supplementary coding scheme related to each research question. The participants' perceptions of the mission to internationalize were coded by attitude to internationalization, relevance to subject area, and desired scope of internationalization. The emergent concepts pertaining to the participants' perspectives of their daily professional experiences included instructional style, interaction with students and colleagues, rationale for service opportunities and experiences, and rationale for grant opportunities and experiences as influenced by the multicultural educational backgrounds of the participants. Characteristics associated with the national background of the participants are included in the table. Column \#1 competencies are clustered under several overarching themes. The competencies under each cluster are listed regardless of frequency or order of occurrence. Column $\# 2$ items 
are the competencies collected from the literature reviewed during the course of the study.

\section{Table 3}

\section{Cultural Competencies}

\section{Column \#1}

Competencies sited by study participants
Column \#2

Competencies sited by literature
Internationalization

Importance

Contemporary issue

Diversity on campus

Diversity in educational system

Broader perspective

Impact on students

Impact on teaching
Cultural Competencies

Power Distance

Individualism/Collectivism

Masculinity

Uncertainty Avoidance
Internationalization as a current issue

Chan \& Dimmock (2008)

Mamiseishvili \& Rosser (2009)

Spring (2008)

Stromquist (2007)

International curricula

Chan \& Dimmock (2008)

Deardorff (2004)

Ellinboe (1998)

Hanson \& Meyerson (1995)

New structures and expectations

Seifert \& Umbach (2008)

Spring (2008)

Diversity on campus

Hser (2005)

Taormina \& Selvarajah (2005)

Theobald (2008)

Stohl (2007)

Cultural Dimensions

Hofstede $(1980,1991,1994,1997$, 2011)

Hofstede \& McCrae (2004)

Han (2008)

Hser (2005)

Marvasti (2005) 
Table 3

Cultural Competencies (continued)

Column \#1

Competencies sited by study participants
Column \#2

Competencies sited by literature
Different patterns of communication

English as a second language

Approach to Leadership

Definition

Defined by national culture

Conditioned by professional life

Multiculturalism

Biculturalism/Multiculturalism

Impact of graduate school

Influence on teaching

Relation to research interests

Relation to grant experiences

Reflection in service

Impact on relationships with colleagues

Beneficial overall
Foote, Li, Monk, \& Theobald (2008)

Han (2008)

Manrique \& Manrique (1999)

Leadership across nations

Dickson, Den Hertog, \&

Mitchelson (2003)

Manning (2003)

Stogdill (1974)

Dimmock \& Walker $(1998,2005)$

Jepson (2009)

Cunningham \& Gresso (1993)

Dorfman (2009)

Cross-cultural differences

The importance of internationalization of U.S. higher education was stressed by all the participants. National background was identified as important in each of the participants' professional experiences. The analysis of the data indicated foreign-born faculty underwent similar experiences in the academic environment. In general, they 
engaged in similar types of activities related to service opportunities on campus.

Foreign-born faculty faced similar challenges as they learned their new roles in academe. Their national background influenced their socialization. In particular, culture influenced the nature of their interactions with students and colleagues. Some of the faculty experienced the lack of collegiality through the lens of their own cultural expectations regarding interactions with peers.

Overall, by becoming a faculty member in the United States, foreign-born faculty members have changed at their professional level, and they have acquired a broader worldview that enhanced both their professional and personal lives. Their experiences have been rewarding on the whole, and their multicultural experiences have increased the scope of their professional life. Therefore, they are likely to have adapted well to the academic profession in the United States. The following section presents the analysis of the interview data with regards to the aforementioned aspects.

\section{Internationalization of Higher Education}

The internationalization of American higher education is a topic gaining much more attention today. There are numerous approaches to provide higher education with an international dimension, such as recruitment of international students, faculty, scholarly and student exchange, and study abroad programs. The presences of foreignborn faculty and the positive impact of their presence can certainly serve as stimuli for a broader perspective in teaching methods. In this study, hiring and retention of foreignborn faculty for U.S higher education was identified as important by 9 out of 11 participants. Professor Ten noticed, "I think it's a part of what makes the system viable...Having new fresh blood and perspectives." Professor Two commented on the nature of his institution, "The university is, I would say, vibrant in terms of providing 
opportunities for international faculty, international issues. There are so many programs that are geared to fulfilling that mission of the university." Professor Six spoke in general terms that foreign-born faculty-members add value to American higher education. She said, "...I think anything that introduces difference and novelty adds to academic life of any kind of organizational or work life." Professor Two stated passionately:

If we don't have internationalization, if we don't include international elements in our style, in our knowledge building in terms of the examples we give to our students, in terms of the assignments we want them to work on what we know in this country...So if we are looking forward into the $21^{\text {st }}$ century, which is actually now, I think it's not a choice to have multicultural faculty, but a necessity.

The value added by foreign-born faculty members can be viewed from different dimensions. Regarding educational leadership programs, foreign-born faculty talent adds to the substance of the faculty pool. Professor Two accurately observed:

I think it's important to have international faculty on board because that would really add one major angle and perspective to the program. Schools today are loaded with so many diverse students and we are preparing principals for those schools as well. Leadership for social justice requires understanding the cultural perspective of those children in order to promote their learning and how to prepare leaders for those schools. And we are to bring international faculty members who may understand the cultural needs and perspectives of these principals when these principals come to our leadership programs.

In addition, foreign-born faculty bring more diversity and different perspectives to the system, which broadens the horizons of its members. Professor One, who felt strongly about the importance of foreign-born faculty as a part of the internationalization processes, commented:

They [students] don't acknowledge how important the international education system is. Most of them are never really exposed to the eastern culture of multiculture... you know... different cultures...I definitely think that introducing international education, or internationalization, or globalization and anything related to that is very important to open my students' eyes. 
Professor Eleven mentioned foreign-born faculty members are resourceful in their international connections, and this facilitates new academic cooperation between the institutions where they work and foreign countries. Professor Eleven stated:

I think international faculty can not only provide that insight, but also can become liaisons with institutions and faculty overseas to do joint programs. Now I have been thinking with the technology I know and have joint programs with the faculty around the world and research projects. You need international faculty to understand the cultures and the systems overseas to create those partnerships.

In general, foreign-born faculty were cognizant of the world events emphasizing the power and size of the United States usually lead Americans to be self-focused. Professor Eleven commented on the different approaches Americans and foreigners take toward education with regard to the benefits of having foreign-born faculty on campus:

They [Americans] have a culture of not looking at the rest of the world and learn lessons. It's a big difference with my country where we constantly learn from other countries. And I think it's a very enriching experience... But you see, the problem is the United States being in the world for so long that the rest of the world is catching up. And they are actually doing much better in many aspects, especially in education. And it's time for them [Americans] to start looking at other models...And I see it as having international faculty with that outlook, with that understanding teaching domestic students.

All faculty members agreed with the obvious that foreign-born faculty members contribute to the element of diversity on campus. The diversity of student population is nothing new, and the diversity of faculty is gaining importance:

You need to really try as much as possible to bring in as much cultural diversity as possible. And when we talk about educational leadership programs, people who have experience in their countries, for example, as teachers, people who have experience as school principals or educational administrators bring really different perspective, different experience. That helps you to see the educational system from a broader perspective rather than really bringing in people with the same set of experience (Professor Two).

The number of foreign-born students enrolled in American higher education has been growing, foreign-born faculty members can serve as role models for these students. 
This would facilitate success on the part of the foreign students and enhance their positive experience in the United States. Professor Eleven provided personal stories describing her interactions with students:

I attract international students. Many of them, especially those who come to me and many times they want to know how I made it. I find myself doing a lot of mentoring to non-English speakers on how I did it, how I handle English... So that's important. And then, I see a lot of students that are interested in the issues of diversity and international exchange programs.

Professor Two reiterated:

Many international students seek my advice. They choose me as their dissertation chair. They always want come talk to me so that I am aware they have cultural clash. They see me as a resource person.

Foreign-born faculty members bring a different perspective to viewing and solving issues, which can be extremely beneficial to all students, foreign and domestic.

Foreign-born faculty members help broaden students' perspectives by their presence.

Professor Nine's explanations were revealing:

I think they [foreign-born] provide other perspective about American society and the culture here in this country. I think just being a foreign-born broadens the perspective of the students here. They [foreign-born faculty] have a different way of looking at things. They have a different set of cultural values. They have been educated in different system, and they have different worldviews. All of that contributes in a great way to how the courses are taught, or what perspectives and views they bring in how to teach courses. And different kind of service...And what kind of service they get involved.

Professor Eleven stated about the benefits of using multicultural international perspective for the curriculum:

I talk about all those [multicultural] experiences teaching my diversity class. And also the other class on organizational theory that I teach, I always talk about other systems in (native country), in Europe, in the world, and I am trying to see the trait this isn't only the United States to have international students. So I am trying to be comparative....And now I am applying this to my research doing international comparative work. 
This approach was endorsed by a number of other faculty members. Professor Four was adamant about the value of her teaching approach:

My teaching is firmly based and that is also my current research on the pedagogy which I call 'A Two-Way Treat'. The research right now on the international students is very limited. It's only focused on the deficits of international students. And with my students, with my teaching I try to work toward another conceptual framework, which is an equal one when both sides have to learn from each other.

Finally, the researcher tried to identify whether the interviewed faculty perceived the international perspective was valued on their campuses. 5 out of 11 participants agreed the international perspective was appreciated. Professor Eight shared her positive experience:

Even before I came to my university, when I checked the Web-site of the university, there was a clear statement about how they tried to be international kind of focus of the university. They stated that in their mission statement. So from that point I thought, "So this university emphasizes international perspective." When I came to this university, there was research or grant opportunities for the international research.

Professor Nine reiterated and provided additional detail:

I've received scholarships, I've received funding for my projects. Especially for my service projects I've received a lot of funding and I've had access to other opportunities...So I know that perspective is valid.

However, the interview data analysis identified 6 out of 11 interviewed foreignborn faculty expressed concern about the support provided for the issues of internationalization at their current institutions. Professor Ten contemplated:

It's a tricky question because on the surface of it yes, you know... internationalization and globalization are huge words... that are used in lots of planning and rhetoric. In practice though it's been difficult to actually internationalize the university.... and it's not been done because of the lack of resources, financial and human, and interests and commitment. 
Professor Eleven was reflective:

They are trying... There's a big push from the administration and it's increasing... I don't see that much in the actual faculty... We'll see what happens but I don't see it in the faculty. I see it in the administrators.

Professor One reiterated and was firm:

Definitely they need to provide the service related to the internationalization of education. They have to realize how much this international education is important. They need to open up a bit...

Professor Five summarized the issue and provided additional insight on the problems with internationalization:

I think they have a long way to go... There's sort of rhetoric about internationalization and that stuff and if it brings money everybody is happy but sort of moving beyond what it means to be an international university or what we would need to do if we have an international student body... I don't think we are even realizing what it would mean. On one level, I think it's understandable because the majority of people that are in charge are US-born, many have never travelled outside the country, or if they have, they have been on brief tours... but never lived in another cultural environment. So, on some level I can understand where the lack of knowledge and understanding comes from...

Overall, the interview data findings were consistent with the literature on the issues of internationalization of U.S. higher education. The interviewed foreign-born faculty members noted the importance of this institutional policy. They confirmed the value of contributions of the international faculty to the processes of internationalization. However, many faculty members expressed concern regarding the process of implementation of internationalization at their respectful universities. The findings of the study emphasize the need to explore the aspect of internationalization with regard to a broader scope of factors related to the issue. 


\section{Cross-Cultural Comparisons}

The analysis of the data suggested cross-cultural comparisons may be useful in understanding the experiences of the foreign-born faculty under consideration. Hofstede $(1980,1991,1994,2001)$ developed a model that identifies four primary Dimensions to assist in differentiating cultures: Power Distance, Individualism, Masculinity, and Uncertainty Avoidance. The Dimensions were generated into the Cultural Dimensions Scale with the scores assigned to a particular culture in regards to the abovementioned cultural categories. The sections in the data that appeared to give evidence of one or more of cultural dimensions proposed by Hofstede (2001) were coded and used for close inspection. Even though all the participants were educated in the United States, they still portrayed vivid examples of the influence of culture on their professional experiences in a host culture. However, not all sections that were identified provided clear evidence of a specific cultural dimension. This confirmed Hofstede's (2001) caution about variations within each group of dominant culture characteristics. In this regard, behavior could be attributed to something else, not just cultural attributes.

\section{Power Distance}

This dimension refers to the extent with which the less powerful members of organization expect and accept that power is distributed unequally (Hofstede, 2001). Professor Eight presented the case a "big gap" between her and her supervisor. She explained:

For example, in terms of my relationship with my department chair, I respect my department chair and I try to listen to what the department chair says. For me, the department chair is superior to me. 
On Hofstede's scale (2001), the national culture of Professor Eight ranked 60 out of 100.

This is probably the evidence of high power distance.

A contrasting case that exhibit different ends of the spectrum was identified for

Professor Nine whose national culture ranked 77 out of 100 of the power distance scale.

When asked about the character of her interactions with students in class, Professor Nine revealed:

We are negotiating with the class on how you want to do assignments or how you want to submit or what the deadlines are. I think creating that contract for class has brought a lot of value. I think some classroom discussions have really been very constructive... I think that's been really very rewarding.

Professor Nine appeared appreciative of collaboration and equality regardless of status in the classroom which would probably be the evidence of low power distance. That finding would contradict Hofstede's (2001) identification on the power distance scale.

Professor Eleven presented the case of a well culturally established power distance identity. Professor Eleven was very self-reflective about her own leadership in professional life:

I think I have very specific and well established standards, ethics, work ethics. My work ethics is very important to me. So I guess I have done well in leadership because I have respected work ethics, but at the same time, that has created problems for me, because not everybody has the same level of ethics that I have. And that becomes a source of frustration for me... But because I am a junior faculty, I am not tenured yet, I have felt powerless to do something about it. That has been very frustrating to not been able to speak up.

The national culture of Professor Eleven ranked 67 out of 100 on Hofstede's (2001) power scale. That would be the evidence of a high power distance.

In sum, the Hofstede's (2001) findings about the power distance dimension identified in his IBM studies and applied for this research yielded results but the findings 
would require additional consideration with regard to the specifics of academic environment.

\section{Individualism}

This dimension reflects the degree to which members of a society value close relationships versus loose ties between individuals. The case that confirmed Hofstede's (2001) placement would be Professor One. She explained the nature of her interactions with students by applying the concept of individualism and collectivism to characterize the differences between the higher education in American academe and her native country:

I normally try to be very accommodating. It looks like American teachers and professors are very strict - deadline is deadline, you know. I have a strict deadline too... Along the way, I try to listen to them more so that they know I try to understand them and I try to accommodate them. And they also get to know better who I am as a course goes. I try to become more flexible in terms of meeting their needs. And also, I am inviting them to my place sharing with me (national culture) food so that they understand who I am. Some of my students appreciate that.

Professor One's national culture ranked 18 out of 100 on Hofstede's (2001) individualism

scale. Professor Eleven described her experiences with students enthusiastically:

When the climate in my class is easy and they are learning, they are relaxed and having fun. They are engaged. I think I enjoy that and seeing they are working and I see their joy. Just pure joy being in class and being engaged doing things... That's great.

The national culture of Professor Eleven ranked 13 out of 100 on Hofstede's (2001)

individualism scale. Professor Ten referred to her relationships with the colleagues in the department:

We work together well on different committees, they are very collegial. I mean everybody is kind of isolated because everyone has to do their own things and has to teach their own stuff and research... But we exist as a program, as the 
department because we meet together, discuss things and make decisions and that's been I consider a collegial atmosphere.

Professor Ten's national culture was placed 39 out of 100 on Hofstede's (2001) individualism scale.

There were, however, some anomalies with regard to this dimension. For instance, Professor Three spoke about her interest and sensitivity while interacting with different people in her professional experience:

I am very sensitive to other individuals who come from cultures different from the United States, to international student. I am always interested in hearing what their background is and I ask them whatever we are talking about something that is relevant to the United States and I ask them to give input and to make comparisons.

Yet, this participant's national culture scores toward the top of Hofstede's (2001) individualism scale with a rank of 90 out of 100 . This transformation may be contributed to the impact of professional events in a new country.

One of the criticisms of Hofstede's (2001) framework was that the cultural dimensions may reflect IBM culture. The counter argument is that while organizations can exhibit their own cultural type, the people in the organizations will behave accordingly to their own cultural norms (Hofstede, 1997, 2001; Ting-Toomey, 1999). However, this anomaly can be explained by the cultural difference between the corporate world and the academic world. As noted earlier, some faculty experienced the lack of collegiality in their departments. This suggests cooperation and connectedness might be more valued in academic culture than in corporate culture. Therefore, while Professor Ten comes from the culture that generally values lose ties among individuals, the professional academic culture may reflect contrast to the dominant cultural values of their countries (Hofstede, 2001). 


\section{Masculinity}

This dimension described the extent to which a society's gender roles overlap. Masculine cultures are "tough and focused on material success"; in feminine cultures, gender roles overlap and "both men and women are supposed to be tender and concerned with the quality of life" (Hofstede, 1997, pp. 82-83). Hofstede suggested one of the attributes of a feminine culture is the emphasis on "working to live" rather that "living to work". A typical case of a low masculine culture was presented by Professor Five, whose national culture ranked 5 out of 100 on the Hofstede's masculinity scale. She stated:

I try to bring art, for example, into my teaching. So I try to basically teach in relation to what students are learning so the idea that there are multiple ways of knowing, multiple ways of coming to know. I try my examples and practices that adhere to that so they come to know, come to understand through different artsbased processes...I think helping students make connections between the course content and everyday life and how those pieces relate can be important... I think it's important for students to find their voices I think as scholars, as thinkers.

Professor One attributed this particular cultural value to the nature of her interactions with colleagues:

A lot of times I invite them [colleagues] to my place and we cook (national culture) food together. Those kinds of things make our relationships with colleagues strong...I normally try to be kind and cooperative. Maybe, this is more (national culture) way of making a working environment I guess.

On Hofstede's scale, Professor One's culture ranked 39 out of 100 on the masculinity index.

Professor Ten was another representative of a feminine culture. She described the most rewarding experiences with her colleagues and was revealing:

Going to and discussing symphony. We have a nice symphony in (local name)... I do love symphonic music and it's nice a lot of my colleagues do too and so we all kind of go to symphony and we discuss the events. So that's been really good. 
In sum, the interview data analysis confirmed the cultural dimensions of masculinity/femininity identified by Hofstede (2001) with regard to the cultural differences shaped by the national cultural background in a higher education workplace.

\section{Uncertainty Avoidance}

This dimension indicates the extent to which members of a society deal with uncertain or unknown situations. It essentially reflects how cultures tolerate the unpredictable (Hofstede, 2001). Professor One would be a specific excerpt in the data that gave evidence of a strong uncertainty avoidance culture. She described the ways she preferred handling a conflict or situation in her professional life:

In the first semester, at the beginning, some students sent emails directly to the director of my department... I mean I am not a scary person and why you can't talk to me when you are having some issues? I talked to my director and my director sent me an email saying, "Hey, I am going to your class tomorrow." I went into her office, "What's going on?" If my students complain, I have to know. She should have told me and discuss with me rather than "Hey, I am going to your class tomorrow" and try to supervise me. I am your faculty, I am your colleague and I am not your employee, right?

Professor One's national culture's uncertainty avoidance index is 85 out of 100 on Hofstede's (2001) scale. Interestingly, the power distance index for this culture would be 60 out of 100 as identified by Hofstede (2001).

Professor Eleven shared her experiences about the influence of her national culture on her professional experiences in U.S. academe:

Here, in this Anglo-Saxon culture, they are avoiding conflict. And being from a (national culture) perspective too politically correct is saying things in very subtle ways. That's not (national culture) style. (National culture) can be actually very aggressive or violent or confrontational... So that has been something I have to work on in my meetings. (National culture) can be very passionate and I kind of learn how conflict is approached here which I have found very frustrating many times... Many times they just covered the conflict and nobody really wanted to deal with it the way I am used to doing it. 
Professor Eleven's national culture ranked 80 out of 100 on Hofstede's (2001) scale for uncertainty avoidance. Therefore, these countries score toward the top of the scale, evidence that these cultures do not tolerate unpredictability well.

Professor One felt students should not challenge professors and she seemed more comfortable teaching in a structured rather than open-ended format: "The students in (local name) are very uptight and critical and they are skeptical. They are judging professors rather than appreciating them." Based upon their observations about the nature of student-faculty interactions in the U.S., one might infer they come from strong uncertainty avoidance cultures. The national culture of Professor One ranked 85 out of 100 ; this seems logical as it is towards the top of the scale.

A caveat with attempting this type of analysis is to note that Hofstede (2001) set out to measure and identify specific constructs. The purpose of the present study was not to test the efficacy of Hofstede's constructs. Therefore, making inferences about Hofstede's dimensions would not be a valid approach. However, the analysis does raise the possibility for further exploring the use of such models to better understand the experiences of foreign-born faculty. It also suggests that it may be possible to develop ways to measure existing constructs within the worldwide academic population, which might even lead to the development of new constructs that solely reflect an academic context.

\section{Communication Patterns}

Hofstede's cultural dimensions (2001) offered cultural characterizations of two communication patterns - high-context and low-context. In high-context culture, the meaning and the context of a message are two inseparable parts of a whole, while in the 
low-context culture, little meaning is placed on the actual context, the whole emphasis being placed on the language code. The latter results in communication that is specific, explicit, and analytical, as opposed to the less specific, context dependent communication of the former.

According to Hall $(1976,1990)$, Asia, Africa, and South America are relational, collectivistic, intuitive, and contemplative. This means that people in these cultures emphasize interpersonal relationships. In these cultures, people are less governed by reason rather than by intuition or feelings. Relating to the impact of her national background on her experiences in U.S. academe, Professor Eleven described:

The communication patterns are different. In the United States, people are very linear in their thinking and communication style. They start and finish it. From beginning to end. And communication continues on from that endpoint to the next one, and that is very linear. In (national culture), we tend to be very disorganized in talking. It's small contextual. You start something here, then you branch and turn things, you come back... You may never come back at some point (laughing)... There is a lot of interruption which is considered rude here. In (national culture), we interrupt each other all the time. And there is more contextuality. Many times you don't say things specifically, but there is a lot of contextual information that the person can get... So all things I have to learn - to listen until people finish, to learn to communicate and to not interrupt. Even in my teaching with my students. And I am very self-aware of that.

In a classroom, differences between low-context American culture and highcontext culture mean that imparting information is not enough for a representative of the latter. In this case, information must be carefully contextualized, eliciting group responses with more high-context characteristics. Professor Two presented another case of a high-context culture. He stated his vision for an appropriate student interaction in his class:

In many cases, when students take their concerns easily that's not what real education is for. Real education makes students fight over ideas. Fighting over ideas I don't mean fighting with each other. It's how you fight with ideas but you 
don't personalize those fights... So that is the kind of environment I had when I was a graduate student in my country when you kind of clash over ideas is the kind of environment that I'd like to introduce in difficult classrooms here in the US.

The cultures of North America and much of Western Europe are low-context group which is logical, linear, individualistic, and action-oriented. People from lowcontext cultures value logic, facts, and directness. Lox-context communicators are expected to be straightforward, concise, and efficient in telling what action is expected (Hall, 1976, 1990). When asked about her preferred way of handling a conflict, Professor Five explained, "I would want people to come and talk to me about it and we can actually look at the specifics. You know you can make a good case why you think you deserve a different grade. I don't believe you should just get a good grade without having achieved that level of performance."

In summary, the findings of the study established the relationship between Hofstede's cultural dimensions (2001) and communication patterns shaped by a particular cultural group. The interaction between cultural dimensions and patterns of communication requires additional exploration considering all the variables pertinent to academic culture.

\section{A Second Language}

In this study, the majority of foreign-born faculty members used the English language as a second language. One participant was a native English speaker. Among the foreign-born faculty interviewed, 3 out of 11 participants explicitly stated about their challenges with English at some point of their professional careers in American higher education. They agreed the language difficulty was probably the first and foremost 
obstacle they needed to overcome as non-native English speakers. Professor Eight commented on the detrimental effect of English to effective professional life and career:

Sometimes I don't want to speak English... When I do not feel like I want to speak English, then I just stop talking. And I don't like going to a meeting or conference where I need to speak English. That sometimes influences my professional world as well.

Professor Eleven conferred:

Things that I have noticed that affect my teaching because of my culture besides my accent and mistakes which I make here and there when I speak and write and I apologize. That does affect my self-confidence in class, and at the presentations and conferences. With time, it's getting better... But it was very difficult the early years building credibility because of the language barrier and you have to prove yourself. And you are also self-aware of your limitations and the students can perceive the level of insecurity. But I am getting much better with years.

The language problem did not occur exclusively among the faculty members who were non-native speakers. A native English-speaker who was interviewed for this study revealed she would sometimes run into situations where she would pronounce words differently and would have hard time been understood:

Every time I open my mouth, it is clear to everybody in the room that I am not American. And so that influences me... In the beginning, as I said, I didn't say anything very much because I didn't want to draw attention to myself. And even now if I am in a very large group I won't say anything very much, because again I don't want people to say, "I don't know what you are saying", or "I don't understand you". I don't want people to dismiss my ideas because they think they are foreign ideas.

Professor Two shared a different perspective with regard to the impact on students:

When you speak English with an accent and the students have never had anybody who speaks English with an accent influenced by his own language they may not feel comfortable. But when they see you in the class and see how much knowledge and perspective, they start to respect you.

To conclude, foreign-born faculty members encountered difficulties in some aspects of their professional lives. Depending on each individual's cultural background 
and preparation, different issues may present themselves as challenges, such as language, faculty-student communication, and cultural conduct.

\section{Cross-Cultural Leadership}

Hofstede $(1980,1997,2001)$ provided a major breakthrough in the application of the cultural constraints to leadership and organizations. Dickson, Den Hartog, and Mitchelson (2003) posited no clear understanding of the definition of leadership and its boundaries exists, and that adding a cross-cultural factor to the mix of leadership research makes the whole process even more intricate. Stogdill observed, "there are almost as many definitions of leadership as there are persons who have attempted to define the concept" (Stogdill, 1974, p.259).

In this study, the foreign-born faculty were interviewed about their approaches to leadership and whether those approaches are impacted by their national culture. 4 out of 11 participants confirmed their leadership philosophies have been developed by their cultural background. Interestingly, 4 out of 11 participants denied the influence of their national culture on their leadership approaches, and 3 out of 11 interviewed faculty members had difficulty identifying the roots of their leadership philosophies. As stated by Professor Ten, "I suppose at some point I just absorb some of the western definitions of leadership." Professor Eight highlighted the importance of knowledge in leadership:

They [leaders] have to have the expertise in their professional field. And with an expertise, they also need to care about their employees or followers... So I think to become a leader, the most important thing is the expertise in the field, they have to know what they are doing. Without knowing that and knowing only how to manage people or how to deal with people is not enough.

Professor Nine spoke about her approach to leadership as related to an individual's self-development. She stated, "Leadership is about personal change more 
than anything else." Professor Five described the leadership which she believes is influenced by her cultural background:

I am interested in the leadership that is transparent, I think collaborative to the extent possible, honest, authentic, sort of collaborative piece based on thinking together how to be able to do things together... I think different people will need to take a lead in consultation with others...I think there is the way in which people get together and come to great results. It takes more time, it's a more difficult process, but I think in the long run it's worthwhile.

Professor Three contemplated about the influence of her traveling experiences on her leadership philosophies:

I would say my experience of being in an Asian culture certainly influences my leadership approach because I had to become much more comfortable with group processes making sure that everybody has a lot of opportunities to discuss issues instead of making decisions. So that certainly influences me.

Professor Four highlighted empowering and organizing qualities of a leader:

A leader is someone who helps others to find their strengths and puts groups together. A leader is not someone who stays always on top but in the background and is a convener and an organizer of effective group activity... A leader may be an expert on some topics but not always.

Professor Two reiterated by emphasizing collaborative leadership effort:

A leader should be somebody who galvanizes and works with other people in the organization in order to get some result but basically my philosophy is that a leader should be somebody who uses leadership as a collaborative undertaking. A leader connects the different entities, units of the organization in a systemic way so that the integration of those units transforms organization to a higher and new level. A leader that leads by himself will fail... A leader should lead by people and not by himself or herself.

In addition, when asked about the influence of the national background on his leadership

philosophies, Professor Two was very revealing:

Actually, on the contrary to what my background suggests... In my culture, leadership is very hierarchical, it's a top-down orientation. Leaders are the ones who set the vision rather than setting the vision in collaboration with the members of the organization. So I have to re-shape or undo much of what I know from what a leader should do when I was in my country. 
Overall, the interviewed foreign-born faculty members adhered to a particular leadership philosophy shaped by their national background, extensive travelling experiences, and professional experiences in U.S. academe. In addition, the participants' approaches to leadership may be influenced by their involvement in socialization processes related to their personal and professional life.

\section{Multicultural Professional Experiences}

Most interviewed faculty members claimed they have completely assimilated to American culture. By assimilation, one assumes becoming bicultural or multicultural while discarding some native elements. The capacity of being bicultural or multicultural was affirmed by most members, but the duration of their stay may reduce their original cultural sensitivity. This may not be a desired result, but being away from their native countries makes it almost impossible to maintain their native sensibilities. Since all the faculty members who were interviewed for this study came to this country during their adult years, it would not be easy for any of them to become completely "Americanized". In fact, they have maintained their own cultural roots, and they are proud of their cultural orientation. In the meantime, they would intentionally bring a different cultural orientation and a different perspective to their work and seek to educate Americans about the diversity in the world.

Among the foreign-born faculty members interviewed with regard to their bicultural or multicultural identities, 4 out of 11 participants interviewed in this study, identified themselves as multicultural; 2 out of 11 participants referred themselves to the group of bicultural individuals; 2 out of 11 participants established themselves in the group of people with both bicultural and multicultural identities. Interestingly, 2 out of 11 
faculty members preferred to be referred by their original culture; and one participant was established as possessing intercultural identity. Table 4 presents the results of participants' cultural self-identification.

Table 4

Cultural Identities

\begin{tabular}{lcc}
\hline Area of Origin & Years in U.S. Academe & Self-Described Cultural Identity \\
\hline Eastern Asia & 4.5 & Multicultural \\
Western Europe & 24 & Multicultural \\
South America & 19 & Multicultural \\
Northern Europe/Africa & 6 & Multicultural \\
Southern Hemisphere & 16.5 & Bicultural \\
Eastern Europe & 15 & Bicultural \\
Africa & 6 & Bicultural and Multicultural \\
South America & 5.5 & Bicultural and Multicultural \\
Eastern Asia & 8 & Original \\
South Asia & 0.6 & Original \\
Eastern Europe & 6 & Intercultural \\
\hline
\end{tabular}

In addition, 7 out of 11 interviewed faculty members stated they never disassociated themselves from their original cultural background for the sake of their professional careers. In alignment with the idea of multiculturalism, almost all professors stressed the importance of maintaining their original cultural identity. When asked about the evidence of downplaying her cultural identity, Professor Six was passionate: 
I honestly say that I do not recall any instance where I was tempted or prompted to downplay my heritage. It would be like denying my birthmarks... It's all over me, who I am. I am proud to be (national culture), to know that beautiful language, its expressive music, its way of being with others. I have found nothing in my life to match that enough that I would make a choice to deny my background.

In summary, the analysis of the interview data provided foreign-born faculty experienced challenges related to teaching, balancing workload, and interacting with students. They tended to value teaching and interacting with students, as well as having the opportunity to conduct research. The following section provides the analysis of the multicultural professional experiences of the interviewed foreign-born faculty members.

\section{The Role of U.S. Graduate School Training}

The foreign-born faculty who were educated in the U.S. began to learn values, norms, and culture of U.S. academe during their graduate training. Graduate school training and the duration of their stay in the U.S. were the important factors mentioned by the faculty members. All of them were trained in American graduate schools where they learned about faculty roles and faculty responsibilities in the United States. A number of faculty members stated their professors helped them learn about how to be a faculty here. Although being a faculty member and being a graduate student are quite different, graduate study, especially for those who were pursuing their doctoral degrees, was a natural channel that exposed them to some aspects of academic life. This is why many faculty members stated by the time they became faculty members, they already knew about American culture and the expectations in academe. Professor Eight said, "My instructional style I think is more influenced by my graduate college experience in the United States." By the same token, Professor Nine commented: "In terms of teaching or training or making presentations here in the U.S., I would say I incorporate teaching 
norms I learned here in the US rather than those norms I was taught when I was growing up in (national culture). So that's a big difference."

Many interviewed foreign-born faculty members expressed the view they maintained good relationships with most of their colleagues and their students which give them incentive to go on. They received a lot of help from their colleagues in the department as well as in the discipline. Some participants confronted culturally different expectations with regard to the nature of faculty-faculty interactions and relationships.

Professor Eleven commented:

I don't really have a lot of collegiality in work, unfortunately. I have great relationships with faculty through the association maybe because of my attachment to the national association. I have great friendships and collaborations writing papers with faculty in other university.

Few participants confronted culturally different standards with regard to work expectations:

As an assistant professor, I have to do the research and scholarship that is recognized here and be the part of this course of research in the United States... So I have been tied. Now when I am approaching tenure, I feel less pressure and I want to do more work that involves (national culture), and is more comparative and is more critical. So being an international person and trying to make it here, I have to follow the rules of the game (Professor Eleven).

Among the interviewed foreign-born faculty members, there was little evidence of discrimination, prejudice, or marginalization. For example, Professor Eleven mentioned experiencing prejudicial behavior being an international graduate student in the U.S.:

My English was not good at that time... Of course, there were a lot of cultural barriers. I didn't interact well with the faculty. I felt very intimidated by them. Plus all of them were males, senior faculty males. I was a (national culture) girl...It just didn't go very well, and I had a lot of problems.

Nonetheless, it is expected that some foreign-born faculty will experience discrimination, prejudice, and marginalization. 
Most faculty members responded that in their opinion, foreign-born faculty members have been treated fairly. More precisely, most of the faculty members did not think nationality matters with regard to being respected and appreciated by their colleagues. Professor Eight was adamant:

It's not because of my cultural differences. Because of my professional achievement I can be respected. It's not because I am from a different country. If I am from a different culture, I don't' think they would respect me, but because I am doing fine in my professional work is why I am respected.

That is, American academe values performance; it is a merit-based system in which nationality or other non-performance related variables do not count.

The following section provides the analysis of the interview data with regard to the cultural contributions of the foreign-born faculty members to multicultural teaching and learning environment in U.S. education system.

\section{Cultural Attitude Toward Teaching}

The way professors interact with students is different from country to country. In some cultures, the teacher-student relation is more relaxed; in some other cultures, the distance between professors and students is profound. Each of the interviewed foreignborn faculty member confirmed the influence of their cultural background on their teaching experiences in U.S. academe. Professor Two described:

I was hired to bring my own perspective which is actually built in my cultural background. I always want students to debate. I want students bring their own ideas. To some degree, I am flexible... But I am also strict. So I don't really water down the curriculum in order to meet the demands of students. In my own perspective, I always have high expectations and I push students to work hard, and I don't bend around rules. This is something that is consistent with my own cultural perspective.

Several participants displayed commonalities in their attitude to teaching profession in their countries of origin. In their cultures, teachers, particularly university 
professors, are highly regarded. Professor One explained in her country teachers on all levels were considered part of the elite, and university professors were particularly venerated. She said,

In (national culture), students are very respectful. They respect their professors, and I've never seen anybody who was trying to challenge their professors... But here, in the U.S., professors are those people who provide them with educational service. So their attitude is, "You are a service provider and I have a right to get this service. You have to spoon-feed me."

Professor Eight reiterated about the respect for higher education professors in her culture:

From my own experience as a faculty, I was highly respected by the students in (national culture). When I teach here, if students respect me in the way I usually respect my faculty then I like it more. And the student behavior is not the one that I think is proper. Sometimes I get really offended... So I kind of expect some respect from my students and I think that influences my teaching.

Given the fact American students who come into the classroom are not

necessarily prepared to take a plunge into the subject matter with great enthusiasm and motivation, Professor Two admitted that is sometimes hard to take in order to generate interest and motivation:

Not all students are really to learn... Some students are here just to get their certification and go back, which means they are not motivated. They may be there just because the rules require them to be in the classroom but they are not fully engaged. When you see that type of students, it's not rewarding. You always fight and you always try to push those students and you may not get any results.

In the meantime, several participants noted their students also served as the source of inspiration that sustained their curiosity, interest, and motivation in their careers.

When asked about her relationship with her students, Professor Ten responded:

I have graduated so far four doctoral students, four Doctors of Philosophy... I think guiding them from their acceptance to their research projects, through the design, through the implementation, and data collection, has been rewarding. They all have different projects and all different ideas, different struggles, different approaches, different learning styles. That's been very rewarding. 
With regard to the impact the foreign-born faculty may have on students, Professor Three said, "I think a lot of students will find it interesting. I think students are curious... Some students no, but some students I think find it very interesting." Professor Two emphasized the positive nature of his interactions with students:

In most cases, maybe $95 \%$ of my students really believe that I move them forward. They receive the perspective I believe from my national background which is very useful and vital to their understanding profile. By teaching local students from an international perspective, I really believe I really define their misconceptions and help them to see their gains.

In addition, Professor Two explained how his cultural background influences the content of his classes:

What I always do is I try to include one class in my course on current international issues, particularly in my country in the course I teach... So I always build something in the syllabus that would help my students to see or to have a broader perspective beyond the US horizons as they understand leadership from the international perspective.

In an overview, the cultural differences analyzed among the interviewed foreignborn faculty as related to teaching were identified as viable and impacting the professional experience of those faculty members. The majority of the participants have adapted to their professional life by learning on the job. Most foreign-born faculty members have become familiar with the way the system works, the people interact, and the way teaching and research operate.

\section{Research Topics}

The researcher attempted to establish the connection between the national culture of the participants and their research areas. The areas of the research topics identified by the participants with regard to their national background are presented as follows: 4 out of 11 participants related their research interests to their national background; 5 out of 11 
participants did not find any ties between their national background and their research activities; and 2 out of 11 professors partially related their research work to their national background. The majority of the interviewed foreign-born faculty members were interested to expand their research area doing international research work. Professor One explained: "One of my colleagues is from Jordan so I want to do some research in that country too. I am definitely interested to expand my research to an international arena." Some faculty members intentionally maintain professional connections with colleagues back home. Professor Two demonstrated characteristics of an integrationist stance because he maintains his affiliation with his original ethno-group, while showing an interest for U.S. academe:

Now I am working with my home university in [national culture] building their Ph.D. program. I am advising three doctoral students for them right now, working with the curriculum and helping some faculty members from [U.S. institution] who work as dissertation advisers for students in my home country... So I am giving back to my home university where I came from.

Additionally, Professor Two highlighted the international character of his research interests:

I know international context and I still have access to some secondary data from my country and to some people with whom I work in collaboration. I want to give back to my country, to contribute not only service-wise, but also in terms of my research too.

When asked about the influence of the national background on her research interests,

Professor Seven commented:

My work is on American schools overseas... And when I was hired here, I was hired because of my knowledge of international issues in education. The main point for my coming was that to be a professional here.

Overall, the research interests of the interviewed foreign-born faculty members were established as related to some extent to their cultural background. The degree of 
connection may vary with regard to the individual cultural dimensions of a faculty member and institution type.

\section{Experiences with Grants}

The majority of the participants identified some kind of problem with relation to their experiences with grants in U.S. academe. Professor One said, "There is a limited number of grants which are provided to the international students and at the same time international faculty, too." Professor Two referred to the experiences of a junior faculty member: "You have to establish yourself as a professor and a teacher, and also researcher and the third piece and component comes once you stand on a grant." Professor Four, who achieved recognition with international grants, stated:

I had to learn it all here because of the application process, and how you do it, and the review system are quite distinct... culturally distinct... So I learned it here, it has nothing to do with my culture.

In summary, the data analysis identified the challenging experiences of the interviewed foreign-born faculty members with obtaining grants. That may be related to the international faculty status in addition to the overall challenges with grants in American higher education.

\section{Experiences with Service}

When asked about the experiences with service and diversity, Professor Four highlighted her service experiences related to international arena:

I am serving on national advisory boards in other countries which do an assessment of the doctorate study in my country. I serve here on national advisory board for the big U.S. grant giving agency. I am asked frequently to serve on many international committees... So actually, my service is very broad at a national and international level. 
Professor Eight shared her experience with diversity initiatives: "When I am participating in a diversity workshop, I think I was chosen because I am from a different country or my nation. They [other committees] are more about my research, not just because of my international background." Professor Ten reiterated and was explanatory:

I've been on different committees for my school and for the college. I've been on the college internationalization committees... You do tend to see international folks, international faculty being attracted to or placed or nominated for internationalization committee.

Professor Three provided an insight on why she is often chosen to participate in service and diversity events:

I always encourage people to take a global perspective. I often ask the questions about the international dimensions. I ask in whatever I am doing service activities I always keep in mind the situation of students from other cultures and countries... And when I work with my professional organizations, I try to represent and make sure that my colleagues from other cultures are being heard.

Professor Six was excited about her participation in the department committee work:

I get the most of enjoyment out of that because when issues come up, we have to do with the values ... or focus on research and teaching or if someone isn't treated well, how do you acknowledge that... make it a more constructive kind of experience... So that probably has been the things I enjoy most.

Professor Nine's service experience for the local communities was unique:

...I brought about a lot from my culture that I've shared with the local communities... I served in several organizations and couple of them were (national culture)-based organizations. Then I also worked in the local community and the city council bringing...programs.

Overall, all interviewed faculty had some experience serving on the college research or internationalization committees. Some faculty members utilized their national background and were active participants in the local communities' events. Those findings were consistent with the literature on the role of foreign-born faculty members in academic and social serving opportunities on campuses and beyond. 


\section{Professional Values}

Since many cultures are gathered in U.S. higher education, it has become a forum where faculty can interact and work with people from many different backgrounds who carry different frames of reference. Such experiences certainly enhance professional development of those faculty members. Professor Three thought most academic professionals share a common set of professional values which include dedication to providing students with a good education, conducting valid and pertinent research, and maintaining a set of professional ethical values. She stated:

My colleagues expect that I will have a (national culture) perspective. They expect that I know a lot about what's going on in (national culture). And they ask me if I can recommend readings and research studies that come out of (national culture). Yes, they expect me to be able to help them if they are interested in my area... And then, when we have comparative conversation and we are able to pull up the best things that do not necessarily belong to one culture. I think this is rewarding when we can identify good practices regardless of cultural context.

Professor Eight related her national background to her professional life in the department:

Because of my background, I am influenced by my own cultural background, the ways I see things or issues are different. So sometimes I raise questions or I raise some concerns about some issues that many other faculty do not even consider as problems... Maybe I can give some fresh ideas or fresh perspective about certain things that people don't even question about.

Those foreign-born faculty members were, therefore, influenced by their national cultures, society cultures, work cultures, and individual personalities.

Since all the faculty members interviewed were adults when they left their native countries, they carried substantial cultural backgrounds with them. It was common to see that junior faculty members were still able to retain a national cultural outlook. As conferred by Professor Eight, "I think I am still heavily influenced by (national background) culture, but I have a lot more open mind to U.S. culture or cultures. So I am 
now more open, but truly not a multicultural person yet". For senior faculty members, their native cultures obviously diluted. Professor Ten described why cultural identification may be blurred throughout the course of professional experiences:

Sometimes I want to tell people that my allegiance is not to a country or to a university. It is to the profession and to the field, to the research. This is how you socialize in graduate schools. This is what happens when you become a professor... But speaking of identity, this socialization component, academic socialization component becomes so prominent that is becomes difficult to answer any question about cultural influence, cultural background.

The interview analysis suggests this phenomenon is not exclusively a matter of the length of stay in the U.S., but of multiple factors at work, such as personality, the distance between cultures, and language. Faculty members from East Asia were influenced by their oriental philosophies and Confucianism. They were perceived by their own work ethic and their approaches to interpersonal relations. For example, Professor Eight provided:

For example, in (national culture), to stay humble is really important. So in my professional world, for me it is really hard to advocate my professional outcomes. I try to... Because being humble is more important than showing what you have accomplished so far. In a sense, it has influence on my professional life.

They tended to maintain informal relationships with their colleagues and students. These tendencies mean they needed more time and effort to adjust to American culture.

On the other hand, faculty members from western cultures may immerse themselves in American culture more easily because of the similarities between cultures. While it is easy to assume faculty members from European countries might have outlooks similar to Americans, it would be erroneous to ignore or oversimplify the cultural differences among various western cultures. Although it may be easy to invoke the concepts of collectivism and individualism to explain the cultural differences between the 
East and the West, there are also similarities shared by both sides. On top of it, it is important to realize these foreign-born faculty members were influenced by their respective disciplines and by the institutions they are affiliated with. Therefore, in some aspects, people from different countries may, in fact, resemble each other. The data analysis attempted to identify how the participant were shaped by their native, disciplinary, and institutional cultures as they strived for successful careers in the United States.

In general, the data analysis showed the foreign-born faculty members have a positive experience in American academe. They have achieved successful careers without experiencing many significant problems. They felt they have been valued, appreciated, and respected, and that the process of becoming an American faculty member has enriched their personal and professional life immensely. Overall, the foreign-born faculty appeared energetic, motivated, and successful individuals, and although they have experienced challenges in their professional life, they have retained a rather positive attitude about their past experiences and a positive outlook about their future.

\section{Document Analysis}

This qualitative study attempted to derive a holistic general picture of the institutional context as it relates to internationalization and diversity on U.S. campuses. Specifically, relevant policies and programs announced and implemented in the participants' institutions were identified and mapped out through document analysis with regards to its history, mission, vision, values, implementation, and desired outcomes. In addition, to gain a better understanding of the participants, the researcher collected their 
professional curriculum vitae on the website and asked for personal documented accounts of critical events with respect to diversity issues at their institutions.

Document analysis was employed in this study as it enabled the researcher to discover information, insights, and meanings relevant to the study purposes. Documents provided direct information about the events, decisions, activities, and processes. Specifically, documents concerned the administration's commitment to promote diversity at the institution, how these efforts were perceived as reported in the public media and as reflected by the participating foreign-born faculty, and how the participants accounted for their psychological and emotional responses to certain events concerning diversity issues on campus. A number of aspects were noted when analyzing the documents. These included the titles of the documents, the targeted readers, the documents' purposes, nature of the information, emerging themes or patterns relevant to the research questions, significance and desired outcomes of the document, implications, and consistency with other sources of information.

With the availability, accessibility, stability, and potential richness of documents, the information was obtained regarding internationalization and diversity on the participants' campuses. The analysis of the obtained information confirms the strategies prioritized for internationalization and cultural diversity in every participant's institution. Internationalization was often referred to as a 'second nature' of an institution. Among the themes identified for the development and implementation with regard to academic internationalization and diversity the following areas were clearly emphasized: fostering and promoting multicultural environment, developing international physical presence, and increasing visibility, communication, and advocacy for international engagement. In 
addition, the majority of institutions were found as attempting to garner their international research status and enhance the quality for international learning experiences for both students and faculty. Internationalization of the curriculum that reflects international and cross cultural perspectives was identified as a top priority targeted on many campuses with regard to the strategies for internationalization and diversity.

Overall, the results of the document analysis were consistent with the issues identified in literature with respect to the current trends in U.S. higher education. The analysis of the documents assumes the importance of the issues of internationalization and its vital role in the life of the participants' higher education institutions.

The results of the document analysis were used for triangulation of the interview data. The results of the interview data were not consistent with the internationalization outlook identified through the document analysis. 5 out of 11 interviewed foreign-born faculty members perceived internationalization as an important strategy being used in their institutions' policies, while 6 out of 11 participants stated internationalization was not valued on their campuses. Those results may be pertinent to the contextual educational framework of each institution. In addition, other aspects of the faculty's experiences in addition to professional events may shape the outlook and perception of the desired outcomes. 


\section{Summary}

Methodology in this qualitative research consisted of data collected from interviews and documents related to the research questions. These two methods complemented each other and overcame each other's shortcomings thus providing a closer exploration of the current standing of foreign-born faculty in American higher education. The foreign-born faculty members serving in educational leadership preparation program in U.S. higher education were interviewed. This method was useful because each faculty member had unique experiences that usually cannot be captured by implementing quantitative methods.

All participants relayed stories about their professional experiences, which provided evidence of the impact of their culture. They perceived their cultural background influenced their interactions and relations with students and other faculty. In addition, their cultural identity influenced how they perceived themselves and felt others perceived them. The researcher assembled data and created a narrative rich in detail and descriptions so that the information possessed transferability. Bias control was attempted through self-reflection and distancing relations between the interviewer and participants. This qualitative study offers information about the influence of culture and national background on the professional experiences. The study offers suggestions as to how recognize, promote, and utilize cultural diversity of the foreign-born faculty on U.S. campus and multicultural educational leadership preparation. The following chapter presents the discussion of the implications for policy and practice and offers suggestions for additional research on this topic. 


\section{CHAPTER V}

\section{DISCUSSION}

\section{Introduction}

The purpose of this study was to gain an understanding of professional experiences of foreign-born faculty members serving in educational leadership preparation programs in the United States. The purpose dictated the methodological approach used to navigate the contours of the study. The methodological approach employed for this study was phenomenology. The instruments used to gather data on the professional experiences of foreign-born faculty were interviewing and document analysis. The data gathering instruments yielded a rich volume of thick descriptions of experiences which were categorized and thematically analyzed under various research questions. This chapter presents the discussion of the findings. It is divided into six sections: (1) Summary of findings; (2) Significance of themes; (3) Limitations of the study; (4) Implications for future research; (5) Recommendations for practice; and (6) Conclusions.

\section{Summary of Findings}

The summary of findings is presented in relationship to the four research questions that framed and guided the study.

\section{Findings Related to Question 1}

Research Question 1: What are the professional experiences of foreign-born faculty serving in educational leadership preparation (ELP) programs?

This research question sought to gain an understanding of the professional experiences of the interviewed foreign-born faculty members with regard to their professional role U.S. educational leadership preparation programs. The findings 
associated with research question 1 concern the issues of internationalization of American campus. Professional experiences of the interviewed faculty members were identified as related to the extent the issues of internationalization are implemented on the participants' campuses.

The interviewed foreign-born faculty members confirmed those institutions that are considered successful in campus internationalization have taken the concept of "comprehensive internationalization" to heart and are not just concerned with rhetoric, but rather with a variety of indicators (Altbach, 2006; Altbach \& Knight, 2007; Chan \& Dimmock, 2008). Internationalization is in their mission statements being systemically encompassed in institution's pedagogy, curriculum and learning goals, campus life, available funding, institutional policies and practices, as well as in faculty and staff's level of international competency. The participants' institutions had designed and implemented a series of initiatives to promote cultural diversity on campus.

However, the interviewed foreign-born faculty confirmed individual schools cannot be entirely held accountable for their level of internationalization efforts. The findings of the study are in compliance with the proposition the internationalization phenomenon in higher education is far more complex and much harder to achieve (Childress, 2009; Mamiseishvili, 2011; Stromquist, 2007). Additionally, the findings support the recent studies regarding the responsibility for implementing internationalization policies apparently rests on the shoulders of U.S. government and the higher education field as a whole (Chan \& Dimmock, 2008; Ellingboe, 1998). First, the nation has historically neglected higher education internationalization as a top priority to the extent that it has been reflected in federal programming (Hanson \& Meyerson, 1995). 
In the past fifty years government support has been little and modestly funded (Hser, 2005; Lee, 2002). Second, U.S. higher educational system has not maintained one commonly accepted definition of internationalization, nor have there been industry-wide overarching indicators that measure a school's success or failure at campus internationalization (Altbach, 2006; Horn, Hendel, \& Fry, 2007).

While traditionally teaching, research, service, and grants have been seen as separate endeavors, some foreign-born faculty members interviewed in this study have begun to integrate their efforts in these areas in hopes of enhancing each by the topics related to international or intercultural education.

Most of the participants classified their experiences with colleagues as collegial and friendly. They intimated having a good working relationship with their colleagues. They also said their scholarship and views were respected. The interviewed foreign-born faculty members saw themselves as contributors to the learning environment of their institutions. They confirmed being team players and generally well-liked and respected by their colleagues in the department. This finding was in agreement with Lee (2004) and Mamiseishvili and Rosser (2009) about the character of interactions between foreignborn and U.S-born faculty in U.S. academe.

While there is no substitute for a climate that fosters camaraderie among senior and junior colleagues, many interviewed faculty members observed formal mentoring structures in their institutions offered a framework for establishing and accommodating environment for handling conflict situations with regard to professional experiences of the foreign-born faculty. The outcome of a collegial department was expressed for the early-career faculty members to feel confident in being able to ask questions and seek 
advice from senior faculty, while senior foreign-born faculty believed it was their responsibility to provide support and receive appreciation for shepherding new foreignborn members of the department. The level of collegiality in a department was perceived differently by the participants, but intra-departmental communications mentioned by the participants offered strong evidence of cooperation.

The data revealed some participants have maintained close professional relationships with their home countries through professional engagement with institutions and colleagues there, membership in professional societies, participation in conferences, or by other means. Building and maintaining professional links and contacts with their home country was established to be incredibly important to the interviewed foreign-born faculty members, and they tend to make special efforts to do that.

When asked how their institutions view diversity, many participants of the study interpreted the term as related to externally visible markers. The findings indicate no matter the statement from the institution, the interpretation of diversity signified the need to increase the underrepresented groups among the ranks of faculty and students.

Language and accent were additional stresses for many interviewed foreign-born faculty members. This finding justified the proposition of Marvasti (2005) about English as a major concern for institutions when hiring foreign-born faculty. There were both communication and perception issues affecting interaction as identified in the interviewed faculty members.

All interviewed participants noted they felt comfortable with American higher education system as a result of having attended graduate school in the United States. They additionally mentioned the benefits of the acquired body of knowledge on teaching 
and research they were introduced to while in U.S. graduate school. This finding confirms the literature reviewed about the importance of graduate school for the prospective faculty members to begin to gain the norms and values of their new professional environment (Marvasti, 2005; Sheppard, 2004).

Some foreign-born faculty interviewed in this study expressed concern about their interaction with students. They revealed the importance of additional skills and institutional opportunities to consider how to address those issues in their classroom. In addition to interaction issues, several participants provided general observations about student behavior and specific comparisons with other countries. These comments were representative of early-career foreign-born faculty at a variety of institutions and range from the view that there are simply cultural differences to overcome between teacher and student to those who decry the poor preparation and limited understanding of American students' worldview. These findings confirm the recent research about the need to increase foreign-born faculty familiarity with American student norms and expectations (Alberts, 2008; Collins, 2008).

In sum, in spite of challenges, the interviewed foreign-born faculty members were perceived as successful in their professional experiences. They culturally adjust to different extents, but remain appreciative of many aspects of individualistic American culture - in particular, the value of tolerance. Their cultural difference also provides benefits to the institution. Several foreign-born professors shared how they perceive the university is enhanced by the presence of foreign-born faculty. They feel their multicultural backgrounds make them more worldly, more open-minded, and better able to relate to and mentor international students who are prominent in their departments. 
Findings Related to Question 2

Research question 2: What role does culture play in professional experience of foreign-born faculty in ELP programs?

This question sought to explore the impact of the cultural background on the professional experiences of the foreign-born faculty members serving in U.S. educational leadership preparation programs. The findings suggest the interviewed faculty members worked on U.S. campuses within a national culture that may be vastly different from their own. They also worked within the cultures of the profession, the discipline, and the institution, which are largely influenced by U.S. national cultural norms.

The findings of the study confirm national culture provided the interviewed foreign-born faculty with deeply rooted values. Those values affect participants' interpretations of their professional experiences and then affect their relationships with their students, colleagues, and their employing institutions as well. The impact of one's home culture, however, as indicated by the participants, changed with gaining multicultural experiences. All foreign-born faculty members expressed appreciation for their national culture. However, they also reported uneasiness when juggling two different cultures and felt a clash between their own values and enacted institutional values. Such uneasiness may result in reduced professional effectiveness of foreign-born faculty. This theme suggests there is a relationship between specific cultural values and certain aspects of professional attitudes and behavior (Skachkova, 2007; Stohl, 2007).

In a broad sense, the findings of the study demonstrate the national culture in which an individual is raised can have a profound influence on the value system - even in the work environment and even among those who chose to leave their native culture and have lived for several years in a new culture. Equally important is the notion that, in 
spite of the difference in the value system, the participants of the study discussed succeeding in a society that allowed them to maintain the values of their native culture and enjoyed what they perceived to be a new tolerant culture (Theobald, 2008; Thomas \& Johnson, 2004).

Culture and values played a significant role in a foreign-born faculty member's ability to be professionally effective. In a discussion of cultural differences, the findings suggest generalizations are broad in scope, with an implicit understanding that there are individual exceptions and variations. The findings of this study reveal tendencies regarding collectivistic and individualistic groups to respond about their professional experience and their faculty role in a higher education institution (Hofstede, 1980, 1991, 2001; House et al., 2004). The interview findings suggest the foreign-born faculty may overestimate the extent to which the U.S. is an individualistic society, and, therefore, underestimate the expectation for or value of socializing in this environment.

In academe, how people relate to authority is reflected in relationships between students and faculty as well as relationships between new and senior faculty. The findings of the study confirmed cultural clashes may be expected in the classroom if a foreignborn faculty comes from a high power distance culture where greater difference is given to the teacher than is customary in the U.S.

The individualism/collectivism dimension was also identified as critical and reflected in the nature of relationships among the department faculty. For instance, the foreign-born faculty from strong collectivist culture may expect closer ties and connections with departmental colleagues than as established in the U.S. 
According to Hofstede's typology (2001), the U.S. has a strong masculine orientation. Therefore, it is expected the foreign-born faculty encounter a culture with a strong work drive influenced by competition. This assumption was confirmed by the interviewed faculty members with an attitude from a collectivistic cultural background.

The placement of the U.S. toward the end of uncertainty avoidance index (Hofstede, 2001) suggests Americans are fairly comfortable with uncertainty. In the study, this was reflected in the interviewed participants' comfort level with students who may welcome debate. However, the foreign-born faculty from strong uncertainty avoidance cultures reported the need to adjust their instructional approach to accommodate U.S. students who may be accustomed to challenging the professor. This research question was designed to additionally explore the phenomena of global mindset: What enables the foreign-born faculty member to cultivate a global mindset, change their thinking, and embrace a new cultural paradigm. Individuals who embrace a global mindset are receptive to ideas differing from their own and readily accept change. The findings of the study confirm the tendency of acculturation reflected in the discussion of the issues of biculturalism and multiculturalism in the professional experiences of the study participants. Acculturation of the interviewed foreign-born faculty members was investigated through their cultural identity. The majority of the interviewed faculty members did not show their resistance and/or anxiety of being acculturated into the dominant culture. They were increasingly vocal in their ability to function well in a new culture preserving their native cultural values and cultural identities. 
Findings Related to Question 3

Research question 3: What factors do foreign-born faculty perceive as having impact on their professional experiences in ELP programs?

This research question sought to identify the key competencies that were perceived by the participants of the study as pivotal in their professional experiences in U.S. academe. The findings suggest the importance of acculturation in a new culture as a critical condition for successful functioning in a new professional environment. Multicultural experiences of the participants of the study were in agreement with Berry and Sam's (1997) four strategies for psychological acculturation: integration, assimilation, separation, and marginalization. Characteristics of both individual immigrants and the host culture might affect the strategy chosen. The participants who were highly open to experience were likely to seek integration, because they can appreciate the values and perspectives of both the original and the acquired culture. Gaining bicultural or multicultural status by the participant of the study would justify their acculturation in a new environment. Some participants mentioned they found themselves in a high uncertainty avoidance culture, and the deviations from the prescribed norm were perceived as threatening. Therefore, they may be forced to assimilate or face marginalization. In such ways, the lives of the interviewed faculty were shaped by the interaction of culture and personality.

Many participants of the study conferred they perceived their international background was a disadvantage in their professional experiences with obtaining grants, even though in terms of formal structure and policy they were treated equally and fairly. However, a chilly climate could be felt by the participating foreign-born faculty as shown 
in their concerns with regard to partaking a research in their own area of interest prior to getting a status of a tenured faculty. This finding is in agreement with the findings of Collins (2008) with regard to the challenges faced by foreign-born faculty on American campuses.

Despite the participants' nationality, a theme of attempting to minimize their foreign identity at their work place was expressed. The participants all stressed it was their diligence and excellent work that won them recognitions. They expressed the wish to be regarded or treated in the same manner as their U.S.-born colleagues, as they believed they could do as well as their colleagues.

In sum, while international programs and global perspectives have increased on American campuses - as reported by the participants of the study - the foreign-born faculty members have not felt they play major roles in this process. This, in part, may stem from the insular nature of department, which already feel pressured to provide representatives to serve on institutional committees, and who define their faculty as resources of research and teaching rather than ethnicity. Personal anecdotes of the interviewed foreign-born faculty members in educational leadership preparation programs testified to their volunteering on campus, taking an active role as a foreign student adviser, or serving on committees of international or general concern to the institutional community.

\section{Findings Related to Question 4}

Research question 4: To what extent, if any, do their ethnicity and culture affect their leadership philosophy as faculty members in ELP programs? 
This research question was designed to explore the influence of national background on the leadership philosophy as perceived by the interviewed foreign-born faculty members. The data revealed different communication styles, different attitudes toward conflict, different approaches to completing tasks and decision-making styles, as well as different approaches toward knowing, were the key factors that influenced the leadership philosophies identified in the interviewed faculty members.

The complexity posed by the challenges and conflicts between leadership and cultural pre-dispositional attributes contribute to the need for a dynamic leadership model that adapts to its environment. Global leadership requires leaders to adapt and promote both individual and cultural respect within the organization. The principles embedded in managing respectfully across cultural boundaries include communicating effectively, giving and seeking feedback, valuing unique contributions, promoting teamwork, and setting the example (Magee \& Galinsky, 2008; Manning, 2003).

The interviewed foreign-born faculty members confirmed leadership competency should include the ability to understand and/or recognize and relate to any group of people in a way that does not conflict with their attitudes, values, belief system, and way of life. Globalization has placed a boundary on how leadership concepts can be migrated to other cultures who do not shear the same attitudes, values, and beliefs or even integrated pattern of knowledge from the concept's place of origin. The interview data analysis of the study identified predominant characteristics of group cognition and behavior may differ across cultures.

Additionally, the analysis of the responses by the representatives of Western and Eastern cultures supported the findings of Magee and Galinsky (2008), who described the 
"Western culture as one that focuses on individual rewards, gains, and success" (p.56) in contrast to the East Asian and African focus which stresses that productive societies should have a relationship and group centered focus.

Finally, the findings of the study were consistent with the studies by Walker and Dimmock (2002), who addressed the influence of culture on leadership styles by arguing leadership styles indicate that in addition to differences in preferred styles by followers in different cultures, there are specific differences in behavior within each context which suggest that effectiveness of a leaders' style may vary from culture to culture.

Significance of Themes

The results of the study replicated and extended the findings from earlier qualitative studies that examined professional experiences of foreign-born faculty members in U.S. academe. The results enriched insight and understanding of the influence of national background on the professional life. They assist in a heightened awareness of understanding diversity in the educational work environment. The results of the study address the concerns of diversity and highlight the importance of gaining knowledge and skills which can aid in the quest to create a multicultural work environment which gives acceptance to the values, attitudes, and beliefs of all.

\section{Cultural Diversity on Campus}

Cultural diversity provides a platform for the expansion of distinctive talents that can be leveraged for advancement of humanity in society. Diversity-competent organizations embrace comprehensive diversity definitions which assist in the ability to continue to strive for excellence (Connerley \& Pederson, 2005). Brown (2004) contended communication of the diversity promotion in higher education offers an expansive variety of choices to students and makes higher education accessible by 
matching educational learning needs and skills which enables institutions in determining organizational missions for colleges and universities for the increased success of higher education institutions. Organizations which value visible social characteristics display respect for the broad assortment of cultural and individual differences (Suarez-Orozco, 2007).

The findings of the study are in agreement with the underlying assumption the future and diversity of higher education in the United States are ultimately linked to the strength of institutions (Sanderson, 2008; Spring, 2008). Therefore, it is important for colleges and universities around the country to continue to attract and retain faculty and students who are racially/culturally diverse. This is the strategy in response to the changing demographics of the country and the increasing awareness of groups who are underserved. In addition to studying how to implement system-wide programs able to include diverse groups in myriad of ways, a higher priority should be placed on educating all faculty members about the issues of diversity on campus (Taormina \& Selvarajah, 2005). To do this, college and university administrators should consider investing time, effort, and funds necessary to create and maintain meaningful diversity programming for faculty development. If diversity is truly valued on campus, it sends a strong message to all potential students, faculty, and staff about the multiplicity of abilities, experiences, and cultures that may lead to innovation and creativity. This could certainly have implications for few developments and varied sources of funding.

The level of interest in and commitment to diversity varies greatly across institutions. Colleges and universities are advised to think of diversity as an opportunity to shape the institution's future (Tsolidis, 2002; Wei, 2007). 
The data of the study revealed many colleges and universities have developed mission statements or formalized processes to increase the diversity of the student body, faculty, and curriculum. However, the past problems indicate few campuses have adequate information about the institutional impact of the diversity and about measurable progress toward the espoused goals. In addition, many campuses tend not to be aware of the connection between their programs and institutional goals for diversity. The data of the study support only those institutions engaged in the day-to-day work on diversity efforts remain focused on diversity results.

The findings of the study confirm the empirical research about the importance of diversity in preparing students for participation in a global and diverse work environment (Hser, 2005; Stromquist, 2007). Students who are educated in diverse arenas are more prepared for participation in the heterogeneous democracy that exists in the United States and worldwide (Gardner \& Enomoto, 2006; Sheppard, 2004). In addition, academic experiences with diversity have positive effects on a wide range of desirable learning outcomes (Frattura \& Capper, 2007). Finally, greater exposure to diverse experiences has been shown to enhance the cognitive development of critical thinking and need for cognition (Banks, 2006; Riehl, 2000).

\section{Impact of Cultural Background on Professional Life}

The culture in which a person is raised is an important aspect of life, and no matter how long one lives in another culture, a person tends to see many things from the perspective of the culture in which they were born or raised (Hofstede, 1980, 1991). Culture is obtained while in youth and then impacts individuals' actions, behaviors, and interpretations of the world (Hall, 1976). Culture is what is used when responding to the 
environment, and it is how the members of one group are distinguished from another. At present, cultures intermingle constantly. As countries continue to connect in multiple ways, cultural borders define and redefine the understanding of how to respond both positively and effectively to the opportunities afforded by crossing (Ting-Toomey, 1999). The findings of the study affirmed in order to function as world citizens, we should be able to understand the value differences that come with nationality differences. Above all, we should be aware of the position of our own national value system as compared to those of various other countries with which we interact. Cultural programs differ from one nation to another in ways which are seldom fully recognized and often misunderstood. Every nation has a considerable moral investment in its own intellectual capacity, which explains why it is not easy to make cultural differences discussable.

According to Hofstede (2001) and Triandis (1994), the values and beliefs held by members of a culture have a direct impact on the degree and the type of behavior enacted within a culture. Culture directly provides a contextual force that determines the type of leadership that the people come to view as effective (Cunningham \& Gresso, 1993). This view of culture agrees with the argument by Magee and Galinsky (2008) that differences in societal culture are associated with differences in personal values and sensitivities to ethical issues. The findings of the study are in agreement with the proposition in an inclusive and supportive work environment, administration should not only facilitate foreign-born faculty in getting access to cultural capital of the dominant group by designing both structured and informal activities (e.g. mentor programs and social events with communities), but also help foreign-born faculty identify and build up their own cultural capital by promoting foreign-born faculty's pride in their home cultures and 
celebrate multiculturalism (House et al., 2004). Specifically, this can be achieved by recognizing, valuing, and rewarding integration of diversity into every part of organizational life in academe, such as development of course content and multicultural knowledge. This would not only build up foreign-born faculty's self-confidence but communicate the value system of the institution. Meanwhile, it provides the majority group with more exposure to multiculturalism. The institution will benefit from making full use of rich and diverse cultures on campus and an increased organizational productivity among its foreign-born faculty.

\section{Impact of Culture on Leadership}

With increasing globalization, there is a need for a greater understanding of the impact of national culture on leadership (Javidan et al., 2006). There is a demand to understand how the attributes of societal culture may influence the choice of acceptable and effective leadership behaviors in any given culture (Hall, 1976; Walker \& Dimmock, 2002). This knowledge can be beneficial for assessing the effectiveness of current leadership theories and their application. It can also help leaders and decision makers alike to devise effective structures and leadership strategies for the well being of the organization.

Javidan et al. (2004) observed two central aspects of interaction between culture and leadership have dominated cross-cultural research: cultural-generalizable and cultural-specific studies. Cultural-generalizable attributes are those common to all cultures, while cultural-specific attributes occur in only a subset of cultures and are not comparable across cultures (p. 19). Ardichvili and Kuchinke (2002) pointed out leadership exists in all societies, and is essential for functioning of organizations within 
societies. However, the leadership attributes observed to characterize effective leadership may vary across cultures (Den Hartog et al., 1999).

The value system of the culture and organizational context in which leadership is practiced determines the acceptable leadership model (Bass, 1997; Hofstede, 2001). Since norms and values differ significantly among different cultures (Hofstede, 1980, 2001), the concept and prototypes of leadership are expected to be different across cultures. Therefore, the need for cultural validation of leadership has been highlighted (Hofstede, 1980, 1994, 2001). This need emerges from the realization a vast majority of leadership theories have been developed in the USA and for the American cultural setting, and those theories may not have a universal application in other cultures (Dimmock \& Walker, 2000). The findings of the study identified a variety of different approaches to leadership revealed by the interviewed foreign-born faculty members. However, some participants had difficulty explaining whether their leadership philosophy was a reflection of their national background. It was, therefore, concluded the leadership approach may develop and merge with a dominant culture with relation to a new environment or related professional experiences.

\section{Multicultural Leadership for Social Justice}

The growing numbers of English language learners in U.S. schools has created urgency for change to occur in public education to be able to meet the needs of this new diverse student population (Marshall \& Oliva, 2006). Administrators and teachers are seeking ways to improve education for students who are English language learners in an effort to close the dismal achievement gap that exists between fully English proficient students and the growing numbers of students who are English language learners 
(Johnson, 2006). Multicultural education can have a strong influence on how children think and how they develop attitudes, opinions, and beliefs. Cultural diversity can be a catalyst that helps children internalize and adopt these beliefs about themselves, others, society, and life. Understanding cultural conceptions is important when conceptualizing, developing, and implementing an effective multicultural education that meets the needs of all students (Connerley \& Pederson, 2005).

School populations are becoming more racially and culturally diverse, with many schools initiating bilingual education programs to help immigrant children make successful transition within the public schools (Bustamante, 2006). Some students speak different languages and may possess unique cultural ways that differ from the cultural norms in United States society. Students need to understand different values and behaviors of people from other cultures to help them form friendships despite their inherent differences (Banks \& McGee-Banks, 2004). Educators need to ask students from different cultures to share their experiences to help students understand diversity should be celebrated and not feared (Frattura \& Capper, 2007).

Leadership that embraces and supports students from diverse linguistic and cultural backgrounds and promotes school-wide cultural proficiency provides the framework for change that needs to occur in educational practices to ensure student success. Marks and Printy (2003) identified this as transformative work to create "diversity-enhanced" schools and school districts that engage the entire school community to support all students. Since cultural diversity is important to minority students, it is suggested for the multicultural individual heightened sensitivity to cultural diversity would also be very probable. 
Banks (2006) asserted pedagogical approaches from a multicultural perspective have to affect the demographic ideologies within society. Banks $(2006,2008)$ theorized multicultural education as a reflection of educational equity conceptually based on accommodating the educational needs of diverse populations of students.

Multiculturalism is a position and movement that believes the gender, ethnic, racial, and cultural diversity of a pluralistic society should be reflected in the staff, values, curriculum, and student body of educational institutions (Banks, 2008; Brown, 2004). It promotes and fosters all cultures so that students experience pride in their country and background (Cambron-McCabe \& McCarthey, 2005).

It is clear school leaders already have so many constraints on their time because of state-required testing and directives from the No Child Left Behind Act (2001). However, initiating school requirements dealing with cultural diversity, as well as encouraging schools to utilize the knowledge of culture and history that immigrant students possess, will enhance the cultural capital of the immigrants and augment a better understanding of cultural diversity and tolerance of native students. School leaders can promote the communication of knowledge between immigrant students and native students in mainstream classes by sharing this vision with their faculty. Shield (2002) emphasized the incorporation of students' lived experiences within a multicultural curriculum legitimizes their diversity as distinctive. Multiculturalism is a necessary part of school curricula, especially in this world which is increasingly affected by globalization (Connerley \& Pederson, 2005). Immigrant students and native students will all benefit in this global society from learning about different cultures and becoming tolerant of cultural differences (Frattura \& Capper, 2007). The mismatch of cultures will 
be addressed through multiculturalism embedded in the school curriculum so that there will be less dominance by established cultural groups and more equilibrium in the school culture.

In sum, school leaders are faced with many demands, the utilization and communication of cultural diversity by means of immigrant students persists as a major issue, given the demographics in today's society. As the enrollment of students in public schools shifted to multiculturalism, the need to design a curriculum that is responsive to the needs of diverse students has been recognized in the school system. Concerning multicultural education, Banks $(2002,2006)$ suggested the United States public education system needs to establish schools across the nation that are multicultural and student centered. Banks' thought was congruent with the study findings. All participants in the study agreed education all over the nation is becoming multicultural thus requiring educational equity and empowerment to address the needs of culturally and linguistically diverse students.

\section{Culturally-Responsive Leadership}

The findings of this study reminded of the importance to create a tolerant, collegial, and inclusive organizational culture where foreign-born faculty may utilize their unique cultural experiences as a form of capital to succeed in U.S. academe. Sensitivity to the divergent viewpoints of the representatives from different cultures may lead to the awareness and understanding of their definite contributions to the dominant culture.

Culturally-responsive leadership acknowledges the cultural backgrounds of various ethnic groups and utilizes their cultural history and customs in the curriculum of 
mainstream classes (Leeman, 2003). The ethnic heritage and the native language of the immigrant students can be cherished as a benefit which augments society. Assimilation will eradicate their language and heritage so that they are lost to the immigrants as well as to the native students and society. The acculturation process, according to Brown (2002) and Bustamante (2006), may be the main approach that leads immigrant students to a lasting success in schools.

The culturally-responsive leader aspires for social justice and interfaces with larger community efforts for social change (Bustamante, Nelson, \& Onwuegbuzie, 2009). This leader encourages the academic community of students and teachers to support and increase the cultural capital of immigrant students by valuing their culture and diversity. Since immigrant students do not belong to the dominant culture group, they are at a disadvantage because they are unfamiliar with the culture and language and may be unable to translate them into academic and social success (Brown, 2004). Ultimately, the educational leader empowers immigrant students to communicate their culture to the student body in classes and in extracurricular activities (Cheng, 1998; Gardiner \& Enomoto, 2006). Additionally, culturally-responsive leadership encourages culturallyresponsive teachers to develop intellectual, social, emotional, and political learning by imparting knowledge, skills, and attitudes through cultural references and maintaining cultural identity (Evans, 2007).

Finally, transformational leadership theories and instructional leadership theories also encompass ideas from culturally-responsive leadership in that they encourage sensitivity to the diversity of other cultures. Transformational leadership theories emphasize the use of charisma, inspiration, and trust to generate awareness and motivate 
others (Den Hartog et al., 1999), while instructional theories contribute to the understanding and creation of shared learning communities and empower both teachers and students to share and achieve (Bustamante, Nelson, \& Onwuegbuzie, 2009).

In sum, culturally-responsive educational leadership profoundly embeds cultural diversity in school curriculum with multicultural themes, emphasizes diversity issues, and acknowledges the legitimacy of the cultural heritages of different ethnic groups. Those aspects have been established as important regarding the demographic realities of today's U.S. society.

\section{Limitations of the Study}

This study attempted to provide a conceptual pattern of thinking about the influence of national culture on the professional experiences of foreign-born faculty members serving in U.S. educational leadership preparation programs. The findings of this study can be transferred to a variety of academic settings that are interested in hiring and retention of foreign-born faculty. However, the findings of the study and the recommendations are based upon findings in educational leadership area. To be relevant outside this area, findings may need to be adapted to the uniqueness and peculiarities of other fields.

The participants' experiences were representative of a small number of national cultures. Findings may have been different if a broader range of national cultures had been studied.

The participants of this study were the foreign-born faculty members who received their doctorate in the United States. In addition to other variables that were not included into this study, it could also have impact upon the findings. Gender and age of 
the participants could influence the development, perception, and description of their professional experiences.

The findings of the study may be subject to other interpretations. One of the philosophical assumptions underlying qualitative research is that "reality is not an objective entity; rather, there are multiple interpretations of reality. The researcher thus brings a construction of reality to the research situations" (Merriam, 1998, p. 22).

Another limitation of this study is reliance on participants' recollections of events and experiences retrospectively. Time can alter memories and participants may recall events and experiences not as they truly happened, but as they remembered them. They may selectively remember important events or experiences. This limits confidence that can be placed in the findings. For example, memories more emotionally laden frequently are recalled much more readily and may be biased and/or distorted. Experiences of distress may be more marked in minds compared to the experiences of support. Therefore, longitudinal research designs are important to address these issues in future studies in this area.

Finally, in this study, data were not collected regarding the actual university setting or specific educational leadership preparation program. Data regarding campus and program demographics, including race, ethnicity, gender, socioeconomic status, degree types and geographic location were not obtained and therefore were not examined. Given the importance of context in influencing professional experiences, one or more of these factors could have been significant for foreign-born faculty members. Collection of such contextual data for future research is important. 
Implications for Future Research

The results of this study indicated there is an influence of national culture on professional experiences of foreign-born faculty members serving in U.S. academe. Cultural values are a key factor in an individual's ability to function effectively in a new professional environment. More research in the area of the influence of national background on professional experiences is needed. Based on the findings of this study further research is needed to create a competency model for foreign-born faculty. The following are recommendations for future research:

1. Replicate the study with a larger sample to determine if the results are similar to the ones in this study.

2. Investigate the students' perceptions of the importance and effectiveness of foreign-born faculty in educational leadership preparation programs.

3. Compare the professional experiences and awareness of issues related to multiculturalism between the foreign-born faculty members and U.S.-born faculty members in educational leadership preparation programs.

4. Conduct a longitudinal study to measure the professional effectiveness of foreign-born faculty members in educational leadership preparation programs. A longitudinal study might also reveal whether foreign-born faculty alter their cultural values with regard to years in U.S. academe.

5. Research recruitment and retention efforts taken by the institutions related to foreign-born faculty members in educational leadership preparation programs. 


\section{Recommendations for Practice}

The abovementioned findings shed light on the professional experiences of foreign-born faculty serving in educational leadership programs in U.S. higher education. A better understanding of those experiences in the first step toward addressing the issues associated with professional life of the identified faculty members. The results of the study have implications for administrative practices geared toward improving foreignborn faculty's professional experiences.

\section{For Academic Affairs}

For the U.S. to sustain its global leadership in academic and scientific accomplishments, academic administrators must be willing to accommodate and successfully integrate academic leaders of foreign cultures by enacting institutional changes that groom cross-cultural acceptance and understanding. It is imperative for the administration to pay attention to the professional experiences of the foreign-born faculty and initiate organizational change to create a more inclusive environment. A starting point for achieving this goal is to incorporate a foreign culture education in the leadership training programs of higher education institutions in the U.S. The curriculum in educational leadership should be reviewed to accommodate studies in the issues of crosscultural leadership. Educational administrators should be trained to value cross-cultural differences and also develop a better attitude in relating to people of other cultures in and outside the U.S. Such changes in the curriculum will not only create a welcoming environment for foreign-born faculty members to perform their professional duties, they will also enhance the nurturing of students that are ready to face the challenges of a multicultural environment. 


\section{For Higher Education Administration}

There are currently more foreign-born faculty members in U.S. higher education than there were a decade ago (Altbach, 2006). Therefore, academic administrators must be strategic in minimizing culture shocks and challenges foreign-born faculty members face as they integrate into the American education system. Academic leaders in American higher education institutions should be encouraged to study and understand at least one foreign culture and how the values of that culture influences the professional environment. Based on the study findings, administration should design and implement tailored diversity initiatives to attract and motivate foreign-born faculty by addressing their specific needs. The training team should be culturally responsive and incorporate people of different cultural knowledge and backgrounds. The content of training should address concerns and problems in foreign-born faculty's professional lives. It is also recommended the institution establish an easily accessible repository of culturallyappropriate resource materials and experiential programs. Benefits of knowing more about another culture should be communicated to every member of the campus community to identify and confront the stereotypes and myths that people may have about those who are different from themselves.

The idea that leadership must be carried out the American way has to change. In the $21^{\text {st }}$ century, leadership is no longer limited by geographical boundaries; it is about the ability of the leader to manage across boundaries where different cultural, educational, and economic systems are encountered. This is a new frontier in leadership American academic leaders have to embrace in order to be relevant around the world. Learning more about other cultures around the world is a path to achieving this goal. 
For Foreign-born - U.S-born Academic Professional Relations

There is a need for better communication between foreign-born faculty members and their U.S.-born counterparts on the cultural values that dominate in their relevant cultures. Therefore, institutions should encourage dialogue that will educate all groups on the uniqueness of the cultures and how differences in culture can affect the perceptions of an identity and professional life of an individual.

Since a university environment requires interactions with colleagues at meetings, on committees, and through collaborative efforts, foreign-born faculty are not exempts from the implications of cultural value differences. An increased awareness of U.S. faculty regarding the perspectives of their foreign-born colleagues might facilitate better relationships among them. This would apply to understanding cultural issues, as well as serving as a better mentor to a foreign-born colleague. This increased awareness can also serve as the basis for institutional, departmental, and personal initiatives.

An orientation program for foreign-born faculty could review basic cultural differences and outline more subtle cultural expectations. The importance of selfpromotion, independent research, and networking can be reinforced through such a program. The department might address a lack of familiarity with techniques of selfpromotion by creating a sample of resumes, grant proposals, tenure packages, or other materials that could serve as an example to a foreign-born faculty member requiring a model for these items. The results of this study demonstrate foreign-born faculty place a great value on their professional adjustment and recognition. At the same time, they can be modest to advertise. Thus, a public commendation of a foreign-born professor's success, either informally or at a departmental meeting, can help to fulfill the professor's 
desire for recognition. Establishing an image of an accomplished researcher early on may facilitate the tenure process for more withdrawn candidates who could be perceived by others to lack initiative. Such traits and expectations can be culturally redefined so that candidates can be viewed as assertive researchers even though they can be softspoken.

Finally, the department members should be sensitive to and recognize the fact foreign-born faculty from collectivist cultures may place a greater emphasis on harmony and might, therefore, be less likely to speak out or disagree with colleagues at meetings. Their opinion might be sought privately, following meetings initially, and then, as their comfort level increased, they might be invited during the debates.

\section{For Education Leadership Preparation Programs}

Multicultural education has become an imperative consideration in the $21^{\text {st }}$ century. Problems facing student success can be alleviated if educators acknowledge the cultural values of other people and acquire skills from multicultural perspective. Theoretical knowledge toward multiculturalism is a strategy for recognizing, promoting, and utilizing cultural diversity of immigrant children. In this time of demographic changes, school leaders have the opportunity to learn more about and implement multicultural research and cultural diversity. The following recommendations should be considered when conducting additional research in the areas of multicultural education:

1. While the numbers of minority students in public schools are increasing rapidly, higher education institutions should consider incorporating multicultural educational competencies into principals and teachers preparation programs. 
2. Institutions should understand the local dominant cultures of the school in order to train professionals to make sustainable and relevant reforms that would address the needs of all students. This practice will fundamentally change the attitude and perception of people, ensure power sharing, cultural pluralism, equality, and empowerment and evade inequalities, racism and prejudice in the system of education at all levels.

3. School leaders should be trained to examine the objectives of multicultural education in a critical manner. They should be able to identify whether those objectives emphasize diversity and cultural differences on a daily basis as part of the curriculum so that increasingly diverse public school populations could learn from them.

4. Culturally-responsive school leaders should hire a culturally-diverse staff and promote culturally-responsive pedagogy and diversity. These teachers with their diverse backgrounds model diversity for immigrant students and help them become bicultural.

\section{Conclusion}

This study is an initial step toward understanding professional experiences of foreign-born faculty members in U.S. educational leadership preparation programs through investigation of the impact of national culture on the professional life of those faculty. The demographics of the United States continue to change, and the ethnical and cultural landscape changes along with it. Exploration and understanding of cultural differences, promotion of multicultural diversity and awareness on campus would essentially sustain multicultural efforts and the critical role of institution in building diversity and cultural initiatives. The findings of this study provide support for the 
implementation and development of internationalization and multiculturalism in U.S. education. Given the early stages of research on the topic of professional experiences of foreign-born faculty members in educational leadership preparation programs, the findings emerged in this study provide a preliminary foundation for a better understanding of this population in U.S higher education institutions and a launching point for further inquiry into the professional life of foreign-born faculty. 


\section{REFERENCES}

Alberts, H. (2008). The challenges and opportunities of foreign-born instructors in the classroom. Journal of Geography in Higher Education, 32(2), 189-203.

Altbach, P. G. (2006). The internationalization of higher education: Motivations and realities.The NEA 2006 Almanac of Higher Education, 27-36.

Altbach, P., \& Knight, J. (2007). The internationalization of higher education: Motivations and realities. Journal of Studies in International Education, 11(3/4), 290-205.

Anderson, K., \& Smith, G. (2005). Students' preconceptions of professors: Benefits and barriers according to ethnicity and gender. Hispanic Journal of Behavioral Sciences, 27(2), 184-201.

Ardichvili, A., \& Kuchinke, P. (2002). Leadership styles and cultural values among managers and subordinates: a comparative study of four countries of the former Soviet Union, Germany, and the US. Human Resource Development International, 5(1), 99-117.

Banks, J. (2002). An introduction to multicultural education ( $3^{\text {rd }}$ ed.). Needham, MA: Allyn \& Bacon.

Banks, J. (2006). Cultural diversity and education: Foundations, curriculum, and teaching. Boston: Pearson/Allyn \& Bacon.

Banks, J., \& McGee-Banks, C. (2004). Multicultural education: Issues and perspectives $\left(4^{\text {th }}\right.$ ed.) New York: John Wiley.

Barnouw, V. (1985). Culture and personality. Homewood, Ill.: Dorsey Press.

Bass, B.M. (1985). Leadership and performance beyond expectations. New York: Free Press.

Bass, B.M. (1997). Does the transactional transformational leadership paradigm transcend organizational and national boundaries? American Psychologist, 52, 130-139.

Bass, B. M. (1998). Transformational leadership: Industry, military and educational impact. Mahwah, NJ, Erlbaum.

Basti, C. F. (1996). A study of the professorate from the perspective of selective foreignborn faculty. (Doctoral dissertation). Available from ProQuest Dissertations and Theses database. (UMI No. 9716530). 
Berry, J., \& Sam, D. (1997). Handbook of cross-cultural psychology: Social behavior and applications. Allyn \& Bacon, Needham Heights, MA.

Bhattacharjee, Y. (2004). Settling in on campus. Science, 304, 56-75.

Bogdan, R.C., \& Biklen, S.K. (2003). Qualitative research for education: An introduction to theory and methods $\left(4^{\text {th }}\right.$ ed. $)$. Boston: Pearson.

Brown, K. (2004). Leadership for social justice and equity: Weaving a transformative framework and pedagogy. Educational Administration Quarterly, 40, 79-110.

Bureau of Labor Statistics (2009). Employment and total job openings by postsecondary education and training category. Available at http://www.bls.gov/news.release/ ecopro. T09.htm.

Bustamante, R. (2006). The "culture audit": A leadership tool for assessment and strategic planning in diverse schools and colleges. Retrieved from: http://cnx.org/content/m13691/latest.

Bustamante, R., Nelson, J., \& Onwuegbuzie, A. (2009). Assessing schoolwide cultural competence: Implications for schools leadership preparation. Educational Administration Quarterly, 45(5), 793-827.

Cambron-McCabe, N., \& McCarthy, M. (2005). Educating school leaders for social justice. Educational Policy, 19(1), 201-222.

Casimir, G.,Waldman, D., Bartram, T., \& Yang, S. (2006). Trust and the relationship between leadership and follower performance: Opening the black box in Australia and China. Journal of Leadership and Organizational Studies, 12(3), 68-84.

Chan, W., \& Dimmock, C. (2008). The internationalization of universities: Globalist, internationalist and translocalist models. Journal of Research in International Education, 7(2), 184-204.

Cheng, K.M. (1998). Can educational values be borrowed? Looking into cultural differences. Peabody Journal of Education, 73(2), 11-30.

Childress, L. (2009). Internationalization plans for higher education institutions. Journal of Studies in International Education, 13(3), 289-309.

Collins, J. (2008). Coming to America: Challenges for faculty coming to United States' universities. Journal of Geography in Higher Education, 32(2), 179-188.

Connerley, M., \& Pederson, P. (2005). Leadership in a diverse and multicultural environment: Developing awareness, knowledge, and skills. Thousand Oaks, CA: Sage. 
Cooper, C. (2009). Performing cultural work in demographically changing schools: Implications for expanding transformative leadership frameworks. Educational Administration Quarterly, 45(5), 694-724.

Corley, E., \& Sabharwal, M. (2007). Foreign-born academic scientists and engineers: Producing more and getting less than their U.S.-born peers? Research in Higher Education, 48(8), 909-940.

Creswell, J.W. (1998). Qualitative inquiry and research design: Choosing among five traditions. Thousand Oaks, CA: Sage.

Cunningham, W.G., \& Gresso, D. (1993). Cultural leadership: The culture of excellence in education. Boston: Allyn \& Bacon.

Cunningham, W.G., \& Cordeiro, P. (2006). Educational leadership: A problem-based approach. Boston: Pearson/Allyn \& Bacon.

Deardorff, D. (2004). The identification and assessment of intercultural competence as a student outcome of internationalization at institutions of higher education in the United States. (Doctoral dissertation). Retrieved from http://proquest.umi.com/ pqdweb?did=765920641\&sid $=5 \&$ Fmt $=6 \&$ clientld $=3505 \&$ RQT $=309 \& \mathrm{VName}=\mathrm{P}$.

Denzin, N.K. \& Lincoln, Y.S. (1994). Handbook of qualitative research. Thousand Oaks, CA: Sage.

Den Hartog, D. N., House, R. J., \& Hanges, P. J. (1999). Culture specific and crossculturally generalizable implicit leadership theories: Are attributes of charismatic/transformational leadership universally endorsed? Leadership Quarterly, 10(2), 219-256.

Derr, B., Roussillon, S., \& Bournois, F. (Eds.)(2002). Cross-cultural approaches to leadership development. Quorum Books: London.

Dickson, M., Den Hartog, D., \& Mitcheson, J. (2003). Research on leadership in a crosscultural context: Making progress, and raising new questions. The Leadership Quarterly, 14(6), 729-768.

Dimmock, C., \& Walker, A. (1998). Comparative educational administration: Developing a cross-cultural conceptual framework. Educational Administration Quarterly, 34(4), 558-595.

Dimmock, C., \& Walker, A. (2000). (Eds.). Future school administration: Western and Eastern perspectives. The Chinese University of Hong Kong.

Dimmock, C., \& Walker, A. (Eds.) (2002). School leadership and administration: Adopting a cultural perspective. Routlege Falmer: New York. 
Dimmock, C., \& Walker, A. (2005). Educational leadership: Culture and diversity. Thousand Oaks, London: Sage.

Dorfman, P. (1995). International and cross cultural leadership. In B. Punnett \& O. Shenkar (Eds.), Handbook for International Management Research (pp. 267-349). Oxford: Blackwell.

Ellingboe, B. J. (1998). Divisional strategies to internationalize a campus portrait: Results, resistance, and recommendations from a case study at a U.S. university. In J. A. Mestenhauser \& B. J. Ellingboe (Eds.), Reforming the higher education curriculum: Internationalizing the campus (pp. 179-197). Phoenix, AZ: American Council on Education and Oryx Press.

Evans, A. (2007). School leaders and their sensemaking about race and demographic change. Educational Administration Quarterly, 43(2), 159-188.

Foote, K., Li, W., Monk, J., \& Theobald, R. (2008). Foreign-born scholars in U.S. universities: Issues, concerns, and strategies. Journal of Geography in Higher Education, 32(2), 167-178.

Frattura, E., \& Capper, C. (2007). Leading for social justice: Transforming schools for all learners. Newbury Park, CA: Corwin.

Gall, M., Borg, W., \& Gall, J. (1996). Educational research: An introduction. White Plains, NY: Longman.

Gardiner, M., \& Enomoto, E. (2006). Urban school principals and their role as multicultural leaders. Urban Education, 41(6), 560-584.

Graen, G., Hui, C., Wakabayashi, M., \& Wang, Z. (1997). Cross-cultural research alliances in organizational research. In Earley, P., \& Erez, M. (Eds.) New perspectives on international industrial/organizational psychology (pp.160-183). San Francisco, CA: Jossey-Bass.

Hall, E. (1976). Beyond culture. Garden City, NY: Doubleday.

Hall, E. (1990). Understanding cultural differences. Intercultural Press: Business \& Economics.

Hallinger, P. (1992). The evolving role of American principals: From managerial to instructional to transformational leaders. Journal of Educational Administration, 30(3), 35-48.

Hallinger, P. (2003). Leading educational change: Reflections on the practice of instructional and transformational leadership. Cambridge Journal of Educational, 33(3), 229-352. 
Hallinger, P. (2005). Instructional leadership and the school principal: A passing fancy that refuses to fade away. Leadership and Policy in Schools, 4(1), 20-46.

Hallinger, P., \& Heck, R. (1998). Exploring the principal's contribution to school effectiveness: 1980-1995. School effectiveness and school improvement, 9(2), 157-191.

Hallinger, P. \& Heck, R. (1999). Reassessing the principal's role in school effectiveness: a review of empirical research, 1980-1995. Educational Administration Quarterly, 32(1), 5-44.

Han, P.C. (2008) An investigation of intercultural effectiveness for foreign-born faculty in Taiwan. The International Journal of Learning, 15(10), 165-173.

Hanson, K. H., \& Meyerson, J. W. (1995). International challenges to American colleges and universities. Phoenix: Oryx Press and American Council on Education.

Heck, R., \& Hallinger, P. (2005). The study of educational leadership and management: Where does the field stand today? Educational Management Administration and Leadership, 33(2), 229-244.

Hoffer, T. B., Welch, V., Williams, K., Hess, M., Webber, K., \& Lisek, B. (2005). Doctorate recipients from United States universities: Summary report 2004. Chicago: National Opinion Research Center. Retrieved from http://www.norc.org/NR/rdonlyres/2E87F80C-82F6-4E26-9F78CA4C6E0B79C6/0/sed2005.pdf.

Hoffman, D. (2003). Internationalization at home from the inside: Non-native faculty and transformation. Journal of Studies in International Education, 7(1), 77-93.

Hofstede, G. (1980). Culture's consequences: International differences in work-related values. Thousand Oaks, CA: Sage.

Hofstede, G. (1991). Cultures and organizations: Software of the mind. Berkshire, UK: McGraw-Hill.

Hofstede, G. (1994). Management scientists are human. Management Science, 40 (1), 416.

Hofstede, G. (2001). Culture's consequences: Comparing values, behaviors, institutions, and organizations across nations. Thousand Oaks CA: Sage Publications.

Hofstede, G., \& McCrae, R. (2004). Personality and culture revisited: Linking traits and dimensions of culture. Cross-Cultural Research, 38(1), 52-88. 
Horn, A., Hendel, D., \& Fry, G. (2007). Ranking the international dimensions of top research universities in the United States. Journal of Studies in International Education, 11(3/4), 330-358.

House, R. J. \& Aditya, R. (1997). The social scientific study of leadership: Quo valis? Journal of Management, 23, 409-473.

Hser, M. P. (2005). Campus internationalization: A study of American universities' internationalization efforts. International Education, 35(1), 35-48.

Huber, S.G. (2004). School leadership and leadership development: Adjusting leadership theories and development programs to values and the core purpose of school. Journal of Educational Administration, 42(6), 669-684.

Javidan, M., Dorfman, P., de Luque, M., \& House, R. (2006). In the eyes of the beholder: Cross-cultural lessons in leadership from Project GLOBE. Academy of Management Perspectives, 67-90.

Jepson, D. (2009). Studying leadership at cross-country level: A critical analysis. Leadership, 5(1), 61-80.

Johnson, L. (2006). "Making her community a better place to live": Culturally responsive urban school leadership in a historical context. Leadership and Policy in Schools, $5(1), 19-36$.

Johnsrud, L.K., \& Sadao, K.C. (1998). The common experience of 'otherness': Ethnic and racial minority faculty. Review of Higher Education, 21(4), 315-342.

Jung, D., Bass, B., \& Sosik, J. (1995). Bridging leadership and culture: A theoretical consideration of transformational leadership and collectivistic cultures. Journal of Leadership Studies, 2, 3-18.

Jung, D., \& Yammarino, F. (2001). Perceptions of Transformational Leadership among Asian Americans and Caucasian Americans. The Journal of Leadership Studies, $8(1), 3-21$.

Kavas, A., \& Kavas, A. (2008). An exploratory study of undergraduate college students' perceptions and attitudes toward foreign accented faculty. College Student Journal, 42(3), 56-72.

Knight, J. (2004). Internationalization remodeled: Definitions, approaches, and rationales. Journal of Studies in International Education, 8(1), 5-31.

Lee, S. (2002). Do Asian American faculty face a glass ceiling in higher education? American Educational Research Journal, 39(3), 695-724. 
Lee, S. (2004). Foreign-born scientists in the United States- Do they perform differently than native-born scientists? (Doctoral dissertation). Retrieved from http://proquest.umi.com/pqdweb?did=828419401\&sid=7\&Fmt=6\&clientld $3505 \&$ RGT $=309$ Vname $=$ PQD.

Leeman, Y. (2003). School leadership for intercultural education. Intercultural education, 14(1), 31-45.

Leithwood, K. (1995). Cognitive perspectives on school leadership. Journal of School Leadership, 5, 115-135.

Leithwood, K., Dart, L., Jantzi, D., \& Steinbach, R. (1993). Total quality leadership: Expert thinking plus transformational practice. Journal of Personnel Evaluation in Education, 7(4), 311-337.

Leithwood, K., \& Duke, D. (1998). Mapping the conceptual terrain of leadership. Peabody Journal of Education, 73(2), 32-50.

Leithwood, K., \& Jantzi, D. (2005). A review of transformational school literature research 1996-2005. Paper presented at the annual meeting of the American Educational Research Association, Montreal, QC.

Leithwood, K., Jantzi, D., \& Fernandez, A. (1994). Transformational leadership and teachers'commitment to changes. In J. Murphy \& K. Seashore Louis (Eds). Reshaping the principalship, insights from transformational reform efforts, (pp.77-98). Thousand Oaks, California: Corwin Press.

Leithwood, K., Jantzi, D., \& Steinbach, R. (1999). Changing leadership for changing times. Open University Press, Philadelphia.

Leithwood, K., \& Montgomery, D. (1982). The role of the elementary school principal in program improvement. Review of Educational Research, 52(3), 309-339.

Leithwood, K., Tomlinson, D., \& Genge, M. (1996). Transformational school leadership. In K. Leithwood, J. Chapman, D. Corson, P. Hallinger, \& A. Hart (Eds.), International handbook of educational leadership and administration (pp. 785840). Dordrecht: Kluwer Academic Publishers.

Lin, Z., Pearce, R., \& Wang, W. (2009). Imported talents: demographic characteristics, achievement and job satisfaction of foreign born full time faculty in four-year American colleges. Higher Education, 57, 703-721.

Lincoln, Y.S., \& Guba, E.G (1985). Naturalistic inquiry. Newbury Park, CA:Sage. 
Liu, M. C. (2001). The adaptation and experience of foreign-born faculty members in the United States. (Doctoral dissertation). Retrieved from http://proquest.umi.com/pqdweb?did $=729842031 \&$ sid $=8 \&$ Fmt $=6 \&$ clientld $=3505$ $\& \mathrm{RQT}=309 \& \mathrm{VName}=\mathrm{PQD}$.

Magee, J., \& Galinsky, A. (2008). Social hierarchy: The self-reinforcing nature of power and status. Academy of Management Annals, 2, 351-398.

Mamiseishvili, K. (2011). Characteristics, job satisfaction, and workplace perceptions of foreign-born faculty at public 2-year institutions. Community College Review, $39(1), 26-45$.

Mamiseishvili, K., \& Rosser, V.J. (2009). International and citizen faculty in the United States: An examination of their productivity at research universities. Research in Higher Education, 50(6).

Manning, T. (2003). Leadership across cultures: Attachment style influences. Journal of Leadership and Orgánizational Studies, 9(3), 20-29.

Manrique, C. G. \& Manrique, G. G. (1999). The multicultural or immigrant faculty in American Society. Lewiston, NY: Edwin Mellen.

Marks, H., \& Printy, S. (2003). Principal leadership and school performance: An integration of transformational and instructional. Educational Administration Quarterly, 39(3), 370-397.

Marshall, C. (2004). Social justice challenges to educational administration: Introduction to a special issue. Educational Administration Quarterly, 40(1), 5-15.

Marshall, A., \& Batten, S. (2003). Ethical issues in cross-cultural research. Connections, 139-151.

Marshall, C., \& Oliva, M. (2006). Leadership for social justice: Making revolutions in education. Boston: Pearson Education.

Marshall, C., \& Rossman, G.B. (2006). Designing qualitative research. Thousand Oaks, CA: Sage.

Marvasti, A. (2005). U.S. academic institutions and perceived effectiveness of foreign born faculty. Journal of Economic Issues, 39(1), 151-176.

McCray, C., Alston, J., \& Beachum, F. (2006). Principals' perceptions of multicultural education and school climate. Multicultural Learning and Teaching, 1(10), 12-22.

McKenzie, K., Skrla, L., \& Scheurich, J. (2006). Preparing instructional leaders for social justice. Journal of School Leadership, 16(2), 158-170. 
Merriam, S.B. (1998). Qualitative research and case study applications in education. San-Francisco: Jossey-Bass.

Mulford, B. (2005). The international context for research in educational leadership. Educational Management Administration and Leadership, 33(2) 139-154.

National Center for Education Statistics. (2010). 2009 National study of postsecondary faculty. Methodology report. Retrieved from http://nces.ed.gov/pubs2006/ 2006179.pdf.

Neves, J.S., \& Sanyal, R.N. (1991). Classroom communication and teaching effectiveness: The foreign-born instructor. Journal of Education for Business, $66(5), 52-67$.

Norris, J. T. (2004). Restrictions on research awards: Troublesome clauses. A report to the AAU/COGR Task Force. Association of American Universities, August, 2004.

North, D. S. (1995). Soothing the establishment: The impact of foreign-born scientists and engineers on America. University Press of America, Inc, Lanham, MD.

O'Donnell, R., \& White, G. (2005). Within the accountability era: Principals' instructional leadership behaviors and student achievement. NASSP Bulletin, 89(645), 56-71.

Open Doors (2009). International scholars (2009). Institute of International Education. Available at: http://opendoors.iienetwork.org/?p=113165.

Open Doors (2010). International students in the United States (2010). Institute of International Education. Available at: http://opendoors.iienetwork.org/?p=113743.

Patton, M.Q. (2002). Qualitative evaluation and research methods $\left(3^{\text {th }}\right.$ ed.). Newbury Park, CA: Sage.

Riehl, C. (2000). The principal's role in creating inclusive schools for diverse students: A review of normative, empirical, and critical literature on the practice of educational administration. Review of Educational Research, 70(1), 55-81.

Robertson, J., \& Webber, C. (2000). Cross-cultural leadership development. International Journal of Leadership in Education, 3(4), 315-330

Robinson, V., Lloyd, C., \& Rowe, K. (2008). The impact of leadership on student outcomes: An analysis of the differential effects of leadership types. Educational Administration Quarterly, 44(5), 635-674.

Rusch, E.A. (2004). Gender and race in leadership preparation: A constrained discourse. Educational Administration Quarterly, 40(1), 14-46. 
Sanderson, G. (2008). A foundation for the internationalization of the academic self. Journal of Studies in International Education, 12(3), 276-307.

Schmidt, P. (2009). Foreign competition: Professors with degrees from abroad are more productive. Chronicle of Higher Education, 55(34).

Seagren, A. \& Wang, H. (1994). Marginal men on an American campus: A case of Chinese faculty. Paper presented at the Annual Meeting of the Association for the Study of Higher Education. Tucson, AZ, Nov. 10-13, 1994.

Seidman, I. (1998). Interviewing as qualitative research. Teachers College Press: New York.

Seifert, T.A., \& Umbach, P.D. (2008). The effects of faculty demographic characteristics and disciplinary context on dimensions of job satisfaction. Research in Higher Education, 49, 357-381.

Sen, A. (1999). Development as freedom. Anchor Book: A Division of Random House, Inc., New York.

Sheppard, K. (2004). Global citizenship: The human face of international education. International Education, 34(1), 34-40.

Shield, C. M. (2002). Cross-cultural leadership and communities of difference: Thinking about leading in diverse schools. In K. Leithwood and P. Hallinger (Eds), Second international handbook of educational leadership and administration (pp.209-44), Dordrecht, Netherlands: Kluwer Academic.

Skachkova, P. (2007). Academic careers of immigrant women professors in the U.S. Higher Education, 53, 697-738.

Slater, C., Boone, M., Price, L., Martinez, D., Alvarez, I., Topete, C., \& Olea, E. (2002). A cross-cultural investigation of leadership in the United States and Mexico. School Leadership \& Management, 22(2), 197-209.

Southworth, G. (2002). Instructional leadership in schools: Reflections and empirical evidence. School Leadership and Management, 22(1), 73-91.

Spradley, J.P. (1979). The ethnographic interview. New York: Holt, Rinhart and Winston.

Spring, J. (2008). Research on globalization and education. Review of Educational Research, 78(2), 330-363.

Stogdill, R. (1994). Handbook of leadership: A survey of theory and research. New York: The Free Press. 
Stohl, M. (2007). We have met the enemy and he is us: The role of the faculty in internationalization of higher education in the coming decade. Journal of Studies in International Education, 11(3-4), 359-372.

Stromquist, N. (2007). Internationalization as a response to globalization: Radical shifts in university environments. Higher Education, 53, 81-105.

Suarez-Orozco, M. (2007). Learning in the global era: International perspectives on globalization and education. Berkeley and Los Angeles: University of California Press, Ltd.

Taormina, R., \& Selvarajah, C. (2005). Perceptions of leadership excellence in ASEAN nations. Leadership, 1(3), 299-322.

Theobald, R. (2008). Internationalization: Institutions, people and programs in Colorado. Journal of Geography in Higher Education, 32(2), 205-216.

Thomas, A. (2002). Self-report data in cross-cultural research: issues of construct validity in questionnaires for quantitative research in educational leadership. International Journal of Leadership in Education, 10(2), 211-226.

Thomas, J. M., \& Johnson, B. J. (2004). Perspectives of international faculty members: Their experiences and stories. Education and Society, 22(3), 47-64.

Ting-Toomey, S. (1999). Communicating across cultures. New York: Guilford.

Triandis, H. (1994). Culture and social behavior. New York: McGraw-Hill.

Trice, A. (2003). Faculty perceptions of graduate international students: The benefits and challenges. Journal of Studies in International Education, 7(4), 379-403.

Tsolidis, G. (2002). How do we teach and learn in times when the notion of 'Global Citizenship' sounds like a cliché? Journal of Research in International Education, I(2), 213-226.

Walker, A. (2005). Educational leadership: Culture and diversity. Thousand Oaks, CA.

Walker, A., \& Dimmock, C. (2000). One size fits all? Teacher appraisal in a Chinese culture. Journal of Personnel Evaluation in Education, 14(2), 155-178.

Walker, A., \& Dimmock, C. (2002). School leadership and administration: Adopting a cultural perspective. RoutledgeFalmer: New York.

Walker, A., \& Shuangye, C. (2007). Leader authenticity in intercultural school contexts. Educational Management Administration and Leadership, 35(2), 185-204. 
Wei, N. (2007). Do we belong here? An exploration of foreign-born faculty's organizational attachment at a U.S. research university.(Doctoral dissertation). Retrieved from http://proquest.umi.com/pqdweb?index $=0 \&$ did $=1534575131 \&$ SrchMode $=1 \&$ sid $=2 \& \mathrm{Fmt}=6 \& \mathrm{VInst}=\mathrm{PROD} \& \mathrm{VT}$ ype $=\mathrm{PQD} \& \mathrm{RQT}=309 \& \mathrm{VName}=\mathrm{PQD} \& \mathrm{TS}=$ $1282946155 \&$ clientId $=3505$.

Witziers, B., Bosker, R., \& Kruger, M. (2003). Educational leadership and student achievement: The elusive search for an association. Educational Administration Quarterly, 39(3), 398-425.

Yan, J., \& Hunt, J. (2005). A cross cultural perspective on perceived leadership effectiveness. International Journal of Cross Cultural Management, 5(1), 49-66.

Yao, Y., Buchanan, D., Chang, I., Powell-Brown, A., \& Pecina, U. (2009). Different drummers: International perspectives on multicultural education. International Journal of Multicultural Education, 11(2), 1-17. 


\section{APPENDIX A: FOREIGN-BORN FACULTY INVITATION LETTER}

\section{Dear Prospective Participant,}

I would like to invite you to participate in the dissertation study entitled $A$ Cultural Approach to Understanding Professional Experiences of Foreign-born Faculty in U.S Educational Leadership Preparation Programs, which will examine the experiences of foreign-born faculty through their national background. This study will explore the influence of the national background and culture on the professional experiences and approaches to the leadership preparation.

You were identified as a possible participant of this study of foreign-born faculty in Educational Leadership Programs based on the information about your national and academic background. With your help, the answers to the interview questions will assist in the effort to understand the impact of national background and culture on the professional life of foreign-born faculty.

The interview will take approximately 45 minutes to complete. The interview questions are designed to address professional issues and are not personal in nature. Please be assured your responses will be held strictly in confidence and will not be identified by name in the final report. Your responses will be audio-taped and kept by the researcher in a strictly confidential place. Your responses will not be available to any unauthorized individual. If I use your responses to open-ended questions in my writing, your confidentiality will be preserved. You name will not be used in the study document and I will only use quotes that would not reveal your identity. All tapes and files will be destroyed once the analysis is complete.

If you have decided to participate in this study, please understand your participation is voluntary and you have the right to withdraw your consent or discontinue participation at any time. You have the right to refuse to answer any question(s) for any reason. If you do not email me that you do not want to participate, I will contact you to further arrange a time for the interview and to answer any questions you may have.

If you have decided not to participate in this study, please accept my apologies and respond via e-mail so that I may remove you from the sampling pool. If you know of other foreign-born faculty members who serve in Educational leadership programs in your institution or elsewhere in the United States, please alert me so that I may contact them regarding this study.

Thank you for your time and attention. If you have any question, please feel free to contact me at ikhrabro@odu.edu or by phone at 757-683-6277.

Sincerely,

Iryna Khrabrova

Doctoral Candidate

Educational Foundations and Leadership

Darden College of Education

Old Dominion University

Norfolk, VA 
APPENDIX B: INFORMED CONSENT

\section{OLD DOMINION UNIVERSITY}

\section{PROJECT TITLE: A Cultural Approach to Understanding Professional Experiences of Foreign-born Faculty in U.S. Educational Leadership Preparation Programs}

\section{INTRODUCTION}

The purposes of this form are to give you information that may affect your decision whether to say YES or NO to participation in this research, and to record the consent of those who say YES. The study of the professional experiences of foreign-born faculty serving in Educational Leadership programs will be conducted by phone in a 45-minute interview which will take place at your institution.

\section{RESEARCHERS}

This study is conducted by the following investigators:

Responsible Principal Investigator: Dr. Karen S. Crum, Assistant Professor, Department of Educational Foundations and Leadership, Darden College of Education, Old Dominion University, Norfolk, Virginia.

Investigator: Iryna Khrabrova, a Doctoral Candidate, Educational Leadership program, Department of Educational Foundations and Leadership, Darden College of Education, Old Dominion University, Norfolk, Virginia.

\section{DESCRIPTION OF RESEARCH STUDY}

Several studies have been conducted looking into the subject of foreign-born faculty in U.S. higher education. None of them have explained the professional experiences of foreign-born faculty serving in Educational Leadership programs. If you decide to participate, then you will join a study involving research of the influence of national background on the professional life of those faculty members. The purpose of this exploratory study is to shed light on the role of national background in professional experiences of foreign-born faculty by contributing to literature regarding experiences of those faculty in social sciences. This study will be performed by phone in forty-five minute interview with the participant on the issues of culture and educational leadership. If you say YES, then your participation will last for forty minutes at the location of your choice. Approximately twelve foreign-born faculty members will be participating in this study. 


\section{EXCLUSIONARY CRITERIA}

You should have completed the Demographic Sheet. To the best of your knowledge, you should not have withdrawn the information that would keep you from participating in this study.

\section{RISKS AND BENEFITS}

RISKS: No risks to participants are anticipated.

BENEFITS: The main benefit to you for participating in this study is the information on how the institution is accommodating foreign-born faculty and giving consideration to their cultural diversity on campus. No direct benefits to participants are anticipated.

\section{COSTS AND PAYMENTS}

The researchers are unable to give you any payment for participating in this study.

\section{NEW INFORMATION}

If the researchers find new information during this study that would reasonably change your decision about participating, then they will give it to you.

\section{CONFIDENTIALITY}

All information obtained about you in this study is strictly confidential unless disclosure is required by law. The results of this study may be used in reports, presentations and publications, but the researcher will not identify you.

\section{WITHDRAWAL PRIVILEGE}

It is OK for you to say NO. Even if you say YES now, you are free to say NO later, and walk away or withdraw from the study -- at any time. The researchers reserve the right to withdraw your participation in this study, at any time, if they observe potential problems with your continued participation.

\section{COMPENSATION FOR ILLNESS AND INJURY}

If you say YES, then your consent in this document does not waive any of your legal rights. However, in the event of harm or illness arising from this study, neither Old Dominion University nor the researchers are able to give you any money, insurance coverage, free medical care, or any other compensation for such injury. In the event that you suffer injury as a result of participation in any research project, you may contact Dr. Karen Crum, the responsible principal investigator, 757-683-6698, or Iryna Khrabrova, the investigator, 757-683-6277, or Dr. David Swain the current IRB chair at 757683-6028 at Old Dominion University, who will be glad to review the matter with you. 


\section{VOLUNTARY CONSENT}

By signing this form, you are saying several things. You are saying that you have read this form or have had it read to you, that you are satisfied that you understand this form, the research study, and its risks and benefits. The researchers should have answered any questions you may have had about the research. If you have any questions later on, then the researchers should be able to answer them:

Dr. Karen Crum, the responsible principal investigator: 757-683-6698; kcrum@odu.edu

Iryna Khrabrova, the investigator: 757-683-6277; ikhrabro@odu.edu

If at any time you feel pressured to participate, or if you have any questions about your rights or this form, then you should call Dr. David Swain, the current IRB chair, at 757-683-6028, or the Old Dominion University Office of Research, at 757-683-3460.

And importantly, by signing below, you are telling the researcher YES, that you agree to participate in this study. The researcher should give you a copy of this form for your records.

Subject's Printed Name and Signature

Date:

\section{INVESTIGATOR'S STATEMENT}

I certify that I have explained to this subject the nature and purpose of this research, including benefits, risks, costs, and any experimental procedures. I have described the rights and protections afforded to human subjects and have done nothing to pressure, coerce, or falsely entice this subject into participating. I am aware of my obligations under state and federal laws, and promise compliance. I have answered the subject's questions and have encouraged him/her to ask additional questions at any time during the course of this study. I have witnessed the above signature(s) on this consent form.

Investigator's Printed Name and Signature Date: 


\section{APPENDIX C: PARTICIPANT DEMOGRAPHIC SHEET}

ID Number (to be completed by the researcher):

Gender: Female Male

Age: $\quad$ under $30 \quad 30-39 \quad 40-49 \quad 50-59 \quad 60$ and above

Native country:

Current Citizenship country:

Race/Ethnicity: Black/African Asian Hispanic/Latino Native American White/European Multiethnic Other not specified:

Native language:

Years of service with this institution:

Years of service at previous institution(s):

Academic department:

Your present job (please circle): part-time full time

If full time, your title: Lecturer Assistant Professor Associate Professor

Professor

Approximately how many students you teach in all of your classes combined (please circle):

Fewer than $25 \quad 25-50 \quad 50-75 \quad 75-100 \quad$ more than 100

What classes/subjects(s) do you teach?

What kind of academic activities do you perform (please circle):

teaching research administration service

Please provide any additional information you would like us to know about you:

Thank You! 


\section{APPENDIX D: INTERVIEW PROTOCOL \\ PROFESSIONAL EXPERIENCES OF FOREIGN-BORN FACULTY IN}

EDUCATIONAL LEADERSHIP PROGRAMS

Directions: I'm going to ask you a number of questions about your experience as a foreign-born faculty member in educational leadership. I'm interested in understanding if your experience as a faculty member from another country and culture has shaped your experiences in academia.

1) Tell me a bit about yourself, what nationality/culture do you belong to?

a) Would you consider yourself bi/multicultural?

b) How does this impact your professional life?

2) Do you find it important to have foreign-born faculty in American higher education? Why (not)?

3) What kind of perspective do you think a foreign-born professor may bring to US academia?

4) I'd like you to share with me any ways that being a foreign-born faculty member may influence your work. I'm particularly interested in how culture may influence teaching, research, service and grants. I'd like to explore each of these one at a time.

4.1 Is your teaching influenced by your cultural background?

What experiences with teaching have you had that are related to your cultural background?

More specifically, does this background influence

(1) Content?

Does your cultural background influence your classroom

(2) Pedagogy?

2.1What are some cultural approaches that support your teaching?

Does your cultural background influence

(1) Assessment strategies you use?

a) How might your student be impacted by having a foreign-born professor?

b) How do you learn about the expectation of your students for your class?

c) Do you experience conflicts regarding those expectations? What are they?

d) How do you adjust to your students' expectations?

4.2 What have your most/least rewarding experiences been with your students?

4.3 What are some other things related to teaching you would like to share? 
4.4 What is your leadership philosophy?

Does your cultural background influence your Leadership philosophy? In what way(s)?

4.5 Is your research agenda and research itself influenced in anyway by your cultural background?

a) Do your research interests take on more of an international perspective? Why (not)? What are the examples of few?

4.6 Is your service to your institution and the leadership field nationally influenced in anyway by your cultural background?

a) What experience have you had participating in diversity initiatives on campus?

b) Would you describe your university as the one that values international perspective? Why (not)?

4.7 What about your grant activities, are there any ways that your background impacts your efforts around grants?

4.8 More specifically to the field of educational leadership, are there any ways that your cultural background may impact your work with colleagues in this area?

a) What have your most rewarding experiences been with your colleagues?

b) Do you feel respected/recognized/appreciated by the people you work with? By your students? Why (not)?

c) Have you had any experiences when you had to disassociate yourself from your ethnicity and/or culture for your career? Why (not)?

5) What other perspectives, experiences, and suggestions would you like to share that are related to the topic of our conversation? 


\section{VITA}

Iryna M. Khrabrova

Department of Educational Foundations and Leadership

Darden College of Education

Old Dominion University

Norfolk, VA 23529

Education

Ph. D. Educational Leadership

Old Dominion University, Norfolk, VA. 2011

M. S. Ed. Educational Administration and Supervision,

B. A. English and German Philology, Secondary School Teaching, Gorlovka State Pedagogical Institute for Foreign Languages, Gorlovka, Ukraine. 1992

Professional Experience

2008 - 2011 Graduate Teaching Assistant, Educational Leadership Services Program Educational Foundations and Leadership, Old Dominion University, Norfolk, VA

2006 - 2008 Chair of the Department for Foreign Languages

Lyceum \# 129, Krivoy Rog, Ukraine

2005 International Program Assistant

The School of Graduate, International and Interdisciplinary Studies

California State University, Chico, CA

2001

Professional Development Seminar for Teachers of English and American Studies, Participant as a national finalist of TEA (Teaching Excellence Awards) Montana State University - Bozeman, MT, USA

Publications

Cunningham, W.G., \& Khrabrova, I.M. (2007). Conflict Management Styles Grid. In Cunningham, W.G. (2007). A Handbook for Educational Leadership Interns: A Rite of Passage. Pearson Education, pp. 154-156.

Awards

2011 Outstanding Doctoral Student in Educational Leadership, Old Dominion University, Norfolk, VA

2004 The Edmund S. Muskie Graduate Fellowship Program: National Finalist in Education Award, Washington, D.C.

2001 National Finalist, TEA (Teaching Excellence Awards), Washington, D.C.

2000 Semi-Finalist, TEA (Teaching Excellence Awards), Washington, D.C.

2000 Teacher of the Year, Krivoy Rog, Ukraine 